\title{
Riding the sulfur cycle - metabolism of sulfonates and sulfate esters in Gram-negative bacteria
}

\author{
Michael A. Kertesz * \\ Institute of Microbiology, Swiss Federal Institute of Technology, ETH-Zentrum, CH-8092 Zürich, Switzerland
}

Received 2 May 1999; received in revised form 1 October 1999; accepted 27 October 1999

\begin{abstract}
Sulfonates and sulfate esters are widespread in nature, and make up over 95\% of the sulfur content of most aerobic soils. Many microorganisms can use sulfonates and sulfate esters as a source of sulfur for growth, even when they are unable to metabolize the carbon skeleton of the compounds. In these organisms, expression of sulfatases and sulfonatases is repressed in the presence of sulfate, in a process mediated by the LysR-type regulator protein CysB, and the corresponding genes therefore constitute an extension of the cys regulon. Additional regulator proteins required for sulfonate desulfonation have been identified in Escherichia coli (the Cbl protein) and Pseudomonas putida (the AsfR protein). Desulfonation of aromatic and aliphatic sulfonates as sulfur sources by aerobic bacteria is oxygendependent, carried out by the $\alpha$-ketoglutarate-dependent taurine dioxygenase, or by one of several $\mathrm{FMNH}_{2}$-dependent monooxygenases. Desulfurization of condensed thiophenes is also $\mathrm{FMNH}_{2}$-dependent, both in the rhodococci and in two Gram-negative species. Bacterial utilization of aromatic sulfate esters is catalyzed by arylsulfatases, most of which are related to human lysosomal sulfatases and contain an active-site formylglycine group that is generated post-translationally. Sulfate-regulated alkylsulfatases, by contrast, are less well characterized. Our increasing knowledge of the sulfur-regulated metabolism of organosulfur compounds suggests applications in practical fields such as biodesulfurization, bioremediation, and optimization of crop sulfur nutrition. (C) 1999 Federation of European Microbiological Societies. Published by Elsevier Science B.V. All rights reserved.
\end{abstract}

Keywords: Sulfonate; Sulfate ester; Organosulfur metabolism; Sulfur cycle; Sulfatase; Sulfonatase

\section{Contents}

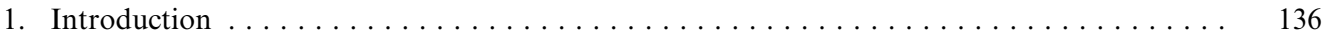

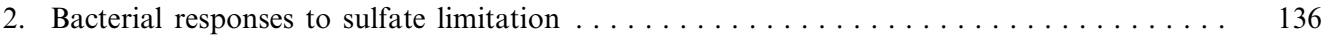

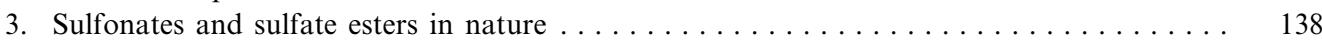

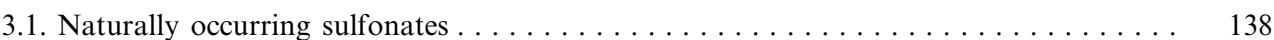

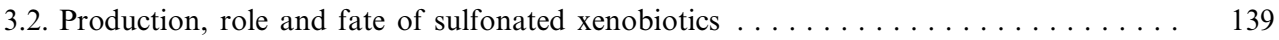

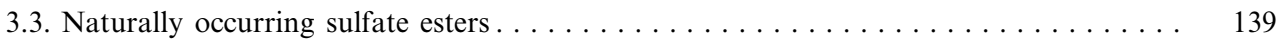

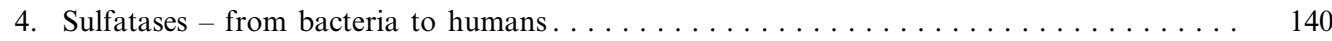

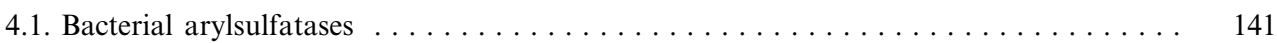

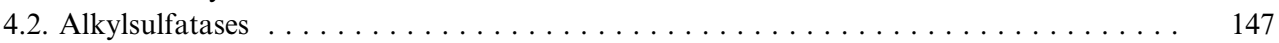

4.3. Carbohydrate sulfatases $\ldots \ldots \ldots \ldots \ldots \ldots \ldots \ldots \ldots \ldots \ldots \ldots \ldots \ldots \ldots$

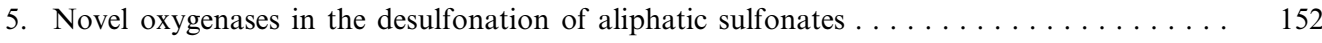

5.1. Taurine desulfurization; $\alpha$-ketoglutarate-dependent dioxygenases . . . . . . . . 154

5.2. Desulfurization of methanesulfonate and other alkanesulfonates; $\mathrm{FMNH}_{2}$-dependent

monooxygenases ............................... 154

6. Desulfonation of aromatic sulfonates - a further adaptation $\ldots \ldots \ldots \ldots \ldots \ldots \ldots \ldots$

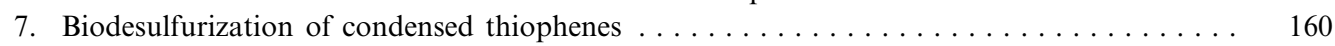

8. Regulation of bacterial organosulfur metabolism $\ldots \ldots \ldots \ldots \ldots \ldots \ldots \ldots \ldots$

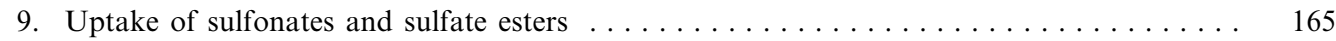

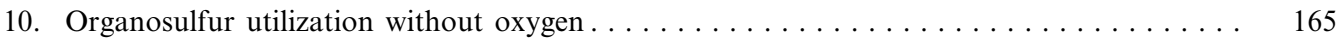

* Tel.: +41 (1) 63233 57; Fax: +41 (1) 63211 48; E-mail: kertesz@micro.biol.ethz.ch 


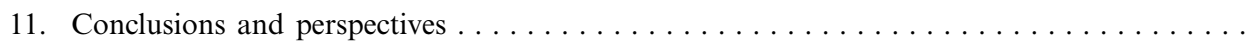

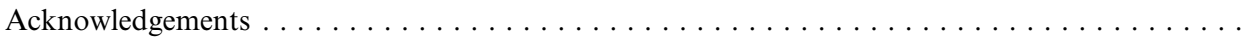

\section{Introduction}

All organisms require sulfur for growth. In bacteria sulfur makes up $0.5-1 \%$ of the cell dry weight, and is needed primarily as a component of the amino acids cysteine and methionine. Sulfur also plays an essential role in a variety of enzyme cofactors, including biotin, coenzyme A, coenzyme $\mathbf{M}$, thiamine and lipoic acid, and is critical in many redox processes, both as a building block for iron-sulfur centers and as the redox-active component of disulfide bonds. Sulfur is common in the environment, making up about $0.1 \%$ of the earth's crust [1], but much of this material is inaccessible to living organisms. Sulfur for biosynthetic processes is derived from the assimilation of inorganic sulfate by plants and bacteria (animals are unable to synthesize methionine and can synthesize cysteine, the key intermediate in most pathways of sulfur metabolism, only by transsulfurylation from dietary methionine [2]). Cysteine biosynthesis by the sulfate assimilation pathway proceeds by the transport of inorganic sulfate into the cell, its activation by conversion to $3^{\prime}$-phosphoadenosine-5' -phosphosulfate (PAPS), subsequent reduction to sulfite and thence to sulfide, and transfer of this sulfide onto an organic moiety to yield the target molecule cysteine (Fig. 1). The biochemistry and genetics of this process have been extensively characterized in both plants and bacteria, and have been the subject of recent reviews [3-5]. However, perhaps because the growth media traditionally used in the laboratory contain high levels of inorganic sulfate (minimal media contain 1-15 mM sulfate [6]; LB medium contains only about $100-150 \mu \mathrm{M}$ sulfate, but excess cysteine), cysteine biosynthesis starting from sulfur sources other than sulfate has not been investigated in detail until quite recently. The purpose of this article is to review recent advances in the genetics and biochemistry of how Gram-negative bacteria utilize organosulfur compounds, in particular sulfonates $\left(\mathrm{R}-\mathrm{SO}_{3}^{-}\right)$and sulfate esters (R$\mathrm{OSO}_{3}^{-}$), to provide themselves with cysteine and methionine for growth. It will concentrate on assimilative sulfur metabolism by aerobic bacteria, though in some contexts it has been necessary to include comparisons with anaerobic organisms and with yeasts and other eukaryotes. For a more detailed description of dissimilative organosulfur utilization by sulfate-reducing bacteria and other anaerobes the reader is directed to recent reviews of this subject $[7,8]$. Sulfur metabolism in yeasts and filamentous fungi has also been reviewed recently $[9,10]$.

Our understanding of the biochemical processes involved in organosulfur utilization by bacteria has leapt forward in recent years, with the characterization of several new sulfur-regulated desulfurizing enzyme systems [11-16]. Additional information has become available through the sequencing of bacterial genomes, 21 of which have been completely sequenced at the time of writing. Where possible, data from these projects have been included in this article. Homologues of many of the genes that are involved in organosulfur metabolism can be identified in other contexts on the chromosomes of other organisms, yielding further information about the substrate flexibility and regulatory complexity of their expression. Conclusions based on this kind of information are necessarily speculative, but may provide useful starting points for future research, and help to put biochemical and physiological flesh on the genetic skeleton supplied by the genome sequences.

Studies of bacterial assimilative organosulfur metabolism are intimately connected with studies of cysteine biosynthesis. Bacterial sulfur assimilation has frequently been assumed to follow the characterized pathway that has been established in enteric bacteria, regulated on a global level as part of the cys regulon [5,17]. More recent studies have shown that in non-enteric bacteria, the regulation of cysteine biosynthesis may be somewhat different (e.g. in Bacillus [18] or in Pseudomonas [19,20]). The initial proteomic study described below suggested that organosulfur metabolism might be controlled by a separate regulatory network to cysteine biosynthesis [21], but by now it has become clear that in most Gram-negative bacteria it is also part of the cys regulon, which is much more extensive than previously recognized (as foreseen by Kredich in his review in 1996 [5]).

\section{Bacterial responses to sulfate limitation}

In the laboratory, bacteria are usually grown either in mineral salts media that provide them with a large excess of sulfur in the form of inorganic sulfate, or in complex media containing not only sulfate but also amino acid sulfur derived from cell hydrolysates. How do they react when they are starved of inorganic sulfate or cysteine? In the absence of these two compounds, bacteria synthesize specific proteins which are required for mobilization of alternative sulfur sources, and for using the last traces of available sulfate. Appropriate sulfate-limited (but not growth-limited) conditions can be provided by supplying the cell with sulfur in organically bound form, e.g. sulfonates, sulfate esters, methionine, sulfamates $\left(\mathrm{R}-\mathrm{NHSO}_{3}\right)$, 


\section{Escherichia coli}

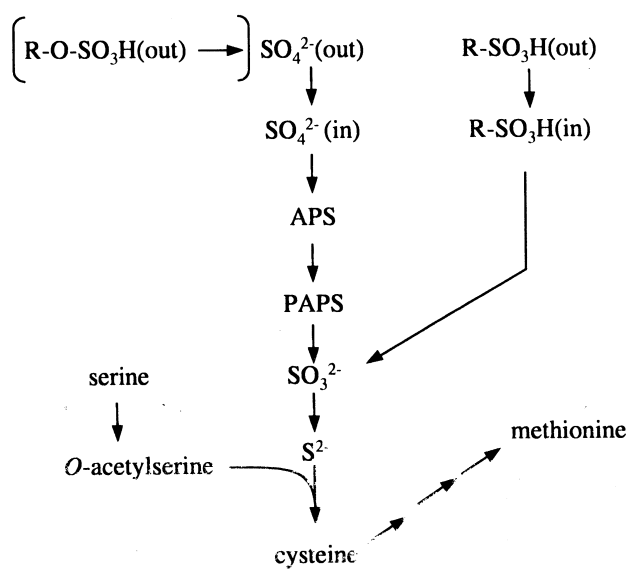

Pseudomonas aeruginosa

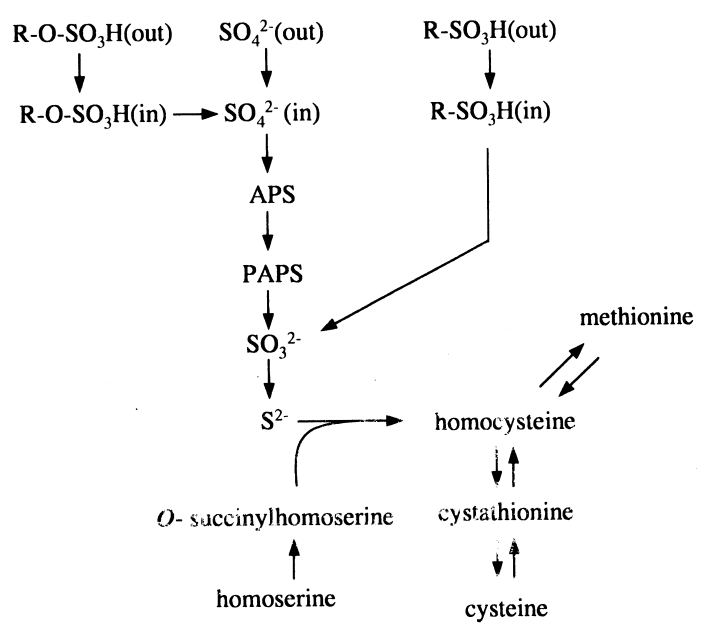

Fig. 1. Cysteine biosynthetic pathways in E. coli and P. aeruginosa. In enteric bacteria, sulfide is transferred to a serine moiety to give cysteine, whereas in $P$. aeruginosa the acceptor molecule is $O$-succinylhomoserine, yielding homocysteine. Although $E$. coli does not desulfurize sulfate esters, other enteric bacteria do so, using periplasmic sulfatases (square brackets, top left). APS: adenosine-5'-phosphosulfate; PAPS: $3^{\prime}$-phosphoadenosine-5'-phosphosulfate.

organosulfides (R-SS-R') or thioethers (R-S-R'), in the absence of inorganic sulfate. The cellular response has been examined in several proteomic studies [20-22].

Under sulfate-limited conditions a set of extra proteins was synthesized by several species of bacteria, and identified by differential screening with two-dimensional electrophoretic techniques [20-22]. These so-called sulfate starvation-induced proteins (SSI proteins) are synthesized only in the absence of 'preferred sulfur sources', which vary according to species, but include sulfate, cysteine and thiocyanate. SSI proteins have been found in Gram-positive and Gram-negative species, in soil bacteria and in human pathogens (Pseudomonas putida, Staphylococcus aureus, Escherichia coli, Pseudomonas aeruginosa). They are not synthesized after heat shock, under phosphorus or nitrogen starvation conditions, or when the cells are grown anaerobically, and therefore appear to constitute a specific response to the absence of sulfate or a related metabolite [20].

The SSI proteins of $E$. coli and $P$. aeruginosa have been characterized by $\mathrm{N}$-terminal sequencing, and by mass spectrometric fingerprinting [20,22-24] (Table 1). The SSI proteins fall into three categories.

(i) They are enzymes and transport systems involved in scavenging and metabolizing alternative sulfur sources from the environment. In this capacity the SSI response can be seen as functionally equivalent to the pho response, which governs the utilization of phosphonates and phosphate esters as a response to phosphate limitation in a variety of species [25-28]. In $E$. coli and $P$. aeruginosa these SSI proteins include periplasmic binding proteins for sulfate, cystine and sulfonates, which are anticipated to be involved in sulfur scavenging, and a variety of sulfonatases (Table 1). (ii) They can be low-sulfur copies of important cellular proteins, in which cysteine or methionine residues which are not critical for function have been replaced by other amino acid residues. Cyanobacteria, for instance, synthesize a second set of phycobilisomal proteins with reduced cysteine/methionine content under sulfate-limited growth conditions [29]. In P. aeruginosa a low-sulfur version of the lipoprotein NlpA was found, which may have structural relevance under sulfate-limited growth conditions. Synthesis of several antioxidant proteins was also upregulated during sulfate starvation (Table 1), including alkylhydroperoxide reductase and a thiol-specific antioxidant protein. Synthesis of these proteins may be a response to peroxide intermediates generated as byproducts of sulfonate metabolism (see below), or may have a more direct link to sulfur metabolism, but this has not yet been explored.

(iii) They could be enzymes involved in mobilization of intracellular sulfur storage compounds (the total sulfur content of $E$. coli, for instance, drops by half during sulfur limitation [30], implying that viability is maintained via a redistribution of sulfur within the cell). As yet, no such SSI proteins have been identified. It is interesting that many of the SSI proteins identified in these studies $[20,22-24]$ had previously been undetected, since even in detailed studies such as the E. coli proteome analysis carried out by the Neidhardt group, the growth media contained $286 \mu \mathrm{M}$ sulfate [6], and the SSI proteins were therefore synthesized only at low levels.

The above study in our laboratory was the first to investigate the synthesis of a set of proteins as part of a global sulfate starvation response in bacteria, but a similar global response to limitation for preferred sulfur sources has been recognized in yeast and in filamentous fungi 
$[9,31,32]$. In bacteria, quite a number of enzymes are known whose synthesis is regulated by sulfur supply, primarily those of the cysteine biosynthetic pathway (Fig. 1). The corresponding cys genes in enteric bacteria are activated by the CysB protein, and constitute the cys regulon. During growth in the presence of excess inorganic sulfate expression of the cys genes is reduced to $40-50 \%$ of fully derepressed values [5]. This degree of repression is, however, much less than for the SSI proteins detected in our initial study, many of which could not be observed at all in cells grown with sulfate [20-22].

Arylsulfatase is the best characterized bacterial enzyme that is known to be strongly regulated by sulfate starvation, in bacteria, algae [33,34], and filamentous fungi $[31,35]$. Surprisingly, it was not identified by the differential two-dimensional analysis technique described above, because the amount of arylsulfatase protein synthesized even under fully derepressed conditions was below the detection limit of the method used [11]. Since arylsulfatase activity is strongly upregulated in the absence of sulfate in a variety of bacterial species [21,35], this suggests that sulfate-regulated enzymes may be synthesized at lower levels than other proteins (corresponding to the cell's lower requirement for sulfur, compared to other macronutrients). It is likely, therefore, that further sulfate-regulated proteins still remain undetected.

The data summarized in Table 1 suggest that the bacterial response to sulfate limitation is largely an adaptation that allows the cells to use sulfonates or sulfate esters as an alternative source of sulfur for growth, in the absence of preferred sulfur sources. These are usually sulfate, sulfite, sulfide or cysteine, but methionine is also a preferred sulfur source in fungi $[9,31]$, and thiocyanate represses the
SSI response in pseudomonads [21]. Since sulfonates and sulfate esters are not generally accepted to be common classes of compounds, we must next ask why such an adaptation may have evolved, and where sulfonates and sulfate esters occur in nature.

\section{Sulfonates and sulfate esters in nature}

Plants can only synthesize cysteine from inorganic sulfate. However, in soil environments sulfate often constitutes only $1-5 \%$ of the total available sulfur, and it has now been conclusively shown that most of the sulfur present is in organically bound form, either as sulfate esters (over $50 \%$ of total sulfur in grassland soils [36]) or as sulfonates (e.g. in forest soils [37]) (Fig. 2). Sulfate for plant nutrition is provided in these systems by sulfur cycling in soil organic matter, catalyzed predominantly by microbial action. Anaerobic soils and sediments also contain considerable quantities of sulfide, due to the action of sulfate-reducing bacteria, and aquatic environments are usually high in inorganic sulfate (both limnic and marine environments - seawater contains an average of $28.7 \mathrm{mM}$ inorganic sulfate [38]). Xenobiotic and naturally occurring sulfonates and sulfate esters available to bacteria as sources of sulfur or carbon are described below.

\subsection{Naturally occurring sulfonates}

Naturally occurring sulfonates have until quite recently been regarded as few in number, and of minimal importance in the biological sulfur cycle, though they often have important biological functions. They include coenzyme M

Table 1

Sulfate-regulated proteins of $E$. coli and $P$. aeruginos $a^{\mathrm{a}}$

\begin{tabular}{|c|c|c|c|}
\hline Protein & Gene locus & Function & Reference \\
\hline \multicolumn{4}{|l|}{ P. aeruginosa } \\
\hline PA1 & $s b p$ & periplasmic sulfate binding protein & {$[20]$} \\
\hline PA2, PA11, PA13 & $s s u E A D C B F, m s u E D C$ & alkanesulfonate desulfurization & {$[20,24]$} \\
\hline PA11 & $l s f A$ & thiol-specific antioxidant & {$[20,24]$} \\
\hline PA9 & $\operatorname{tau} A B C D$ & taurine desulfurization & {$[20,24]$} \\
\hline PA7 & $n l p A$ & lipoprotein & {$[20,24]$} \\
\hline PA4 & atsK & unknown & {$[20,24]$} \\
\hline PA19 & similar to E. coli fliY & putative amino acid transport protein & {$[24]$} \\
\hline PA17 & similar to $P$. putida asfC & putative periplasmic sulfonate binding protein & {$[24]$} \\
\hline PA14 & similar to $E$. coli ahpC & alkylhydroperoxide reductase subunit & {$[24]$} \\
\hline AtsA & ats $A$ & arylsulfatase & [11] \\
\hline AtsRBC & ats $R$, ats $B C$ & transport of sulfate esters & {$[136]$} \\
\hline \multicolumn{4}{|l|}{ E. coli } \\
\hline TauA, TauD & $\operatorname{tau} A B C D$ & taurine desulfurization & {$[218]$} \\
\hline SsuE, SsuD & $s s u E A D C B$ & alkanesulfonate desulfurization & {$[22]$} \\
\hline Sbp & $s b p$ & periplasmic sulfate binding protein & {$[22]$} \\
\hline FliY & fii $Y$ & periplasmic cystine binding protein & {$[22]$} \\
\hline AhpC & $\operatorname{ahpC}$ & alkylhydroperoxide reductase subunit & {$[22]$} \\
\hline
\end{tabular}

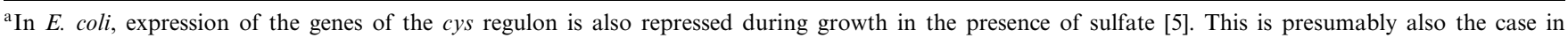
$P$. aeruginosa, though it has not yet been demonstrated. For simplicity, the cysteine biosynthetic genes have been omitted from this table. 

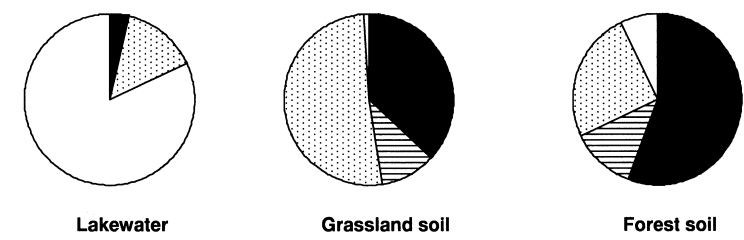

Fig. 2. Sulfur speciation in lakewater [323], and in forest [37] and grassland [36] soils. The sulfur composition is shown as inorganic sulfate ( $\square$ ), sulfate ester sulfur ([: $:$, amino acid sulfur $(\boxminus)$, and sulfonate sulfur (ם). For lakewater, amino acid and sulfonate sulfur are combined in one fraction.

in methanogenic bacteria [39], taurine in mammals [40], methanesulfonate as a degradation product of dimethylsulfide produced by marine algae [41], and sulfoquinovose in the plant sulfolipid [42] (Table 2). Aeruginosin B, a phenazine derivative synthesized by $P$. aeruginosa, is the only known natural aromatic sulfonate [43]. The sulfur in aerobic soils is almost entirely found in organically bound form (Fig. 2), and has been characterized on the basis of chemical reactivity as hydriodic acid-reducible sulfur (sulfate ester sulfur), Raney-nickel reducible sulfur (amino acid sulfur) and residual organically bound sulfur (sulfonate sulfur). Whereas this last assignment appears somewhat generous, it has been confirmed by very recent studies of sulfur composition in marine sediments, and in soils. Using X-ray absorption near edge structure spectroscopy, Vairavamurthy and co-workers have shown that up to $37 \%$ of the sulfur in several sediment and humic substance samples was indeed sulfonate sulfur [44], and that sulfonates made up $20-40 \%$ of the organic sulfur in marine sediments down to at least $50 \mathrm{~cm}$ depth [45]. Low molecular mass sulfonates have also been found in micromolar concentrations in the porewater of marine microbial mats [46]. Sulfonates are also present in all soil strata, including the humus layer. They may be derived from biogenic sulfonates such as plant sulfonolipid, or they may be oxidation products of cysteine, as has been suggested for the sulfonates present in humic substances carried in river water [47]. It has also been suggested that sulfonates may arise in sediments by a chemical process involving the addition of sulfide to carbon-carbon double bonds [48]. Since sulfide is omnipresent in soils and sediments, due to the action of sulfate-reducing bacteria, this theory appears attractive. In situ labelling studies using radiolabelled sulfate in forest soils have shown not only that sulfate is rapidly incorporated into the sulfonate fraction, but that there is a significant flux of sulfur through this sulfonate pool, and that it ultimately reappears as sulfate $[36,49,50]$. Humus chemistry is complex, due to the enormous structural diversity of the substrate [51], but it seems clear that both sulfonate synthesis and desulfonation reactions take place in humus at considerable rates, and that much of this activity is microbially mediated.

Sulfur present in humus will ultimately make its way into sulfur-containing compounds in oil and coal. Re- search into specific desulfurization of such compounds, without degrading the backbone carbon structure, makes up an important objective of many research groups [52]. In the past 20 years, success in reducing the sulfur content of oil, primarily by hydrodesulfurization, has led to a dramatic decrease in $\mathrm{SO}_{2}$ pollution in the industrialized world. An unexpected result of this success is the emergence of the phenomenon of sulfur limitation for crops, as the plants can no longer absorb the sulfur they require from the atmosphere, but are forced to rely on the lower levels of inorganic sulfate provided by the soil.

\subsection{Production, role and fate of sulfonated xenobiotics}

Xenobiotic sulfonates are used in a wide variety of applications, as diverse as dyestuffs and brighteners, detergents, cement additives, and industrial chemical intermediates. Many of these compounds, and intermediates from their synthesis, are released into the environment and can be detected in rivers [53-56] or in sewage sludge-amended soils [57,58]. Most applications make use of the amphiphilic nature of aromatic sulfonates, with a highly charged sulfonate group $\left(\mathrm{p} K_{\mathrm{a}}<0\right)$ attached to a lipophilic aromatic ring. The most widespread aromatic sulfonates are probably the linear alkylbenzenesulfonate surfactants (LAS), with an annual world production in 1995 of 2.8 million tons, predicted to reach 4 million tons by 2005 [59]. Although LAS are not toxic to higher organisms [60], they may have toxic effects on algae and invertebrates at the levels found in polluted waters [61-64]. They accumulate in some natural compartments, particularly in sediments and other anaerobic environments [65-67], but under aerated conditions are generally subject to ready biodegradation, and are quickly mineralized.

\subsection{Naturally occurring sulfate esters}

Unlike aryl sulfonates, aromatic sulfate esters are not common xenobiotic compounds. The widespread occurrence of bacterial arylsulfatases therefore provokes the question of the identity of the natural substrates of these enzymes. In part, the problem is a misleading one. Arylsulfatases have often been defined as such because they are capable of hydrolyzing standard aromatic sulfate substrates such as 4-nitrophenyl sulfate or nitrocatechol sulfate [68], although their natural substrates are aliphatic or carbohydrate sulfates. Nonetheless, aromatic sulfates are certainly found in nature. In mammals sulfation is a key step in the detoxification and excretion of aromatic xenobiotics, since the sulfate conjugates are generally more water-soluble and less reactive than the parent compounds. Sulfation may occur either directly on a hydroxyl group (e.g. of dietary catechols), or after initial hydroxylation by cytochromes P450 [69], and the conjugates are subsequently excreted in the urine or in the bile. It should be noted that although this mechanism is geared towards 
detoxification, in occasional cases it may also lead to bioactivation of e.g. aromatic amines or benzylic alcohols to carcinogenic derivatives [70]. Bacteria also utilize this strategy for xenobiotic detoxification [71], though this does not appear to be widespread.

Sulfation of tyrosine residues is a common post-translational modification that occurs in the eukaryotic transGolgi network [72-74], and up to $1 \%$ of the tyrosines in a cell may be sulfated [75]. In mammals, sulfation and desulfation reactions regulate the concentrations of biologically active molecules such as estrogens, which are transported around the body as the sulfate esters and hydrolyzed in the target tissue to the active steroid [70]. Sulfate esters are therefore common, biologically active molecules to which bacteria are commonly exposed.

As described above, a large proportion of the sulfur in various soil and sediment environments is present as sulfate esters. These may arise in humus itself, through chemical sulfation of lignin-derived phenols, or they may be biogenic in nature. In addition to the aromatic sulfates described above, carbohydrate sulfates contribute to natural deposition of sulfate esters. Glycosaminoglycans (heparin and heparan sulfate, chondroitin sulfate, dermatan sulfate and keratan sulfate) are highly $O$-sulfated and $N$-sulfated, and are important components of connective tissue, playing roles in modulation of many extracellular processes [76]. In vivo, these polymers are subject to lysosomal hydrolysis [77] (most of the mammalian sulfatases characterized so far are specific for carbohydrate sulfates [78]). A variety of glycosaminoglycan lyases have also been characterized from bacterial sources [76]. These are extracellular enzymes that cleave the glycosaminoglycan backbone to yield di- to hexasaccharides. Most of the bacteria that catalyze this reaction have been isolated from soil, suggesting that soil environments are rich in glycosaminoglycan products, presumably of animal origin.

Alkyl sulfate surfactants in detergent formulations have now been largely displaced from the market by the alkylbenzenesulfonates described above, though alkyl sulfates are still in use in special laundry applications, and in products such as toothpastes, antacids or car-cleaning shampoos [79], and are therefore released to the environment. It has long been recognized that both primary and secondary alkyl sulfate surfactants are rapidly degraded by environmental bacteria [60], and so they are not present in high concentrations in the environment. A number of naturally occurring alkyl sulfate esters are also known, ranging from methyl sulfate to long-chain, partially chlorinated aliphatic sulfates derived from algae (reviewed in [35]). The ability of bacteria from pristine sites to degrade xenobiotic alkylsulfates is believed to derive from their previous exposure to these natural compounds [80], since alkylsulfatases are found even in sites which have not been exposed to surfactant pollution $[80,81]$.

From the above, it is clear that a variety of natural and xenobiotic sulfonates and sulfate esters are to be found in the environment. In principle, bacteria can utilize these compounds in at least two ways. They can degrade the carbon skeleton to provide carbon and energy for growth, in which case the sulfur atom is released in excess of growth requirements for sulfur. In this case, the processes concerned are regulated, as far as they have been investigated, primarily by substrate induction of the corresponding genes, and by catabolite repression. Alternatively, sulfonates and sulfate esters can be desulfurized to provide sulfur for growth, a process which is controlled by the sulfur supply to the cell (i.e. derepression in the absence of preferred sulfur sources such as sulfate). Both carbon-cycle and sulfur-cycle regulation have been observed for metabolism of organosulfates and organosulfonates in laboratory studies with pure bacterial cultures. In the following sections, the emphasis will be on metabolism of organosulfur compounds as part of the sulfur cycle in bacteria, concentrating on aerobic systems.

\section{Sulfatases - from bacteria to humans}

Sulfate esters provide a readily available source of sulfur for bacteria in soil and enteric environments, and microorganisms have responded with the synthesis of a battery of sulfatase enzymes. Many of these appear to be related, and their activity is dependent on a formylglycine residue within the active site. Although several bacterial arylsulfatases are well characterized, the structure of the alkylsulfatase enzymes and the genetic details of their expression are still almost completely unknown, and elucidation of these problems will provide interesting challenges in the future.

Sulfatases (EC 3.1.6.-) have been isolated from bacteria [35], fungi [9,31], algae [34,82,83], sea urchins [84-86], and higher eukaryotic organisms [78], but there is only scanty evidence for their occurrence in plants [87-89]. Because arylsulfatase activity is widely distributed in soils, it is often used as a test of soil quality, along with e.g. urease, amylase and alkaline phosphatase (e.g. [87,90-92]). At first sight, there appears to be a contradiction in the simultaneous presence of high levels of sulfate esters and sulfatases in soils, but this can be rationalized if one considers that much of the sulfate ester sulfur may be protected from sulfatase attack by soil structure [93-95]. In humans most sulfatases are located in the acidic environment of the lysosomes, and are involved in the desulfation of glycosaminoglycans such as heparan sulfate, chondroitin sulfate and dermatan sulfate [77,78]. Other mammalian sulfatases are located in the microsome and in the endoplasmic reticulum/Golgi apparatus [78]. As already noted, although these enzymes are known as arylsulfatases, their natural substrates are predominantly carbohydrate sulfates, and not aromatic sulfate esters. Genetic deficiencies in most of the individual sulfatase genes are associated with specific human diseases $[78,96]$. In addi- 
tion, there is a rare lysosomal storage disease in humans called multiple sulfatase deficiency (MSD), in which all the sulfatases are defective. This syndrome is caused by the loss of the post-translational modification system that generates the essential formylglycine in the active site of all the sulfatases [97].

Bacterial arylsulfatases and alkylsulfatases were last reviewed in detail in 1982 [35]. Since that time there has been a considerable increase in our understanding of the genetics of arylsulfatases, and much progress has been made in understanding the mechanism of sulfatase action, both in eukaryotes and in microorganisms.

\subsection{Bacterial arylsulfatases}

Bacterial arylsulfatases have been identified and studied in a variety of species, including the enterobacteria (Klebsiella [98-100], Salmonella [101,102], Enterobacter [103,104], Proteus [105,106], Serratia [107]), pseudomonads (Pseudomonas $[11,108,109]$, Comamonas [110]), mycobacteria, and cyanobacteria [111]. In recent years, however, genetic and biochemical studies have concentrated primarily on the arylsulfatase enzymes from Pseudomonas aeruginosa and Klebsiella pneumoniae, at least in part because these enzymes are closely related to the human arylsulfatases. Earlier work has been comprehensively reviewed [35], and is therefore only summarized briefly here.

Two main conclusions can be drawn from the early biochemical studies: (i) most of the strains studied contained multiple arylsulfatase isozymes, and (ii) the arylsulfatase enzymes can be divided into two groups according to $\mathrm{pH}$ optimum, with one group showing optimal activity at $\mathrm{pH}$ values $6.5-7.1$, and the other group at higher $\mathrm{pH}$ values of 8.3-9.0. Thus, Proteus rettgeri was reported to contain nine arylsulfatase isozymes, with $\mathrm{pH}$ optima at 6.7 and 8.3 [105,112], Serratia marcescens contains multiple isozymes with a broad $\mathrm{pH}$ optimum of 6.8-8.2 [107], $P$. aeruginosa has two isozymes with $\mathrm{pH}$ optima 9.0 and 8.4 [109,113], and Salmonella typhimurium has five enzymes, all with optimum $\mathrm{pH} 6.7$ [102]. It should be noted, however, that multiple arylsulfatase bands have also been reported in two species ( $P$. aeruginosa and $K$. pneumoniae) where later work revealed only one functional arylsulfatase gene. The earlier observations of multiple isozymes may therefore be in part artefactual. Some of the earliest work on arylsulfatase was done with Enterobacter (Aerobacter) aerogenes (ATCC 9621). This strain has since been reclassified as $K$. pneumoniae, and so the data obtained $[103,104,114,115]$ must be compared with later studies with the latter species.

Arylsulfatases are also commonly found in multiple forms in the mycobacteria, but there has been no attempt to characterize the enzymes in detail. However, arylsulfatase activity patterns have been used as a means of identifying and distinguishing different Mycobacterium species $[116,117]$, and the presence of arylsulfatase is routinely used as a phenotypic test for the genus Mycobacterium [118].

\subsubsection{The arylsulfatase enzymes of P. aeruginosa and K. pneumoniae}

The bacterial arylsulfatases that have been studied most in the last decade are the enzymes from $K$. pneumoniae and $P$. aeruginosa. These two proteins are relatively similar at the protein sequence level $(37 \%$ amino acid identity, see Fig. 3), and in size (60 kDa for the Pseudomonas enzyme [11], and $62 \mathrm{kDa}$ for the mature Klebsiella sulfatase [119]. However, there are also significant differences, both at the protein and at the gene level. The Klebsiella sulfatase is a periplasmic enzyme, and analysis of the gene sequence reveals a typical signal peptide, whereas the Pseudomonas enzyme is an intracellular protein, since the N-terminal amino acid sequence corresponded with the $5^{\prime}$-end of the gene, and attempts to detect the Pseudomonas enzyme in periplasmic shock fluids were unsuccessful. The pH optimum for the Klebsiella enzyme is 7.5 [120], whereas the Pseudomonas sulfatase shows highest activity at a more alkaline $\mathrm{pH}$ value of 8.9 [11]. Two arylsulfatase isozymes were originally reported in $P$. aeruginosa $[109,113]$, which differed in their isoelectric points and $\mathrm{pH}$ optima. Unfortunately these data were obtained with an incompletely characterized strain, and in more recent work, using the standard strain PAO1 [121], only one isozyme was detected by native isoelectric focussing, and in-gel activity staining [11]. In addition, deletion of the arylsulfatase gene (ats $A$ ) in this strain led to complete loss of arylsulfatase activity. The previously reported isozymes may therefore have been either experimental artifacts or degradation products, as has been suggested for additional sulfatase bands that appeared during purification of the Klebsiella enzyme [35]. However, it should be noted that two further putative sulfatase genes have been detected during sequencing of the $P$. aeruginosa genome [122] (see below), and it is possible that these genes are cryptic in strain PAO1 but were expressed in the strain studied previously.

In addition to the enzymes described above (Fig. 3), a further sulfatase has recently been characterized from the marine bacterium Alteromonas carrageenovora [83]. The Alteromonas enzyme is considerably smaller (36 kDa) than the other bacterial sulfatases, and does not display sequence similarity to any of the sulfatases above. It shows a broad optimum in its activity at $\mathrm{pH}$ 8.5. The enzyme appears to be located in the periplasm, and is probably involved in desulfation of sulfated polysaccharides [83]. Although expression of the Alteromonas arylsulfatase is not repressed by sulfate [83], the protein is low in cysteine (only one residue), a typical characteristic of sulfate-regulated enzymes (cf. the Klebsiella arylsulfatase (zero cysteines) and the Pseudomonas arylsulfatase (zero cysteines)).

\subsubsection{Post-translational modification of sulfatases}

All the arylsulfatases characterized to date (Fig. 3), ex- 
Table 2

Natural and synthetic sulfonates and sulfate esters

\section{Natural sulfates and sulfonates}

\section{$\underline{\text { Structure }}$}<smiles>NC(C[OH2+])C(=O)O</smiles><smiles>O=S(=O)(O)CCS</smiles><smiles>NCC[SeH](=O)(O)O</smiles>

$\mathrm{H}_{3} \mathrm{C}-\mathrm{SO}_{3} \mathrm{H}$<smiles>CC1=CC(C)C2Cc3ccc(C)cc3C(C)C2C1</smiles>

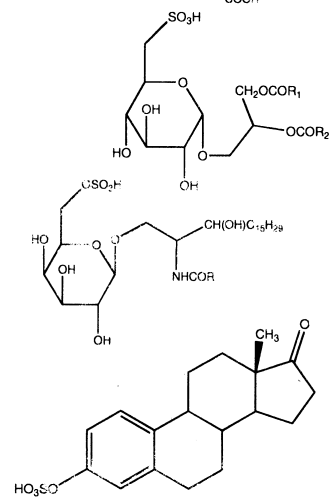<smiles>C[C@H](Cc1ccc(OC(=O)[O-])cc1)C(=O)O</smiles>

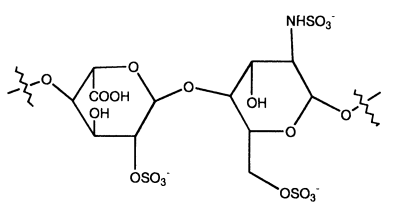

\section{$\underline{\text { Xenobiotic sulfates and sulfonates }}$}

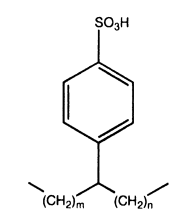

\section{Linear alkylbenzene-} sulfonate (LAS)

(surfactant)

\section{Compound}

cysteate

coenzyme $\mathrm{M}$

taurine

methanesulfonate

aeruginosin $\mathrm{B}$

sulfoquinovose

cerebroside sulfate

estrone sulfate

tyrosine sulfate

heparin<smiles>Cc1ccc(S(=O)(=O)O)cc1</smiles>

toluenesulfonate

(hydrotropic agent)

\section{$\underline{\text { Source }}$}

Wool

methanogenic archaea

mammals

atmospheric photoxidation product of dimethylsulfide

Pseudomonas aeruginosa

plant sulfonolipid in

photosynthetic membranes

human nerve tissue

humans

eukaryotic protems

a representative

glycosaminoglycan cept for the Alteromonas enzyme, contain a conserved amino acid sequence motif in the active site, which is required for enzyme activity. This sulfatase motif (C/S-X-P-X-R$\left.\mathrm{X}_{4}-\mathrm{TG}\right)$ is conserved in both prokaryotic and eukaryotic sulfatases, and in all cases examined it directs a post-translational modification of the initial cysteine or serine in the sequence to a 2-oxoalanine (formylglycine; FGly) residue. The presence of this FGly residue has been demonstrated 


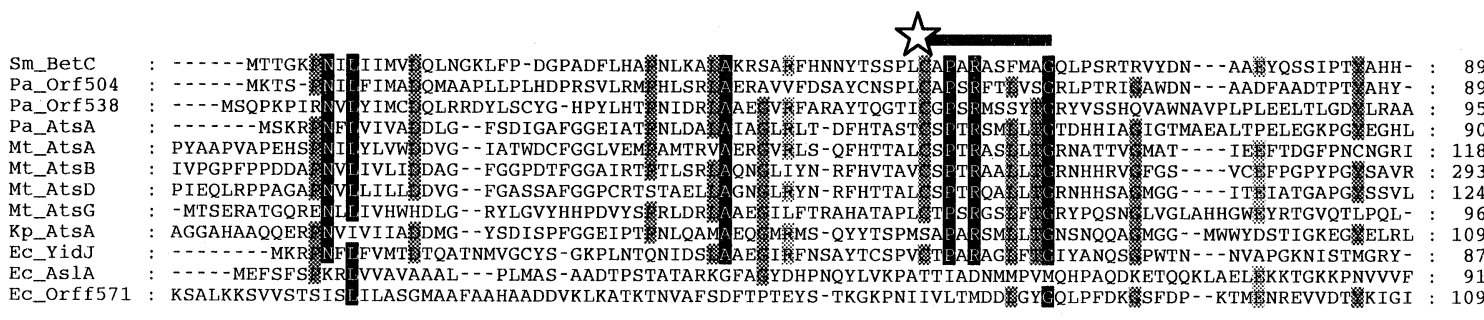

$\begin{array}{ll}\text { Sm_BetC } & : \\ \text { Pa_Orf504 } & : \\ \text { Pa_Orf538 } & : \\ \text { Pa_AtsA } & : \\ \text { Mt_AtsA } & : \\ \text { Mt_AtsB } & : \\ \text { Mt_AtsD } & : \\ \text { Mt_AtsG } & : \\ \text { Kp_AtsA } & \vdots \\ \text { Ec_YidJ } & \vdots \\ \text { Ec_As1A } & : \\ \text { Ec_Orff571 } & \end{array}$
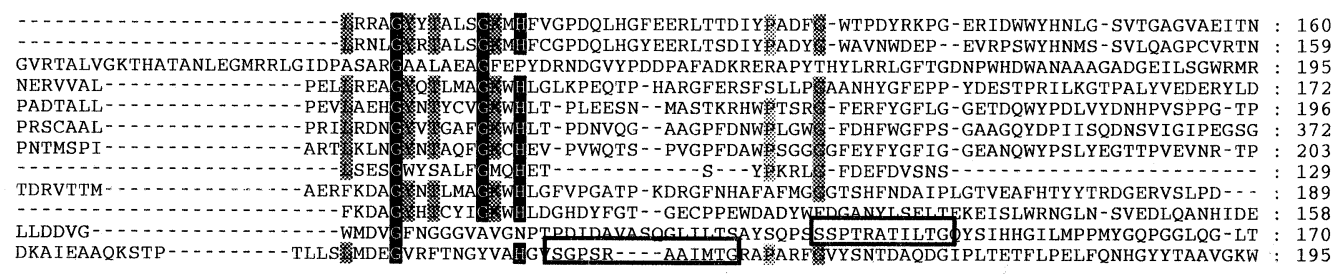

Sm_BetC
Pa_Orf504
Pa_Orf538
Pa_AtsA
Mt_AtsA
Mt_AtsB
Mt_AtsD
Mt_AtsG
Kp_AtsA
EC_YidJ
EC_As1A
Ec_Orff571
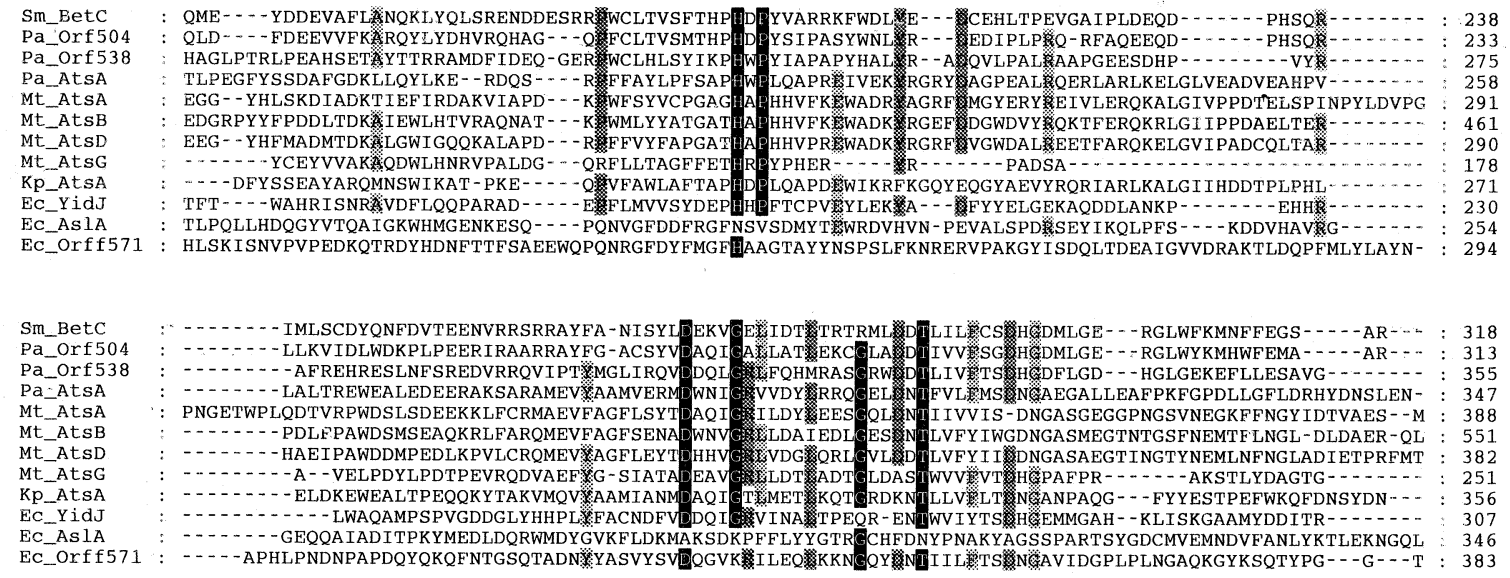

$\begin{array}{lc}\text { Sm_BetC } & : \\ \text { Pa_Orf504 } & \vdots \\ \text { Pa_Orf538 } & \vdots \\ \text { Pa_AtsA } & \vdots \\ \text { Mt_AtsA } & \vdots \\ \text { Mt_AtsB } & \vdots \\ \text { Mt_AtsD } & \vdots \\ \text { Mt_AtsG } & \vdots \\ \text { Kp_AtsA } & \vdots \\ \text { Ec_YidJ } & \vdots \\ \text { Ec_AslA } & \vdots \\ \text { Ec_Orff571 } & :\end{array}$
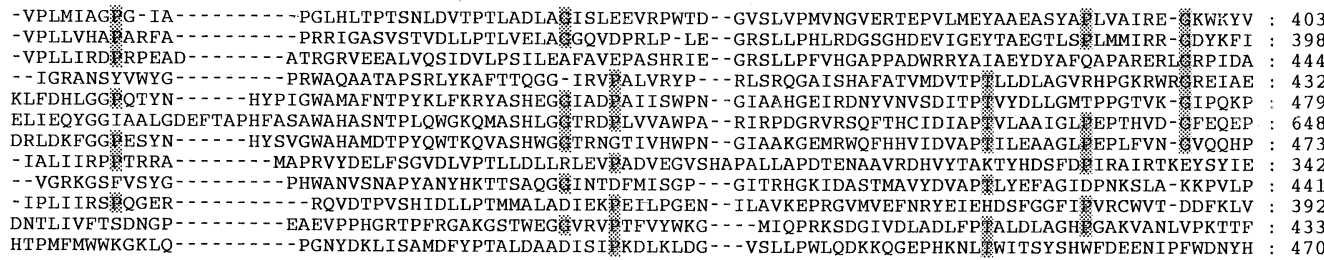

$\begin{array}{lc}\text { Sm_BetC } & : \\ \text { Pa_Orf504 } & : \\ \text { Pa_Orf538 } & \vdots \\ \text { Pa_AtsA } & : \\ \text { Mt_AtsA } & : \\ \text { Mt_AtsB } & : \\ \text { Mt_AtsD } & : \\ \text { Mt_AtsG } & \vdots \\ \text { Kp_AtsA } & : \\ \text { Ec_YidJ } & \vdots \\ \text { Ec_As1A } & : \\ \text { Ec_Orff571 } & :\end{array}$

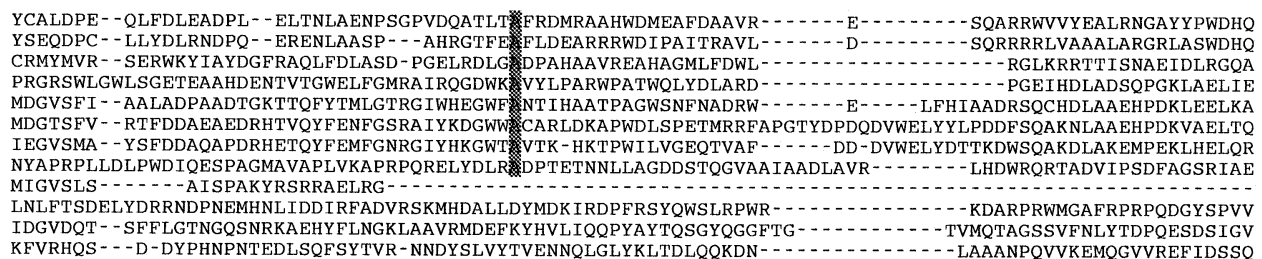

SQARRWVVYEALRNGAYYPWDHQ

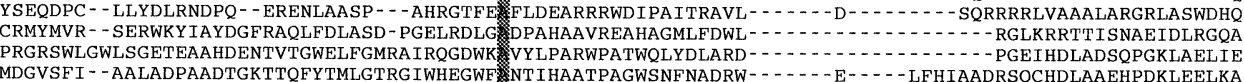

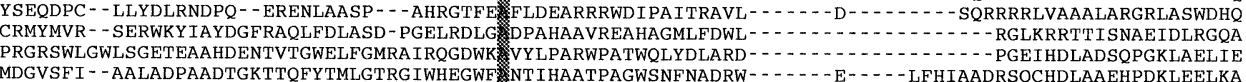
MDGVSFI - -AALADPAADTGKTTQFYTMLGTRG IWHEGWF NTI I HAATPAGWSNFNADRWIEGVSMA - -YSFDDAQAPDRHETQYFEMFGNRG IYHKGWT' VTK - HKTPWILVGEOTVAF- - - - -DD-DVWELYDTTKDWSQAKDLAKEMPEKLHELQR NYAPRPLLDLPWDIQESPAGMAVAPLVKAPRPQRELYDLR DPTETNNLLAGDDSTQGVAAIAADLAVR - - - - LHDWRQRTADVIPSDFAGSRIAE LNLFTSDELYDRRNDPNEMHNLIDDIRFADVRSKMHDALLDYMDK IRDPFRSYQWSLRPWR- -1 Ec_AslA

$: 483$
$: 475$
$: 521$
$: 512$
$: 565$
$: \quad 746$
$: 563$
$: \quad 434$
$: \quad 464$
$: 576$
$: 549$

Fig. 3. Sequence comparison of bacterial arylsulfatases and related proteins. The proteins shown are: S. meliloti BetC (512 aa), P. aeruginosa Orf504 (504 aa), Orf538 (538 aa) and AtsA (536 aa), M. tuberculosis AtsA (787 aa), AtsB (970 aa), AtsD (787 aa) and AtsG (465 aa), K. pneumoniae AtsA (464 aa), E. coli YidJ (497 aa), AslA (551 aa) and Orf f571 (571 aa). The alignment was done with CLUSTALW, and identical residues are indicated by shading. The cysteine/serine that is modified to formylglycine is indicated with a star, and the consensus modification sequence motif (PROSITE Sulfatase box 1) is overlined. In the AslA and Orf f571 proteins, this consensus sequence does not align well with the other sequences, and is boxed separately.

in the human lysosomal arylsulfatases A $[123,124]$ and B [125]. A lack of the ability to carry out the Cys $\rightarrow$ FGly modification is the cause of the lysosomal storage disease MSD, in which the activities of all the lysosomal sulfatases are severely reduced [97]. The FGly residue is also found in the sulfatase of the alga Volvox carteri [126], and in the two bacterial sulfatases from $P$. aeruginosa [13] and $K$. pneumoniae [98]. In $P$. aeruginosa it is formed by mod- 
ification of a cysteine residue, as in the eukaryotic sulfatases, whereas in $K$. pneumoniae it arises by modification of a serine residue. Modification of the bacterial sulfatases was demonstrated by reduction of the aldehyde group of the purified enzymes with $\left[{ }^{3} \mathrm{H}\right]$ sodium borohydride, tryptic digestion, and radiosequencing of the corresponding peptide. This revealed that cysteine-51 of the Pseudomonas arylsulfatase and serine-72 of the Klebsiella enzyme had been modified, and the nature of the modification was confirmed by MALDI-MS of the peptide in its native state, and after treatment with nitroaniline, which reacts with aldehyde groups [13]. A striking difference between the two enzymes was that the Klebsiella sulfatase was only circa $40 \%$ modified $[98,119]$, whereas the Pseudomonas enzyme was $100 \%$ converted to the FGly form [13], probably reflecting a difference in the efficiency of the cysteine and serine modification processes.

X-ray structural analysis of the human arylsulfatases A and B $[127,128]$ has shown that the FGly in these proteins is present in the active site of the enzyme, as its hydrate or sulfate ester hemiacetal, at the base of a positively charged pocket. This hydrate is thought to play an essential role in the putative catalytic mechanism outlined in Fig. 4. Replacement of the cysteine in the active site of the human sulfatases by serine led to a complete loss of enzyme activity [125]. It is therefore particularly interesting that the serine residue of the Klebsiella sulfatase can be modified to FGly. The initial study showed that this was carried out with arylsulfatase isolated from $K$. pneumoniae [98], but the enzyme was also active when expressed in $E$. coli [99,119]. The Pseudomonas enzyme was also active when expressed in E. coli, but all activity was lost when the cysteine- 51 residue was replaced by a serine or an alanine [13]. Identical results were obtained when the Pseudomonas sulfatase and its C51S and C51A mutant forms were transformed into a $\Delta$ atsA strain of $P$. aeruginosa or into $K$. pneumoniae [13]. These data suggest that two separate systems exist for modification of cysteine or serine residues within the conserved sulfatase motif, and that the Ser-specific modifying system of $E$. coli is incapable of recognizing the serine form of the Pseudomonas sulfatase.

The proposed classification of sulfatase-modifying enzymes into Cys-specific and Ser-specific systems has mechanistic implications (Fig. 5). Conversion of a serine residue to FGly requires merely an oxidation, whereas the modification of cysteine to FGly proceeds formally via oxidation to the thio-aldehyde, followed by a hydrolytic step. The activation enzymes for serine and cysteine have not yet been identified in any organism, but they are therefore likely to be oxidoreductases. Schirmer and Kolter [129] have compared this reaction with the oxidative conversion of aspartate to oxaloacetate via iminoaspartate [130], but this has not yet been tested experimentally. These authors postulate an oxygen-dependent reoxidation of the cofactor. However, there must be other mechanisms, since the Pseudomonas arylsulfatase can be overexpressed in active form in E. coli cells grown under anaerobic conditions [131]. As mentioned above, the Cys-type Pseudomonas sulfatase is an intracellular enzyme, whereas the Ser-type sulfatase of Klebsiella is periplasmically located. This correlation between sulfatase type and putative cellular location has also been found in all other hypothetical sulfatases that have been identified through genome analysis (see below) This leads to the interesting possibility of a spatial separation between the two modifying systems, i.e. that the Cys-modifying system is located in the cytoplasm, whereas the Ser-modifying enzyme either is located in the periplasm or is obligatorily linked to transport through the membrane. An analogous situation to the latter is found for human sulfatases, for which the modification process occurs at a late stage of protein translocation into the endoplasmic reticulum [125].

Searching the databases for the consensus sequence for the arylsulfatase consensus motif led to the discovery of several other enzymes that contain this motif and catalyze related reactions. Thus, the alkaline phosphatase of $P$. aeruginosa (accession number AF047381) and the phosphonate monoester hydrolase of Burkholderia caryophylli [133] also contain the modification sequence, though it has not yet been shown that either of these is indeed modified in the active site. In addition, if the essential core sequence C/S-X-P-X-R [119] is combined in a search with mismatched versions of the auxiliary element AALLTGR, then further proteins are found that almost match the consensus [134]. It will be interesting to determine in future whether any of these indeed contain FGly, and if this modification therefore plays a wider role in cellular metabolism.

\subsubsection{Arylsulfatase genes in P. aeruginosa and K. pneumoniae}

An obvious candidate for the Ser-modification enzyme is found immediately when the genetic structure of the arylsulfatase gene in K. pneumoniae is examined. This is the ats $B_{K p}$ gene product, which is encoded in a bicistronic operon with the ats $A_{K p}$ gene, encoding the arylsulfatase (Fig. 6) [99,119] (for clarity's sake, a subscript is added to the ats genes here, $K p$ for $K$. pneumoniae, and $P a$ for $P$. aeruginosa). The ats $B_{K p}$ gene product is required for synthesis of active arylsulfatase, and was originally proposed to be a transcriptional activator for the ats $B A$ operon [135]. However, the $45-\mathrm{kDa}$ AtsB protein does not show any of the motifs expected for a transcriptional regulator (e.g. helix-turn-helix DNA binding regions), and expression of the ats $A_{K p}$ gene behind the strong lac promoter in $E$. coli in the absence of ats $B_{K p}$ yielded only inactive arylsulfatase [119]. When this inactive arylsulfatase was purified, it was found that the serine at position 72 was completely unmodified. However, co-expression of the ats $A_{K p}$ and ats $B_{K p}$ genes on separate plasmids led to synthesis of an active sulfatase, in which the arylsulfatase ser- 72 was $50 \%$ modified to FGly [119]. The AtsB protein 
contains 12 cysteine residues in three clusters whose arrangement (cluster 1: $\mathrm{C}-\mathrm{X}_{3}-\mathrm{C}-\mathrm{X}_{2}-\mathrm{C}$; cluster 2: $\mathrm{C}-\mathrm{X}_{5}-\mathrm{C}$ $\mathrm{X}_{14}-\mathrm{C}$; cluster 3: $\left.\mathrm{C}-\mathrm{X}_{2}-\mathrm{C}-\mathrm{X}_{5}-\mathrm{C}-\mathrm{X}_{3}-\mathrm{C}-\mathrm{X}_{18}-\mathrm{C}\right)$ is reminiscent of [Fe-S] iron sulfur centers [129]. This structure is consistent with the putative function of the modification enzyme as an oxidoreductase. The deduced protein does not carry a signal peptide, and appears to be a soluble, cytoplasmic protein. Since the Klebsiella arylsulfatase is a periplasmic enzyme, this implies that modification of the serine-72 residue occurs prior to translocation into the periplasm. An arylsulfatase-negative mutant of $K$. pneumoniae could be complemented with the ats $B A_{K p}$ genes, demonstrating that this strain contains only one sulfatase isozyme that was expressed under the conditions used [99].

In $P$. aeruginosa the ats genetic organization is somewhat different. Since the Pseudomonas arylsulfatase is a cytoplasmic enzyme, an uptake system is required to transport the charged sulfate esters into the cell. The genes encoding such an uptake system are indeed found upstream of the ats $A_{P a}$ gene (Fig. 6) ([136], accession number Z48540). Similarity searches revealed that the ats $B C_{P a}$ genes are similar to the permease and ATP binding components of ABC-type transporters, respectively. Transporters of this type are normally composed of two permease components within the cell membrane, each of which is made up of six transmembrane helices, and two ATP binding subunits which are located peripherally to the cytoplasmic side of the cell membrane $[137,138]$. In addition, a high-affinity substrate binding protein located in the periplasm is responsible for delivering the specific substrate to the membrane component. The $58-\mathrm{kDa}$ ats $B_{P a}$ gene product is larger than most characterized permease components, and contains 12 putative transmembrane helices. It is therefore equivalent to a dimer of six-helix components, and presumably interacts with two molecules of the AtsC protein, which was identified as the ATP binding subunit by the presence of the conserved Walker motifs $\mathrm{A}$ and $\mathrm{B}[139,140]$. The ats $B$ and ats $C$ genes overlap by four nucleotides. A fourth gene, ats $R_{P a}$, lies divergent to the ats $B C A$ operon, and encodes a periplasmic protein. The role of these proteins was confirmed by insertional inactivation of either the ats $R_{P a}$ or ats $B_{P a}$ genes with a gene cassette encoding gentamicin resistance (Gm) [136]. Both atsR::Gm and atsB::Gm mutant strains were unable to grow with aromatic sulfates, and whereas the atsR: :Gm mutant still produced arylsulfatase, the polar effect of the ats $B_{P a}$ insertion led to a loss of arylsulfatase activity as well. Complementation of the ats $B_{P a}$ mutant with the $a_{S A} A_{P a}$ gene under lac control led to restoration of arylsulfatase activity but not of growth with arylsulfates.

The ats $R_{P a}:: G m$ and ats $B_{P a}:: G m$ mutants are also defective in utilization of hexyl sulfate as a sulfur source, and the AtsRBC transport system therefore constitutes a general transporter for sulfate esters. It also plays a role in the transport of aromatic sulfonates, as discussed below. Interestingly, the Pseudomonas arylsulfatase does not hydro- lyze alkylsulfate esters, so an alkylsulfatase gene must also be present elsewhere on the chromosome.

$P$. aeruginosa contains only one gene with significant similarity to the ats $B_{K p}$ gene, nirJ, whose gene product shows $25 \%$ identity to $\mathrm{AtsB}_{\mathrm{Kp}}$ in the N-terminal domain. However, since the nirJ gene is part of an extensive ANRregulated operon encoding the dissimilatory nitrite reductase [141], it seems unlikely that the NirJ protein is involved in sulfatase maturation. It is also interesting to note that Synechocystis contains an ats $B_{K p}$ homologue (ORF slr1507 [142]), but does not contain any genes encoding putative sulfatases. Together, these data suggest that (i) although the ats $B_{K p}$ gene product is essential for Ser-type sulfatase maturation in enteric bacteria [119], other species have developed alternative strategies to carry out this modification, and (ii) there may be other proteins that require the FGly modification for activity.

\subsubsection{Putative sulfatase genes in bacterial genome sequences}

In recent decades there has been no systematic search for bacterial species that possess arylsulfatase activity, and since earlier screens were done before it was recognized that expression of bacterial arylsulfatase genes is often repressed in the presence of sulfate [35], the value of these studies is somewhat limited. Since the start of the 'genomic age' it has become possible to complement biochemical searches by in silico screening of published bacterial genome sequences for open reading frames with sequence similarity to known sulfatase genes. The arylsulfatase gene sequences from $P$. aeruginosa, $K$. pneumoniae and $A$. carrageenovora were used as probes to search the nonredundant GenBank database, the completed bacterial genomes, and the $P$. aeruginosa partial genome sequence for arylsulfatase homologues using the BLAST algorithm [143].

The results are summarized in Figs. 3 and 6, and were somewhat surprising. Putative sulfatases were found in E. coli, P. aeruginosa, and Mycobacterium tuberculosis, i.e. in exactly those species where arylsulfatase enzymes have already been studied. In the 19 other complete genomes and 20 incomplete genome projects examined, only three species contained arylsulfatase homologues: Bordetella pertussis [144] and Salmonella typhi [144] each contained two putative Cys-type sulfatases, and Yersinia pestis [144] had two Cys-type and one Ser-type sulfatases. The sulfatase sequences in these three organisms were not examined further, as the genome sequences are not yet complete. P. aeruginosa, M. tuberculosis and E. coli were also found to contain multiple arylsulfatase genes $[122,145,146]$. Thus, $P$. aeruginosa contained three arylsulfatase copies, of which one is presumably choline sulfatase [147], a second is an arylsulfatase [11], and the third is similar to a published phosphonate monoester hydrolase [133]. M. tuberculosis contained four different sequences with similarity to arylsulfatases [146]. The best described 
set of sulfatase genes is the three putative sulfatases found in E. coli [29], and is particularly interesting because this organism does not grow with sulfate esters as sulfur sources, and the putative sulfatase genes are all cryptic. All the putative sulfatase genes encoded proteins which contained the FGly modification sequence, carrying either a cysteine or a serine in the position to be modified. The putative Ser-type sulfatases also carried a putative signal sequence, for export to the periplasm, as noted by Schirmer and Kolter [129], whereas the Cys-type sulfatases appear to be cytoplasmic.

More information can be obtained from the genetic environment of the putative sulfatase genes (Fig. 6). The Sertype sulfatases found in enteric bacteria (aslA and orf f571 in E. coli and ats $A_{K p}$ in $K$. pneumoniae) are all found in close proximity to a gene encoding the putative activator protein (aslB, orf $f 390$ and ats $B_{K p}$, respectively). An activator of this sort was not found near the genes encoding the Cys-type sulfatases (indeed, there is no evidence that either $P$. aeruginosa or $M$. tuberculosis contain an ats $B_{K p}$ homologue). The Cys-type sulfatases almost all occur in gene clusters which encode transport proteins of some sort, underlining the putative location of the Cys-type sulfatases within the cell, and perhaps providing some evidence about their function. Thus, the ats RBC genes of $P$. aeruginosa are thought to be involved in uptake of aliphatic and aromatic sulfate esters, and the genes preceding the choline sulfatase in this species may be connected with choline sulfate transport. The E. coli yidJ gene, encoding a putative Cys-type sulfatase (Fig. 6), is distal to a gene encoding a putative glucose transporter, implying a possible function in glucose-sulfate uptake.

The presence of multiple arylsulfatase genes in each genome where sulfatase genes were found makes it tempting to draw conclusions about the occurrence of arylsulfatase isozymes often reported earlier [35]. For example, if one of the three sulfatases present on the genome of $P$. aeruginosa were cryptic in one isolate, and expressed in another, this would explain the observed differences in the number of isozymes in different reports $[11,109]$. Several species of enteric bacteria, in particular, seem to contain several sulfatase genes. It will be interesting to learn whether these are all pseudogenes, or whether the encoded proteins are expressed under conditions that have not yet been discovered and catalyze the desulfation of substrates that have not yet been tested.

\subsubsection{Regulation of bacterial arylsulfatase expression}

With the exception of the arylsulfatase from $A$. carrageenovora [83], expression of all the bacterial arylsulfatases which have been studied biochemically is subject to repression during growth in the presence of inorganic sulfate, and derepression during growth with organosulfur sources such as methionine or alkanesulfonates $[11,21,35]$. This regulatory pattern strongly suggests that the role of these enzymes in nature is exclusively in the assimilation of sul- fur for bacterial growth, and that the arylsulfatases are an important part of the bacterial sulfate starvation response.

However, arylsulfatase expression is repressed not only by sulfate, but also during growth with cysteine or with cysteine biosynthetic intermediates such as sulfite or sulfide. This pattern of regulation is reminiscent of the control of cysteine biosynthesis, which has been best characterized in enteric bacteria [5,17]. In these species, activation of the genes of the cys regulon is mediated by the CysB protein, together with $N$-acetylserine, which acts as a co-inducer, and with sulfide or thiosulfate, which act as anti-inducers. In $P$. aeruginosa, expression of ats $B$ : : lac $Z$ and ats $R$ : :lac $Z$ fusions was also found to require an active CysB protein [136]. Although the pathways of cysteine and methionine biosynthesis in P. aeruginosa and $E$. coli differ slightly $[19,20,148]$ (Fig. 1), this demonstrates that the arylsulfatase gene cluster constitutes an extension of the cys regulon in the former species.

The question of how sulfate, sulfite and sulfide cause gene repression in $P$. aeruginosa is more complex. In principle, sulfate may exert its repressive effect either directly or after conversion to another metabolite, probably (but not certainly) in the cysteine biosynthetic pathway. In order to isolate the effects of different intermediates of the pathway, defined mutants were constructed in the cys $N$ (sulfate activation) and cysI (sulfite reductase) genes of $P$. aeruginosa, and the ability of sulfate, sulfite or sulfide to repress arylsulfatase synthesis in these mutants was studied (Table 3). Inorganic sulfate did not repress sulfatase formation in a cys $N$ mutant, but did so in a cysI strain, suggesting that either PAPS or sulfite was acting as a repressor. $c y s N$ and $c y s I$ mutants grown with sulfide also did not synthesize arylsulfatase, and since cysteine does not repress arylsulfatase completely in $P$. aeruginosa [20], it seems likely that sulfide is also a repressor. At least two independent compounds are hence active as repressors in vivo in this species. Alternatively, the active repressor of sulfatase synthesis is a separate, uncharacterized molecule that can be synthesized from either of these two precursors.

A similar study was carried out in $K$. pneumoniae by Adachi et al. [100], but with very different results. Here, too, a strategy was adopted that made use of mutants in cysteine biosynthesis, but the mutants were defined only physiologically, and not at a genetic level. Synthesis of arylsulfatase was repressed independently by intracellular sulfate and by cysteine, but not by sulfite, sulfide or thiosulfate directly. Unfortunately, the role of CysB in regulation of arylsulfatase expression in K. pneumoniae has not yet been examined.

Arylsulfatase synthesis in enteric bacteria is regulated not only by sulfur supply, but also by monoamine compounds such as tyramine, dopamine, or norepinephrine. In the presence of tyramine, sulfate-mediated repression of arylsulfatase synthesis is overridden, and arylsulfatase is expressed, together with other genes of the monoamine 
(moa) regulon, including monoamine oxidase (mao $A$ ), tyramine oxidase $(\operatorname{tyn} A)$ and several uncharacterized genes [135]. This effect has been shown to be mediated by the positive regulator protein MoaR, a $26-\mathrm{kDa}$ protein which is related to response regulators of the two-component sensor-regulator family. Expression of moaR is subject to catabolite repression [149], and the expression of arylsulfatase as part of the moa regulon may therefore imply its involvement in central metabolism. It has indeed been proposed [135] that the monoamine regulon in enteric bacteria is primarily concerned with utilization of dopamine sulfate, since dopamine, like many other phenols and catechols, is transported in human systems as its less reactive sulfate ester. A similar derepression of arylsulfatase expression by monoamine compounds has been observed in several other enteric bacteria, including $S$. typhimurium, $S$. marcescens, and also $E$. coli, in which the cryptic ats $A$ gene was found to be induced by tyramine, using an ats $A:$ : lac $Z$ fusion as a reporter system [150]. Tyramine does not derepress arylsulfatase synthesis in $P$. aeruginosa [11].

A mutant of $K$. pneumoniae has also been reported in which arylsulfatase was expressed constitutively, regardless of the sulfur source supplied [100]. The wild-type phenotype was regained when the mutant was transformed with the ats $R_{K p}$ gene [151]. The encoded protein showed significant similarity ( $89 \%$ identity) to the dihydrofolate reductase of $E$. coli. Expression of the ats $R$ gene on a plasmid led to increased dihydrofolate reductase activity in the cells, and the $E$. coli folA gene was also able to complement the ats $R$ mutation in $K$. pneumoniae. However, the significance of this link between arylsulfatase synthesis and C-1 metabolism remains unclear.

A further important regulatory aspect of arylsulfatase synthesis is how synthesis of the corresponding modification system(s) is controlled. Very little is yet known on this subject, but it is clear already that the modification systems are not regulated by sulfur supply, since in E. coli both the Pseudomonas and Klebsiella arylsulfatases are expressed in active form after growth in LB medium, if the ats $A$ genes are expressed behind the lac or $\mathrm{T} 7$ promoters $[13,119]$. It seems possible that the modification systems are important in another role that has yet to be identified, and that their expression is therefore either constitutive or regulated by other factors.

\subsection{Alkylsulfatases}

Alkylsulfatases differ from arylsulfatases not only in their substrate range, but also from a mechanistic point of view. Whereas arylsulfatases cleave the O-S bond of their substrates (a mechanism which is consistent with (but not indicative of) the presence of a FGly hydrate in the active site (Fig. 4)), the long-chain alkylsulfatases break the $\mathrm{C}-\mathrm{O}$ bond and do not form a covalent enzyme-sulfate intermediate (reviewed in [35]). It therefore seems unlikely that the long-chain alkylsulfatases share the FGly modification found in the arylsulfatases. By contrast, the short-chain alkylsulfatase synthesized by the coryneform strain B1a also catalyzes cleavage of the O-S bond [152], but no further data are yet available concerning its mechanism.

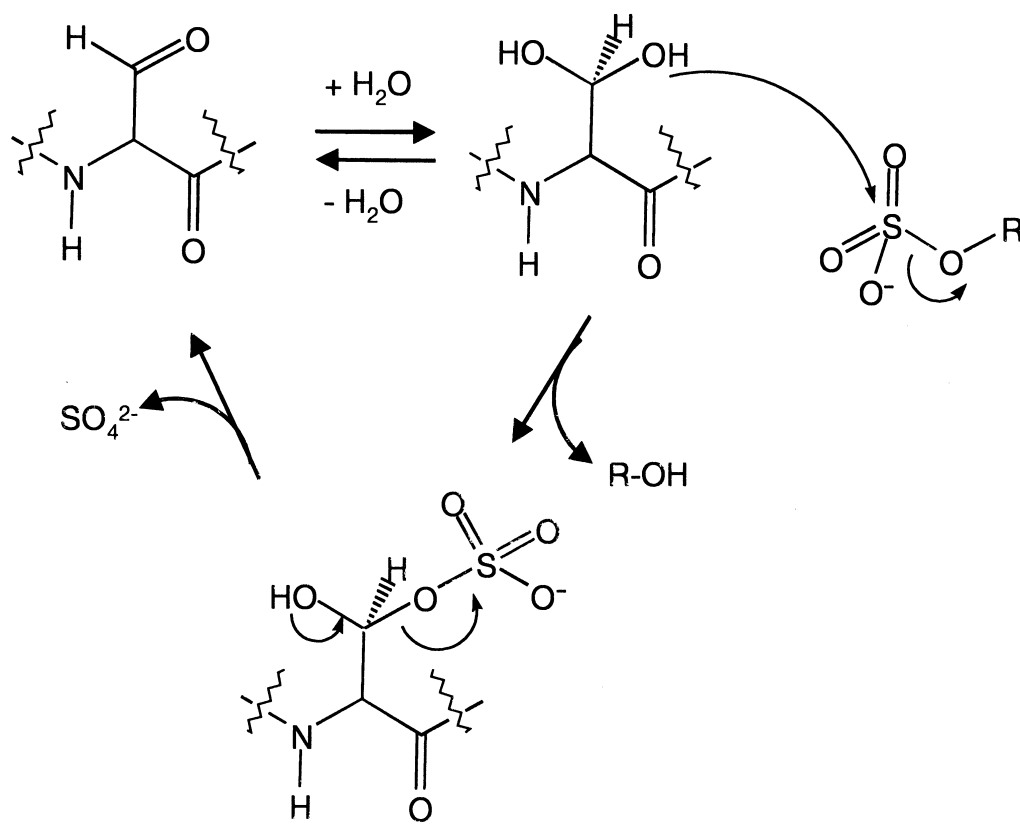

Fig. 4. Proposed mechanism of sulfate ester cleavage in arylsulfatases (adapted from [96]). The hydrate form of the active site formylglycine attacks the sulfate ester, breaking the S-O bond and forming a covalent enzyme-sulfate intermediate. This intermediate decomposes to regenerate the aldehyde form, which is then rehydrated in the active site by addition of a water molecule. 


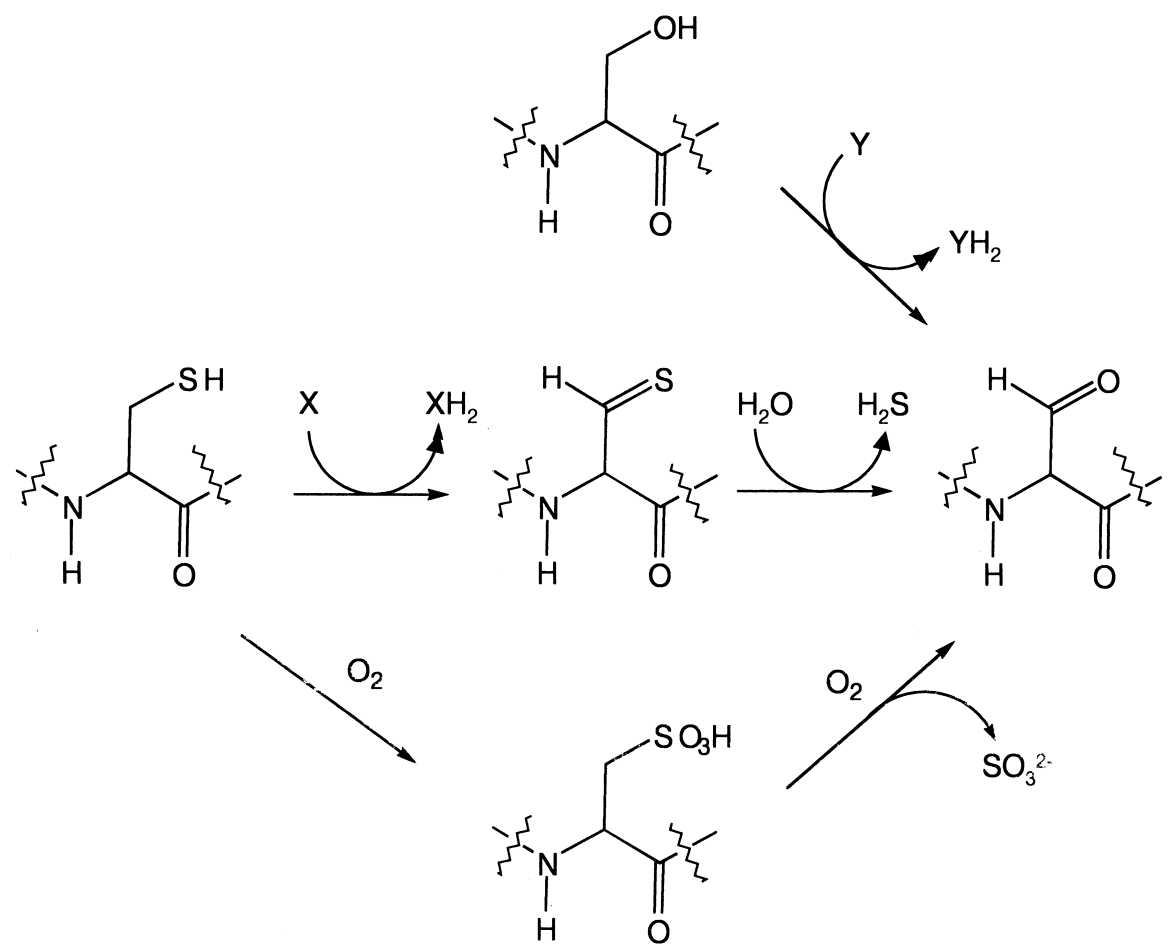

Fig. 5. Mechanisms for formylglycine formation in Cys-type and Ser-type arylsulfatases. Conversion of serine requires only an oxidative step, with unknown electron acceptor, whereas cysteine conversion requires an additional hydrolytic step. Alternatively, cysteine oxidation to cysteate and subsequent oxygenolytic cleavage would also lead to the desired aldehyde.

All of the alkylsulfatases described to date come from Gram-negative bacteria, though a Bacillus cereus strain is known that will grow with dodecyl sulfate [153]. Alkylsulfatases were included in an extensive review in 1982 [35], which detailed many of the earlier results obtained. Much of this work was carried out with the strain Pseudomonas $\mathrm{C}_{12} \mathrm{~B}$, an isolate from a sewage outlet which synthesizes as many as five separate alkylsulfatases. Two of these are specific for primary sulfates, but differ in the pattern of their regulation, one being constitutively expressed, and the other inducible. The remaining three alkylsulfatases are specific for secondary sulfate esters; two of these are constitutive enzymes that specifically hydrolyze either Dor L-isomers, while the third secondary alkylsulfatase is an inducible enzyme. The two inducible enzymes are also repressed by primary alcohols (the products of the sulfatase reaction), and by tricarboxylic acid cycle intermediates, suggesting that catabolite repression plays a role in regulation of these enzymes.

This regulatory pattern immediately suggests that these enzymes are not part of the sulfur cycle, but are used to provide carbon and energy for bacterial growth. It should be noted, however, that most alkylsulfatase studies have been done with enzymes from bacterial strains that were isolated on the basis of their ability to mineralize sulfate esters completely (Pseudomonas $\mathrm{C}_{12} \mathrm{~B}$, for instance, was isolated for its ability to grow with dodecylsulfate as carbon source [154]). In their earlier review, Dodgson et al. [35] listed only two alkylsulfatases whose expression was repressed by inorganic sulfate: the lithocholate sulfate sulfatase of P. aeruginosa [155] and cholinesulfatase of Pseudomonas V-A [156]. In both these studies it is notable that the sulfate ester was supplied solely as sulfur source, and carbon for growth was provided by benzoate or citrate, respectively. It seems likely that more sulfate-regulated bacterial alkylsulfatases still await discovery if suitable growth conditions are chosen.

Studies with the Pseudomonas $\mathrm{C}_{12} \mathrm{~B}$ alkylsulfatases revealed that these were specific for medium- or long-chain sulfate esters, but had little or no activity with substrates with a chain length less than $\mathrm{C}_{5}$. However, organisms have subsequently been isolated from soil, canal water and sewage which are able to grow with short-chain alkylsulfates as carbon source [157], and several of these have been examined in more detail. The sulfatase of the coryneform isolate $\mathrm{B} 1 \mathrm{~A}$ was active on $\mathrm{C}_{3}-\mathrm{C}_{7}$ primary alkylsulfates, but not on longer or shorter-chain homologues, nor on choline sulfate [152]. Methyl and ethyl sulfates acted as inhibitors of this enzyme ( $K_{\mathrm{i}}$ values of $5.3 \mathrm{mM}$ and 3.9 $\mathrm{mM}$ respectively), though these compounds were not themselves hydrolyzed by the enzyme. In two environmental isolates, Agrobacterium sp. strain M3C and Hyphomicrobium sp. strain MS223, methyl sulfate was not metabolized by a hydrolytic mechanism, but via an oxidative pathway $[158,159]$. Although initial studies had suggested that the Hyphomicrobium pathway might involve a hydrolytic enzyme, an elegant study using ${ }^{13} \mathrm{C}$-labelled methyl sulfate demonstrated that in both species methylsulfate is 
E. coli

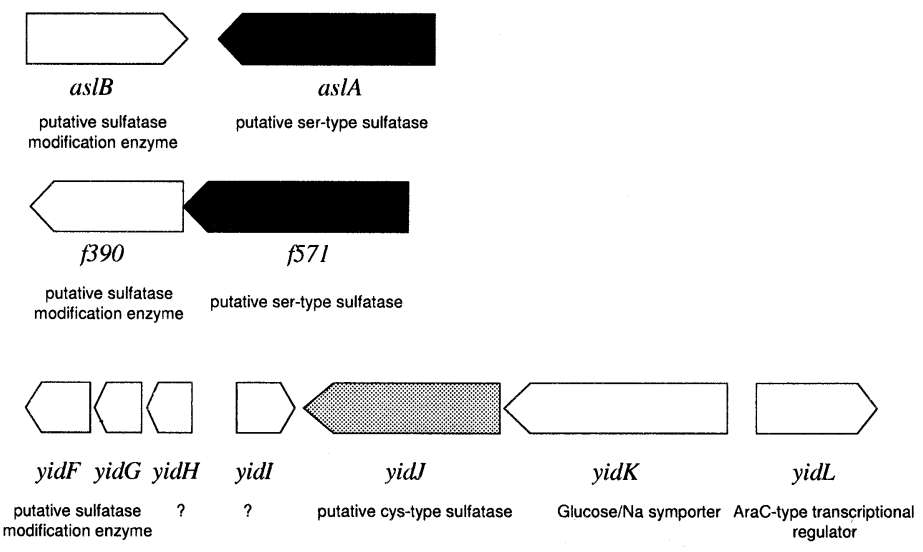

\section{K. pneumoniae}

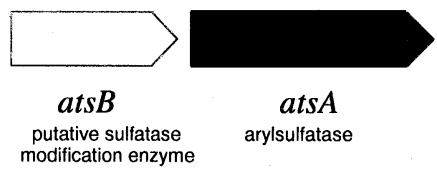

S. meliloti

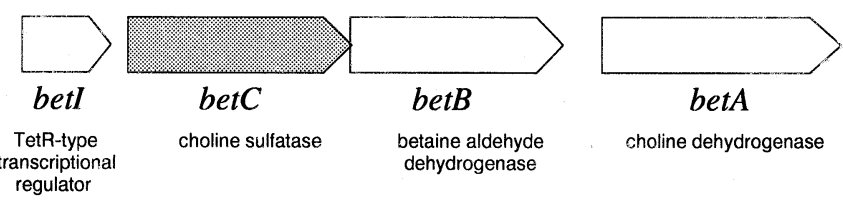

\section{$P$. aeruginosa}

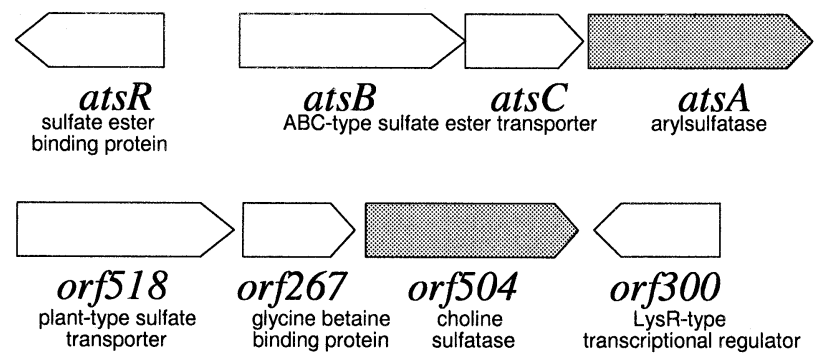

Fig. 6. Genetic structure of selected bacterial sulfatase gene clusters. Hypothetical function assignment of uncharacterized ORFs was done using BLAST [143]. The sequences are from: E. coli [129,145], P. aeruginosa [11,122,136], K. pneumoniae [99,119], S. meliloti [162]. Genes containing Ser-type sulfatases are shaded black, and those encoding Cys-type sulfatases are shaded gray.

converted directly to formaldehyde and sulfate, and that methanol is not an intermediate in this process [160]. A mechanism was proposed involving initial oxygenation to methanediol monosulfate by a monooxygenase, followed by spontaneous decay of the hemiacetal to yield formaldehyde and sulfate. Electron microscopic studies have revealed that whereas the long-chain-specific sulfatases of Pseudomonas sp. strain $\mathrm{C}_{12} \mathrm{~B}$ were localized on the outer cell wall, the short-chain-specific enzymes in a coryneform species were intracellular [161].
From a genetic point of view, very little is known about alkylsulfate degradation, either in the carbon cycle or in the sulfur cycle. Gene sequences have been determined for a choline sulfatase (betC) from Sinorhizobium meliloti [162], for a bile acid sulfatase from Comamonas testosteroni $[163,164]$, and for a putative dodecylsulfate sulfatase ( $s d s A$ ) from the detergent-degrading strain Pseudomonas sp. ATCC $19151[165,166]$. The proteins encoded by the two latter genes appear to be related, and do not contain an FGly modification motif. The bet $C$ gene from $S$. meli- 
loti, by contrast, belongs to the same family as the eukaryotic arylsulfatases and the $P$. aeruginosa arylsulfatase, and is a Cys-type sulfatase that appears to be located within the cell (no signal sequence was found) (Fig. 6).

The alkylsulfatase gene of Pseudomonas sp. ATCC 19151, $s d s A$, was identified by complementation of several mutants derived from a previously described SDS-utilizing strain. Two genes were identified that were required for SDS utilization, $s d s A$ and $s d s B$. The putative SdsB protein is a member of the LysR family of transcriptional regulators, and is closely related to the regulatory protein required for arylsulfonate desulfonation in $P$. putida, described below. The regulatory role of the $\mathrm{SdsB}$ protein was confirmed by the fact that the SDS-negative phenotype of an $s d s B$ mutant could be complemented by an $s d s A$ gene expressed constitutively behind the T7 promoter. SdsB therefore seems to be required for expression of the $s d s A$ gene, which encodes a $59-\mathrm{kDa}$ protein. This protein was expressed in $E$. coli, but did not show detectable sulfatase activity. The lack of a signal peptide suggests that the encoded protein is intracellular, which contrasts with the observations that sulfatase activity in Pseudomonas sp. ATCC 11951 is periplasmically located, and it was suggested that the secretion sequence might be an atypical one, and not recognized in the heterologous host. Homologues of SdsA are found in E. coli (YjcS; 73 kDa, 32\% amino acid identity to SdsA), and in $P$. aeruginosa (30\% identity over the full length of the protein), and are related to lactamases from several organisms.

A homologue of SdsA (27\% identity) has also been identified in Comamonas (Pseudomonas) testosteroni, where it catalyzes the hydrolysis of bile acid sulfates [163]. The organism was identified in a collection of strains for its ability to utilize lithocholic acid as a source of carbon and sulfur for growth, and the sulfatase was isolated and found to be a homodimer of 53-kDa subunits. Sulfatase activity was $\mathrm{Mn}^{2+}$-dependent. Synthesis of the sulfatase was found to be completely repressed by $800 \mu \mathrm{M}$ inorganic sulfate. Since the organism was grown with $2 \mathrm{mM}$ lithocholic acid sulfate as carbon source, it is not clear why the excess sulfate released as a result of the differential cellular requirements for carbon and sulfur did not repress synthesis of the enzyme in vivo. One can speculate that the sulfatase is involved only in release of the sulfur, whereas the carbon-based degradation of the steroid skeleton was carried out by a separate system, leaving the sulfate ester bond intact. A second, biochemically similar sulfatase has recently been isolated from the same organism [167], but sequence data have not yet been reported.

A further type of alkylsulfatase has recently been reported in S. meliloti [162]. The BetC protein catalyzes the hydrolysis of choline sulfate to choline, and is part of a pathway that synthesizes the osmoprotectant glycine betaine. However, the organism can also utilize choline sulfate as a source of carbon, nitrogen and sulfur for growth. Expression of the sulfatase was induced by choline or choline sulfate, but not by sulfate limitation. This induction was slightly decreased under osmotic stress, and the sulfatase may therefore be involved in the metabolism of choline, rather than in osmoprotectant synthesis (choline sulfate itself showed only low osmoprotectant activity). Choline sulfatase has also been characterized from $P$. aeruginosa [147]. Its synthesis is tightly regulated in this species, since the level of enzyme produced depended on whether the substrate was being utilized by the cell as a source of carbon (22.8 nmol min $\mathrm{mg}^{-1}$ protein), nitrogen $\left(18.5 \mathrm{nmol} \mathrm{min} \mathrm{mg}^{-1}\right)$, or sulfur (4.1 nmol min $\mathrm{mi}^{-1}$ $\left.\mathrm{mg}^{-1}\right)$. The product of the putative $P$. aeruginosa choline sulfatase gene (orf504, Fig. 6) [122] shows 45\% identity to the $S$. meliloti BetC protein, and both contain the signature for a Cys-type sulfatase. Inhibitor studies carried out with the $P$. aeruginosa choline sulfatase [147] are consistent with a FGly residue constituting the active site as in arylsulfatases, but the presence of the modification has not yet been demonstrated.

\subsection{Carbohydrate sulfatases}

Most of the eukaryotic sulfatases are in fact carbohydrate sulfatases, acting on glycosaminoglycans as substrates [78]. Several bacterial sulfatases have also been characterized that belong to this group, including enzymes from Proteus vulgaris, Flavobacterium heparinum (now called Cytophaga heparina), and Bacteroides thetaiotaomicron. Glycosaminoglycan breakdown by these bacteria has been reviewed in detail [76], and involves the cleavage of the polymer by a lyase, usually extracellular, followed by desulfation of the resultant sulfated disaccharides and hydrolysis to the monosaccharide level by a glucuronidase. Bacteria that can carry out this process have been isolated primarily from soil, and degrade glycosaminoglycans as a source of carbon and energy for growth. No attempts appear to have been made to isolate bacteria that can utilize glycosaminoglycans solely as sulfur source for growth.

A further family of bacterial carbohydrate sulfatases has also recently been identified, which cleave the sulfate moiety from mucin. Mucin is particularly heavily sulfated in the mouth and in the colon, where bacteria are normally common, and the sulfation appears to help provide the mucin with a degree of protection from bacterial attack [168]. Strains of $B$. thetaiotaomicron, $P$. aeruginosa and Burkholderia cepacia were found to contain high levels of mucin sulfatase activity [169,170], a finding which is of importance in studies of cystic fibrosis, since the latter two species contribute significantly to the severity of this disease. Interestingly, an E. coli strain was also found to contain mucin sulfatase activity [170], and this may suggest a role for the uncharacterized sulfatase genes previously identified in the $E$. coli genome sequence [129]. 
The only putative bacterial carbohydrate sulfatase for which genetic data are available is the arylsulfatase of the marine Gram-negative aerobe $A$. carrageenovora. This enzyme has been proposed to play a role in degradation of sulfated fucans from brown algae [83], though these compounds were not directly tested as substrates for the enzyme. At the level of sequence similarity the Alteromonas ats $A$ gene product is not related at all to the arylsulfatases described above, and also lacks the conserved sulfatase motifs required for generation of the active site formylglycine residue that it present in the latter proteins. However, sequence homology searches indicate that the Alteromonas sulfatase is part of a family of proteins that include the product of the $E$. coli elaC gene, and a number of hypothetical proteins from several other species. No function has yet been assigned to other members of this family, though the $e l a C$ gene may be involved in lanthanide resistance (G. Huisman, personal communication), but they share a zinc binding motif with the glyoxalase and $\beta$-lactamase families [171]. These genes have nonetheless been grouped together as the AtsA/ElaC family [171], and many have been annotated in GenBank as putative sulfatases. The dissimilarity of this protein family to most characterized sulfatases underlines the dangers of assigning function directly from protein sequence similarities without further biochemical analysis.

Since most of the bacterial carbohydrate sulfatases are involved in pathways involved in utilization of glycosaminoglycans as carbon sources, it is not surprising that their expression is induced by their substrates, and is subject to catabolite repression. Most studies of glycosaminoglycan degradation have concentrated on the lyase enzymes, and have paid little attention to the sulfatases. Thus, synthesis of the chondroitin sulfate lyases (chondroitinases) from $C$. heparina and $P$. vulgaris is induced by chondroitin sulfate or dermatan sulfate in the growth medium [76]. In B. thetaiotaomicron chondroitinase was induced only by the polymeric substrate, and not by its disaccharide breakdown products [172]. In this species all the enzymes in the degradation pathway (lyase, two sulfatases, and glucuronidase) are induced by chondroitin sulfate [172], and repressed during growth with glucose [173], suggesting that catabolite repression may play a role in regulating expression of this pathway. The specificity of the chondroitin sulfatases from $C$. heparina has been studied, with the aim of using these enzymes as tools in structural studies of chondroitin sulfate. Chondro-4-sulfatase was found to desulfate sugar residues both at the reducing end and at internal positions of an oligosaccharide, whereas chondro6-sulfatase could only attack the end positions [174].

Degradation of heparin and heparan sulfate has been best studied in $C$. heparina. The breakdown pathway is initiated in this species by one of a family of three different heparinase enzymes that are located in the periplasm, and induced during growth with heparin. The resulting oligosaccharide sulfates are degraded further to the $N$ - and
$O$-sulfated monosaccharides. Desulfation is then carried out by a suite of monosaccharide sulfatases, several of which have been purified and characterized. These include a glyco-6- $O$-sulfatase [175], a glyco-3- $O$-sulfatase [176], both of which appear to be specific for monosaccharide residues, and a glyco-2- $O$-sulfatase which also accepts the terminal residue of oligosaccharides as substrate [177]. In addition, a sulfamidase has been purified from the same organism [178]. The glycosulfatases showed molecular masses of $58-64 \mathrm{kDa}$, very close to those reported for the bacterial arylsulfatases, and had optimum activity at $\mathrm{pH} 7.5-8.0$ for the 6-O- and 3-O-sulfatases and $\mathrm{pH}$ 5.5-6.5 for the glyco-2-O-sulfatase. By contrast, the sulfamidase is somewhat larger in size $(81.5 \mathrm{kDa})$, with a $\mathrm{pH}$ optimum of 7.0. No sequence data for these proteins are yet available at either the DNA or the protein level.

Evidence that glycosulfatases may be related to arylsulfatases comes from a study using $B$. thetaiotaomicron. A transposon mutant of this organism in the gene $c h u R$ was found to be unable to utilize either heparin or chondroitin sulfate as growth substrates [179]. This double phenotype was unexpected, since the two degradation pathways were thought to be independent of each other in this species. Biochemical characterization revealed that the mutant strain was defective in one of the two sulfatases involved in chondroitin sulfate degradation, chondroitin-6-sulfatase. Since the strain contains a second sulfatase, chondroitin-4-sulfatase, it was not clear why growth with chondroitin sulfate should have been disrupted, but as a chondroitin-4-sulfatase mutant was also unable to grow with chondroitin sulfate, a toxic effect due to accumulation of sulfated disaccharides was suggested. In addition, 2D-PAGE analysis of the chuR mutant showed reduced or zero synthesis of a number of proteins that were induced in the wild-type by chondroitin sulfate or hyaluronic acid (a related, non-sulfated polysaccharide) [180]. The initial conclusion was therefore that $c h u R$ encoded a regulatory gene that affected expression of chondroitin-6-sulfatase and an unidentified component of the heparin degradation pathway [179].

When the $c h u R$ gene was sequenced, it was found that the ChuR protein is $35 \%$ identical to the $\mathrm{AtsB}_{\mathrm{Kp}}$ protein of $K$. pneumoniae, which is required for expression of active Klebsiella sulfatase, and is thought to be involved in the modification of the active-site serine to a FGly (see above) $[119,129]$. It has therefore been proposed that the $c h u R$ gene product is responsible for a similar activation step of chondroitin-6-sulfatase, and of a sulfatase or sulfatases involved in heparin degradation [129]. If this is true, it would seem likely that the B. thetaiotaomicron sulfatases are Ser-type sulfatases, since $A_{t s} B_{K p}$ is involved in activation of a Ser-type sulfatase in $K$. pneumoniae [119]. Two arguments speak against this hypothesis. First, the $B$. thetaiotaomicron chondroitin sulfatases have been shown to be intracellular [181], and all the Ser-type sulfatases identified to date carry a signal sequence for export 
to the periplasm. Secondly, the changes in protein expression observed by 2D-PAGE in the chuR mutant are inconsistent with a role of ChuR solely as a modifying protein, though such an effect could be caused by decreased stability of the target proteins if they remain unmodified (as has been observed for the C51A mutant of $P$. aeruginosa arylsulfatase [13]). At least one sulfatase in $B$. thetaiotaomicron (chondroitin-4-sulfatase) also remained unaffected by the $c h u R$ mutation.

The regulation of the heparin degradation pathway has also been well studied, primarily in C. heparina. The earlier part of this work has been reviewed by Dodgson et al. [35]. Heparin lyase is most strongly induced in the presence of heparin or heparan sulfate, although the disaccharide breakdown products are also good inducers [182]. However, induction was also seen in the absence of heparin when the cells were grown in a sulfate-free medium with methionine as sole sulfur source [183]. During continuous growth in low-sulfate medium with methionine as sulfur source, synthesis of heparinase or heparin sulfatase could be temporarily turned off by addition of limited amounts of sulfate [16]. The critical concentration causing repression was found to be between 10 and $70 \mu \mathrm{M}$, at which levels the sulfatase activity was not itself directly inhibited. Similar concentrations of sulfate have been shown to repress desulfurization of sulfonates and sulfate esters in P. putida [184]. In C. heparina, repression of both heparinase and sulfatase was seen when cysteine was added. As pointed out by Cerbelaud et al. [16], the immediate drop in enzyme activity after addition of sulfate implies either the presence of specific proteases, or a high endogenous turnover rate for the enzymes. Similar arguments have been invoked by Beil et al. [184] to explain the repression of aromatic sulfonatases by sulfate or cysteine observed in P. putida S-313 (see below).

Bacteria hence synthesize a range of sulfatases in order to use the sulfur available to them as sulfate esters, and in the cases that have been studied, the hydrolytic mechanism involves a novel active-site residue, FGly, rather than a serine as might be expected by comparison with phosphatases. Cleavage of sulfonates also follows novel pathways in the sulfur cycle, as will be seen below.

\section{Novel oxygenases in the desulfonation of aliphatic sulfonates}

The widespread occurrence of sulfonates in natural environments (Table 2) leads one to expect that a range of bacteria may have evolved the capacity to degrade them as either carbon or sulfur sources for growth, and this is indeed the case. Recent studies have shown that aerobic bacteria that use sulfonates as sulfur sources catalyze the desulfonation reaction using one of several unusual oxygenases, including $\alpha$-ketoglutarate-dependent dioxygenases [12] and monooxygenases that make use of reduced flavin as a cosubstrate $[14,132,185]$, and not as a bound prosthetic group.

Early biochemical work on sulfonate degradation concentrated on isolates that are able to use the carbon of compounds such as $n$-alkanesulfonates or taurine. Pseudomonas isolates that can degrade simple alkanesulfonates have been known for many years [186]. The initial desulfonation step in these strains is catalyzed by a monooxygenase, and yields the corresponding aldehydes. These isolates were able to grow with a range of straight-chain sulfonates $\left(\mathrm{C}_{4}-\mathrm{C}_{7}\right.$ and $\mathrm{C}_{8}-\mathrm{C}_{12}$ for the two strains studied), and presumably synthesize a single enzyme which accepts a range of substrates [187]. Oxygenolytic cleavage of the carbon-sulfur bond is also involved in degradation of the secondary alkanesulfonate sulfosuccinate, in Pseudomonas sp. B1. Monooxygenation at the $\alpha$-position to the sulfonate yielded the unstable bisulfite adduct of oxaloacetate, which was proposed to decompose spontaneously to sulfite and oxaloacetate [188]. A similar reaction was observed in sulfonate-utilizing Comamonas acidovorans and Rhodococcus isolates [189], which desulfonated the branched-chain 2-propanesulfonate to acetone co-metabolically, although they were only able to grow with linear alkanesulfonates. This type of spontaneous decomposition of $\alpha$-substituted sulfonates has been proposed to play a key role in many desulfonation steps involving oxygenative activation [190]. A similar type of reaction is also found in the methanesulfonate utilization pathway. Methanesulfonic acid is a major atmospheric decomposition product of dimethylsulfide, and can be utilized by several methylotrophic isolates as a source of carbon for growth [41,191]. The initial step in methanesulfonate mineralization in Methylosulfomonas methylovora [192] is catalyzed by a multicomponent methanesulfonic acid monooxygenase system (MSAMO) that hydroxylates methanesulfonic acid to the unstable intermediate hydroxymethanesulfonate [193-195]. This then decomposes to sulfite and formaldehyde, a common intermediate in methylotrophic metabolism [196]. MSAMO consists of a hydroxylase and an electron transport system (NADH reductase/ferredoxin); the latter transfers electrons from NADH via a [2Fe-2S]-Rieske center to the hydroxylase [194]. The hydroxylase consists of a two-component system (MsmAB) of the mononuclear iron type, which is most similar in sequence to dioxygenases containing Rieske centers [197]. MSAMO is therefore an atypical monooxygenase, since these usually lack the ferredoxin component, though a similar situation is known for two toluene monooxygenases $[198,199]$ and is also seen in sulfate-regulated aromatic desulfonation in P. putida [185] (see below).

Taurine utilization as a carbon source, by contrast, can proceed by two pathways, neither of which involves oxygenation. In Pseudomonas $[200,201]$ an initial step is required to activate the sulfonate bond by transamination to sulfoacetaldehyde, and this intermediate is then cleaved by sulfoacetaldehyde lyase to acetate and sulfite. Alterna- 

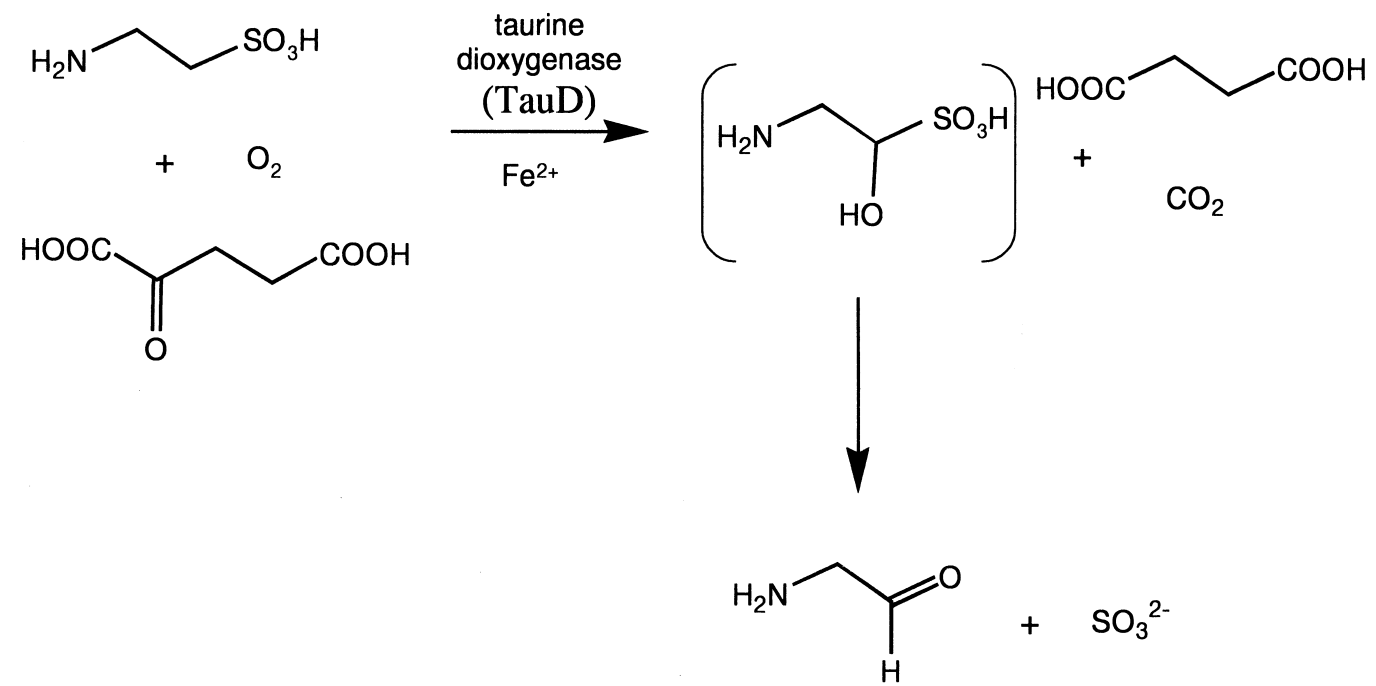

Fig. 7. Proposed mechanism for taurine desulfonation by the $\alpha$-ketoglutarate-dependent taurine dioxygenase TauD [12]. Oxygenation of taurine leads to an unstable $\alpha$-hydroxysulfonate intermediate, which decomposes to yield the product aminoacetaldehyde with release of sulfite.

tively, a taurine dehydrogenase may be involved, which catalyzes oxidative deamination to the sulfoacetaldehyde [202]. This compound is a key intermediate in the metabolism of natural sulfonates, as it is also involved in isethionate degradation in Acinetobacter and sulfoacetate utilization in Comamonas and Aureobacterium strains [204], though cell-free conversion of the sulfoacetate could not be observed in the latter isolates. The taurine degradation pathway via sulfoacetaldehyde, involving a taurine:pyruvate aminotransferase and a thiamine pyrophosphate-dependent sulfoacetaldehyde lyase is also active in several anaerobic species, including Alcaligenes sp. [205], Clostridium pasteurianum [206] and the novel isolate, strain GKNTAU.

Surprisingly, there seems to have been little work on the bacterial degradation of plant sulfonolipid. Since it is an important component of the photosynthetic membranes in all plants and algae, and most photosynthetic bacteria, it is probably the commonest sulfonate on earth, and plays an important role in the sulfur cycle [42]. Although the bleaching processes that take place during plant senescence involve chloroplast degradation, metabolism of the sulfolipid appears not to be catalyzed by the plant, and recycling of the sulfur is carried out purely by soil bacteria [208], but this process has not yet been investigated in detail.

The ability of bacteria to use aliphatic sulfonates as carbon sources is often limited to strains which have been specifically isolated using enrichment cultures that select for this phenotype. By contrast, natural sulfonates such as cysteate, isethionate or taurine can be used as a sulfur source for growth by a wide range of enteric bacteria, soil bacteria and yeasts [209-213], reviewed by Seitz and Leadbetter [214]. Of 100 random bacterial strains isolated nonselectively from freshwater, soil and freshwater sediments, 94 were able to grow with taurine as sulfur source, 96 with isethionate, and 87 with sulfoacetate [213]. By contrast, only about $10 \%$ of the strains were able to utilize the carbon moieties of these molecules for growth. Synthetic alkanesulfonates (including fluorinated sulfonates [215]) can also be used as sulfur sources by many species, and physiological experiments with $P$. aeruginosa [216] showed that desulfonation of several synthetic alkanesulfonates in the sulfur cycle appeared to follow the same pathway as in the carbon cycle, i.e. via monooxygenation and release of sulfite from a hydroxy-

Table 3

Synthesis of active arylsulfatase during growth of P. aeruginosa [20] or K. pneumoniae [100] with various inorganic sulfur-containing compounds

\begin{tabular}{llcc}
\hline Strain & Mutation & \multicolumn{2}{c}{ Sulfur compound tested } \\
\cline { 3 - 4 } & & sulfate & sulfite \\
\hline P. aeruginosa & wild-type & - & - \\
PAO1 & sulfate activation $($ cys $N)$ & + & - \\
AC309 & sulfite reductase $($ cys $I)$ & - & - \\
AX18 & wild-type & - & - \\
K. pneumoniae & sulfate transport & - & - \\
W70 & sulfite reductase & - & + \\
K170 & & & - \\
K152 & & & + \\
\hline
\end{tabular}


sulfonated intermediate. When the sulfur-regulated desulfurization process was examined at the molecular level, however, a different set of enzymes was found to those used to provide carbon for growth. Two main enzymatic desulfonation routes have been characterized, an $\alpha$-ketoglutarate-dependent dioxygenase pathway that is active with taurine (Fig. 7), and an $\mathrm{FMNH}_{2}$-dependent monooxygenase system that catalyzes the desulfonation of a range of aliphatic sulfonates (Fig. 9). Both of these systems have been found in several Gram-negative species, and they are examined in more detail below.

\subsection{Taurine desulfurization; $\alpha$-ketoglutarate-dependent dioxygenases}

In E. coli, physiological experiments showed that taurine sulfur enters the cysteine biosynthesis pathway at the level of sulfite [217], but the detailed biochemistry of this reaction has only recently been elucidated. The $\alpha$-ketoglutarate-dependent taurine dioxygenase of $E$. coli (TauD) was originally identified during screening for $E$. coli proteins whose synthesis was repressed in the presence of sulfate, but expressed during growth with alkanesulfonates [22] (see above). The corresponding gene, $\operatorname{tau} D$, and two further genes in the same operon, $\tan B$ and $\tan C$, were also identified as sulfate-repressed genes using a genetic screening strategy with a bank of $\lambda$ plac $\mathrm{Mu} 9$ insertion mutants [218]. From sequence comparisons, the TauD protein belongs to the family of $\alpha$-ketoglutarate-dependent dioxygenases, and this has been confirmed by biochemical studies with the purified TauD protein [12]. The immediate product of taurine oxygenation by TauD is an unstable hydroxytaurine intermediate, which desulfonates spontaneously to yield aminoacetaldehyde and sulfite (Fig. 7). The product appears similar to that which would arise from a monooxygenase reaction. However, whereas monooxygenases transfer one oxygen atom of the oxygen molecule to an organic substrate and the second atom to water, $\alpha$-ketoglutarate-dependent dioxygenases transfer both oxygen atoms to organic acceptor molecules. One oxygen atom is used to hydroxylate the reaction substrate itself, and the second is transferred to the cosubstrate, usually $\alpha$-ketoglutarate, which is thereby converted to succinate and carbon dioxide (Fig. 7). Desulfonation of taurine by TauD requires equimolar amounts of $\alpha$-ketoglutarate as cosubstrate, and though $\alpha$-ketoadipate also leads to a low level of desulfonation, other $\alpha$-ketoacids are not accepted as cosubstrates. TauD is quite specific for taurine as substrate, and though it will also desulfonate shortchain alkanesulfonates $\left(\mathrm{C}_{4}-\mathrm{C}_{6}\right)$, the $K_{\mathrm{m}}$ values are an order of magnitude higher than for taurine [12].

Known $\alpha$-ketoacid-dependent dioxygenases catalyze reactions of a variety of substrates, including 2,4-dichlorophenoxyacetic acid (2,4-D), the amino acids lysine, aspartate, proline and $\gamma$-butyrobetaine, gibberellins, $\beta$-lactams, flavonoids and alkaloids [219,220]. They are found in plants, animals and bacteria, and carry out not only classical hydroxylation reactions, but also desaturations and ring expansions. Sequence comparison of the characterized enzymes show that they make up a diverse group that probably arose by convergent evolution, rather than from a common ancestor. This is reflected in the varied structure of members of the enzyme family. The subunit sizes vary from 26 to $85 \mathrm{kDa}$, and the native enzymes are monomers or homodimers (though one $\alpha_{2} \beta_{2}$-heterotetramer is known) [220]. TauD is a homodimer with subunit molecular mass of $32 \mathrm{kDa}$. At a sequence level it is related to the dichlorophenoxyacetate dioxygenase encoded on plasmid pJP4 of Ralstonia eutropha (30\% amino acid identity) [221], though the two enzymes do not react with each other's substrates [12]. TauD does not show significant sequence similarity to other characterized $\alpha$-ketoacid-dependent dioxygenases, including bacterial enzymes of this family.

However, comparison of tauD with sequences arising from various genome sequencing projects indicates that close relatives of the tauD gene are not uncommon. Thus, open reading frames of unknown function which are related to E. coli TauD have been identified in Yersinia pestis (70\% sequence identity to TauD [144]), Saccharomyces cerevisiae (32\% identity; accession number Z47973), $M$. tuberculosis $(36 \%$ identity; accession number Z77165), B. pertussis (three ORFs, with $32 \%, 39 \%$ and $48 \%$ sequence identity [144]), and $P$. aeruginosa (three ORFs, with $37 \%, 40 \%$ and $60 \%$ sequence identity [122]). In $P$. aeruginosa one of the three tau $D$ homologues can definitely be assigned to tau $D$ since it occurs in the same operon structure as tauD does in E. coli; an $\alpha$-ketoglutarate-dependent taurine dioxygenase activity has also been observed in this strain (unpublished results). The second tauD homologue is also regulated as part of the sulfur cycle, since it has been identified as an SSI protein (protein PA4 [20]). The third homologue is likely to be similarly regulated, since it is located adjacent to the gene encoding the PA4 protein. In the absence of biochemical studies of these proteins, it is not yet clear if they are all active as $\alpha$ ketoglutarate-dependent dioxygenases, and if so, with what substrates. However, the presence of three such genes, all induced under sulfate limitation conditions, suggests that the corresponding proteins may well play a role in organosulfur metabolism.

\subsection{Desulfurization of methanesulfonate and other alkanesulfonates; $\mathrm{FMNH}_{2}$-dependent monooxygenases}

E. coli strains that have been mutated in the tauD gene are no longer able to grow with taurine as sole sulfur source, but their growth with a variety of other sulfonates is unimpaired. At least one other desulfonation system must therefore exist in the cell. This system has been identified as the $s s u$ operon, which has been characterized in $E$. coli [222], P. putida [132], and B. subtilis [223] (Fig. 8). 
Synthesis of the ssu gene products is repressed in the presence of inorganic sulfate, and indeed they were originally identified in E. coli [22] and $P$. aeruginosa [20,24] by differential 2D-PAGE in a screen for sulfate starvation-induced proteins.

Desulfonation of alkanesulfonates is catalyzed by the products of the $s s u D$ and $s s u E$ genes, which encode an $\mathrm{FMNH}_{2}$-dependent monooxygenase and an NAD(P)Hdependent FMN reductase, respectively (Fig. 8). In all species so far studied, the $s s u$ operon also contains genes encoding a putative ABC-type transport system that presumably catalyzes uptake of alkanesulfonates into the cell. In the pseudomonads, but not in E. coli or B. subtilis, the distal gene in the operon ( $s s u F)$ encodes a small protein related to putative molybdopterin binding proteins of C. pasteurianum, but the significance of this is not yet clear (molybdenum does not appear to be required for growth with sulfonates [132]). $P$. aeruginosa also contains a second operon ( $m s u E D C$ ) comprising closely related copies of the sulfonatase and reductase genes, which encodes a methanesulfonate sulfonatase system [14]. Although PCR and
Southern analysis showed that the $s s u D$ gene is widespread among pseudomonads [14], in the bacterial genomes that have been completely or partially sequenced to date further ssuD homologues have been found only in $M$. tuberculosis and in $Y$. pestis.

The ssuD gene product is most closely related to the monooxygenase components of two-component enzyme systems that catalyze the oxygenation of EDTA [224], nitrilotriacetate (NTA) [225], pristinamycin $\mathrm{II}_{\mathrm{B}}$ [226] and dibenzothiophene dioxide [15,227] (the latter three are encoded by the ntaA, snaA and $d s z A$ genes, respectively). These monooxygenases are characterized by their requirement for reduced FMN supplied by a second, NAD $(\mathrm{P}) \mathrm{H}-$ dependent FMN reductase component, and the enzymes themselves do not contain a bound flavin molecule. This use of reduced flavin as a cosubstrate, rather than as a bound prosthetic group, is a significant difference from other characterized mono- and dioxygenases, including the mammalian flavin monooxygenases. Studies with the NTA and EDTA oxygenase enzyme systems [224,225], and with MsuED [14], suggest that the flavin reductase

E. coli
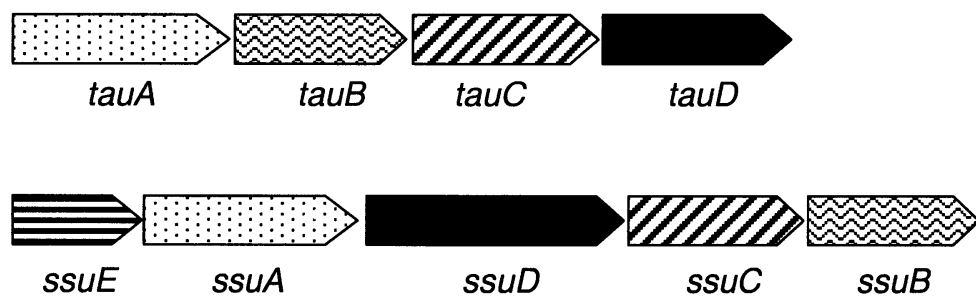

B. subtilis
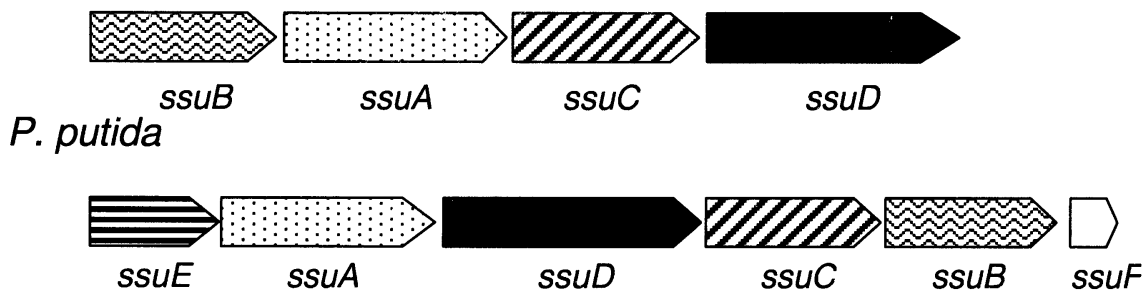

$P$. aeruginosa

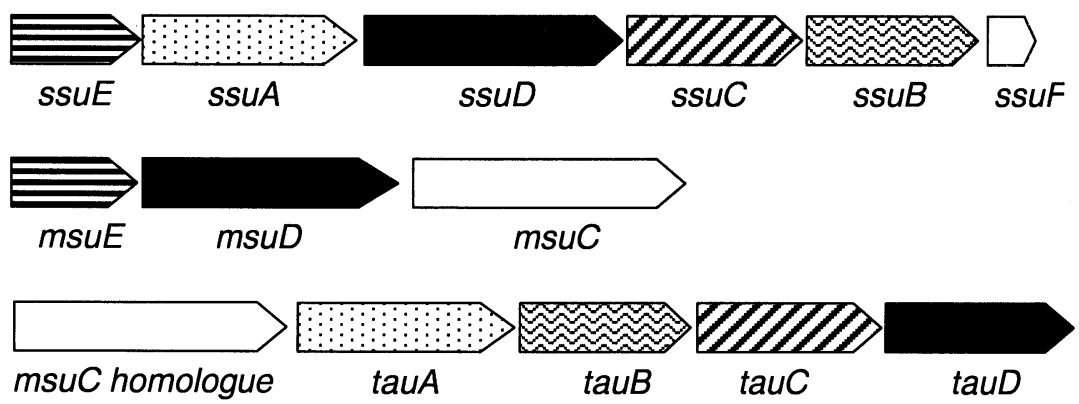

Fig. 8. Genetic organization of bacterial sulfonatase-encoding operons. The enzymes encoded in each gene cluster are putative oxygenases ( $\square$ ), NADH-

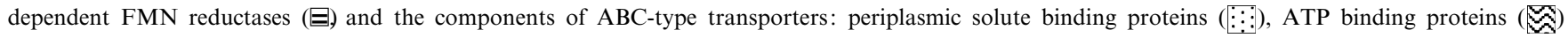
and permease proteins (t). No definite function is known for the products of the $s s u F$ and $m s u C$ genes [14,132]. The genes are from: E. coli [218,222], B. subtilis [223], P. putida [132,185], and P. aeruginosa [14,122]. 
component may be associated with the monooxygenase as part of a loose complex (the two components co-purified over anion exchange, but were dissociated during further purification steps). No evidence for complex formation was found for the dibenzothiophene system [15]. In addition, the flavin reductase enzymes of the NTA and EDTA oxygenases were interchangeable, and could also be replaced by the flavin reductase from Vibrio fischeri [224]. It therefore appears that the flavin reductase enzymes are not essential parts of a complex, but that their role is limited to providing reduced FMN for the oxygenase component.

This conclusion is also supported by the genetic organization of the $\mathrm{FMNH}_{2}$-oxygenases and their cognate flavin reductases. Whereas the reductase and oxygenase components of the $P$. aeruginosa and $P$. putida sulfonate-desulfurizing systems (SsuED and MsuED) are each co-expressed as part of an operon (msuE and $m s u D$ even overlap by two base pairs), this organization is the exception. In Rhodococcus erythropolis the $d s z D$ flavin reductase gene is unlinked to the $d s z A B C$ genes, in $S$. pristinaespiralis sna $A$ and sna $C$ are separated by at least $24 \mathrm{~kb}$, and in Chelatobacter the ntaA and $n t a B$ genes, though adjacent, are divergently oriented [225]. The operon containing the B. subtilis ssuD gene lacks a flavin reductase gene (Fig. 8) [223]. Analysis of the genome sequence did not reveal any gene products related to known flavin reductases such as the Fre protein of E. coli [228], MsuE/SsuE genes of E. coli or pseudomonads $[14,24,132]$, or the DszD protein of $R$. erythropolis [15], accession number AF048979). The B. subtilis FMN reductase must therefore belong to another, hitherto uncharacterized family of flavin reductase enzymes. The monooxygenases described fall into two families, with the SsuD/MsuD enzymes $60-92 \%$ identical to each other, and the NtaA/SnaA/DszA group 39-46\% identical, with about $20 \%$ identity between the two groups. Sequence comparison of the cognate reductases shows that these are much less related, and can be divided into at least three groups, with less than $15 \%$ identity between groups.

The products of the $P$. aeruginosa $m s u D$ and $m s u E$ genes have recently been overexpressed in E. coli and partially characterized. They catalyze the desulfonation of meth- anesulfonate and, at a lower rate, several related alkanesulfonates [14]. The monooxygenase gene $m s u D$ is closely related to the $s s u D$ genes, and appears to be redundant in $P$. aeruginosa, since an $m s u D$ mutant was able to grow with all sulfur sources tested, including a range of sulfonates. This functional redundancy has been ascribed to the ssuD gene - although no detailed studies of $s s u D$ have yet been made in $P$. aeruginosa, the $s s u D$ gene of $P$. putida has been shown to be required for methanesulfonate utilization in that species [132]. In contrast, E. coli K12, despite possessing a closely related $s s u D$ gene $(77 \%$ identity at protein level) is unable to grow with methanesulfonate as sulfur source (though E. coli B can do so), and the overexpressed SsuD enzyme shows very low activity with methanesulfonate as substrate (E. Eichhorn, personal communication). This suggests that the E. coli SsuD protein contains an altered active site that cannot bind methanesulfonate, or that an additional essential factor for this reaction is present in the pseudomonads which is lacking in the enteric species.

The function of the third gene in the $m s u$ operon, $m s u C$, is less well defined. The presence of excess MsuC leads to an increase in the rate of MsuD-catalyzed desulfonation of methanesulfonate, but MsuC itself does not catalyze the desulfonation reaction [14]. The $m s u C$ gene product is quite similar ( $42 \%$ identity) to another $\mathrm{FMNH}_{2}$-dependent monooxygenase, the enzyme that carries out the initial step in the dibenzothiophene (DBT) desulfurization pathway in $R$. erythropolis IGTS8 (see below). This enzyme catalyzes the stepwise oxidation of DBT to DBT-dioxide, and because of the similarity of the MsuC and DszC enzymes it is tempting to speculate that the natural substrates of MsuC in P. aeruginosa may therefore be organosulfides. Oxidation of these to the corresponding sulfonates would then provide suitable substrates for the cognate sulfonatase. However, $P$. aeruginosa is unable to grow with either aromatic or aliphatic sulfides as sulfur sources, so MsuC presumably plays another role. Both $\mathrm{MsuC}$ and DszC are related to the family of eukaryotic short-chain-specific acyl-coenzyme A dehydrogenases (24$25 \%$ identity over nearly the full length of the protein). Although this has been commented on by several authors $[15,229]$, its significance is still unclear. The glutamate res-

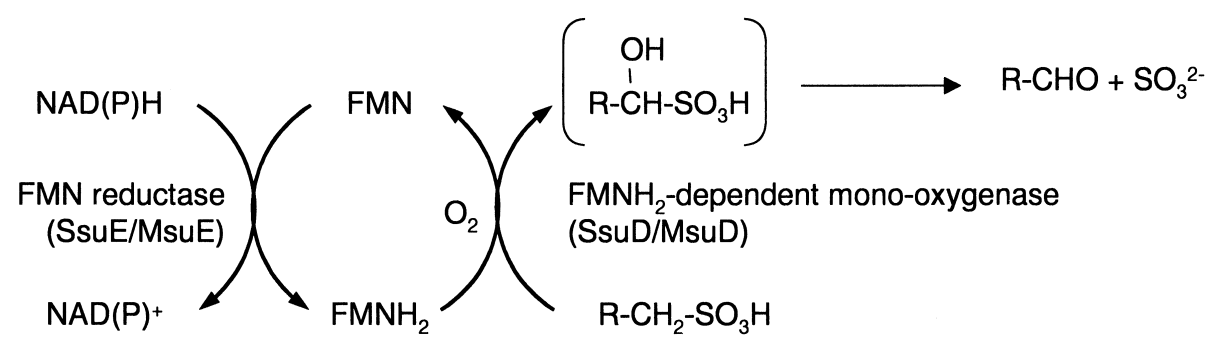

Fig. 9. Proposed mechanism for the $\mathrm{FMNH}_{2}$-dependent oxygenolytic desulfonation of alkanesulfonates. FMN is reduced by the FMN reductase, using either NADH or NADPH as electron donor. The reduced FMN acts as a cosubstrate in desulfonation by the SsuD or MsuD proteins, yielding the $\alpha$ hydroxysulfonate which decomposes to the product aldehyde with release of sulfite. 
idue which is required for acyl-CoA dehydrogenase activity [230,231] is not conserved in MsuC or DszC. Possibly MsuC plays a role in flavin binding - reduced flavin bound to acyl-CoA dehydrogenases has been shown to be resistant to oxidation by molecular oxygen [231,232], and this may have relevance for stabilization of the flavin reducing equivalents required in the monooxygenase reactions.

The importance of sulfonates within the natural bacterial life cycle has only been recognized recently, and is exemplified by the fact that in the organisms in which sulfur-controlled sulfonate metabolism has been studied, two or even three discrete desulfonation systems have been found, with overlapping substrate ranges. Many soil bacteria can utilize sulfonates as sulfur source [14,209,213], as can a number of enteric bacteria [210]. Although it seems odd that enteric bacteria should contain several sulfate-repressed desulfonative oxygenase systems, since the gut contains high levels of sulfate and is largely anaerobic, these genes may be crucial for survival outside the gut environment. Further studies are still required to determine whether the genes responsible for alkanesulfonate uptake and desulfonation in enteric bacteria are regulated entirely by sulfur supply in the gut, or whether they also respond to other environmental stimuli.

\section{Desulfonation of aromatic sulfonates - a further adaptation}

Like aliphatic sulfonates, aromatic sulfonates can in principle provide bacteria with either sulfur or carbon for growth. The enzyme systems required in both cases are oxygenases. Desulfurization of aromatic sulfonates uses the same oxygenase as for their aliphatic counterparts, though an additional electron transport chain is required. Full mineralization proceeds by pathways that are similar to well known routes for the degradation of other aromatic compounds.

Desulfonation of aromatic sulfonates and ring degradation to provide carbon for bacterial growth can proceed by several pathways, which have recently been reviewed [7,233]. Desulfonation usually occurs prior to ring cleav- age [234-236], but can also take place after ring cleavage [237-239] or even simultaneously with ring cleavage, as in the degradation of 2-aminobenzenesulfonate [190]. The desulfonatase enzymes that have been characterized are multicomponent dioxygenase systems that are induced in the presence of their substrates. Many of these are plasmid-encoded [240,241], thus facilitating their horizontal transfer between species.

Bacteria are also capable of growing with aromatic sulfonates as sulfur source, even when they do not further metabolize the carbon skeleton of the compounds. Both the biochemistry and the regulation of sulfur-regulated systems are quite different from those which mediate arylsulfonate utilization as a carbon and energy source. Three independent studies have reported that under sulfate-limiting conditions arylsulfonates are desulfonated to the corresponding phenols, in P. putida S-313 [242], Klebsiella oxytoca KS3D [243] and the mixed culture L6 [244]. ${ }^{18} \mathrm{O}_{2}$-incorporation experiments with the $P$. putida and $K$. oxytoca strains showed that the phenol oxygen atom was derived from molecular oxygen, and that the reaction is therefore catalyzed by a monooxygenase. The substrate range of this enzyme is very wide indeed $-P$. putida S313 can desulfonate several hundred different aromatic sulfonates [7], whereas the L6 culture was able to desulfonate the complex mixture of compounds that is present in commercial LAS [244]. Because of this substrate tolerance, the $K$. oxytoca system has been considered for the industrial synthesis of phenols that are inaccessible by traditional methods [243].

However, does this catalytic proficiency arise from the action of one enzyme or of a family of related enzymes? Transposon mutagenesis of $P$. putida $\mathrm{S}-313$ yielded several groups of mutants which were deficient in growth with benzene sulfonate, representatives of which are shown in Table 4. One of these mutants (strain SN34) was unable to grow with a variety of organosulfur sources, including alkane and arenesulfonates, aromatic and aliphatic sulfate esters, methionine, and methionine biosynthetic intermediates such as homocysteine or cystathionine, though it grew normally with inorganic sulfate. This strain carried a transposon insertion in the ssuE gene, and complementation analysis with constructs carrying in-frame deletions in

Table 4

Growth of $P$. putida S-313 and derivatives with various organosulfur sources

\begin{tabular}{|c|c|c|c|c|c|}
\hline \multirow[t]{2}{*}{ Strain } & \multirow[t]{2}{*}{ Genotype } & \multicolumn{4}{|l|}{ Growth $^{\mathrm{a}}$ with: } \\
\hline & & aromatic sulfonates & aliphatic sulfonates & aromatic sulfate esters & aliphatic sulfate esters \\
\hline S-313 & wild-type & + & + & + & + \\
\hline SN34 & ssuE::miniTn5 & - & - & - & - \\
\hline SN34/pME4433 & $\Delta s s u D$ & - & - & - & - \\
\hline SN34/pME4431 & $\Delta s s u E$ & - & + & + & + \\
\hline SN57 & ats $B:: \operatorname{miniTn} 5$ & - & + & - & - \\
\hline PW15 & atsR::miniTn5 & + & + & - & - \\
\hline SN36 & asf $A:: \operatorname{miniTn} 5$ & - & + & + & + \\
\hline
\end{tabular}

${ }^{\text {a } O r g a n o s u l f u r ~ c o m p o u n d s ~ w e r e ~ s u p p l i e d ~ a s ~ s o l e ~ s o u r c e s ~ o f ~ s u l f u r ~ f o r ~ g r o w t h, ~ a t ~ a ~ c o n c e n t r a t i o n ~ o f ~} 100-500 \mu \mathrm{M}$. 


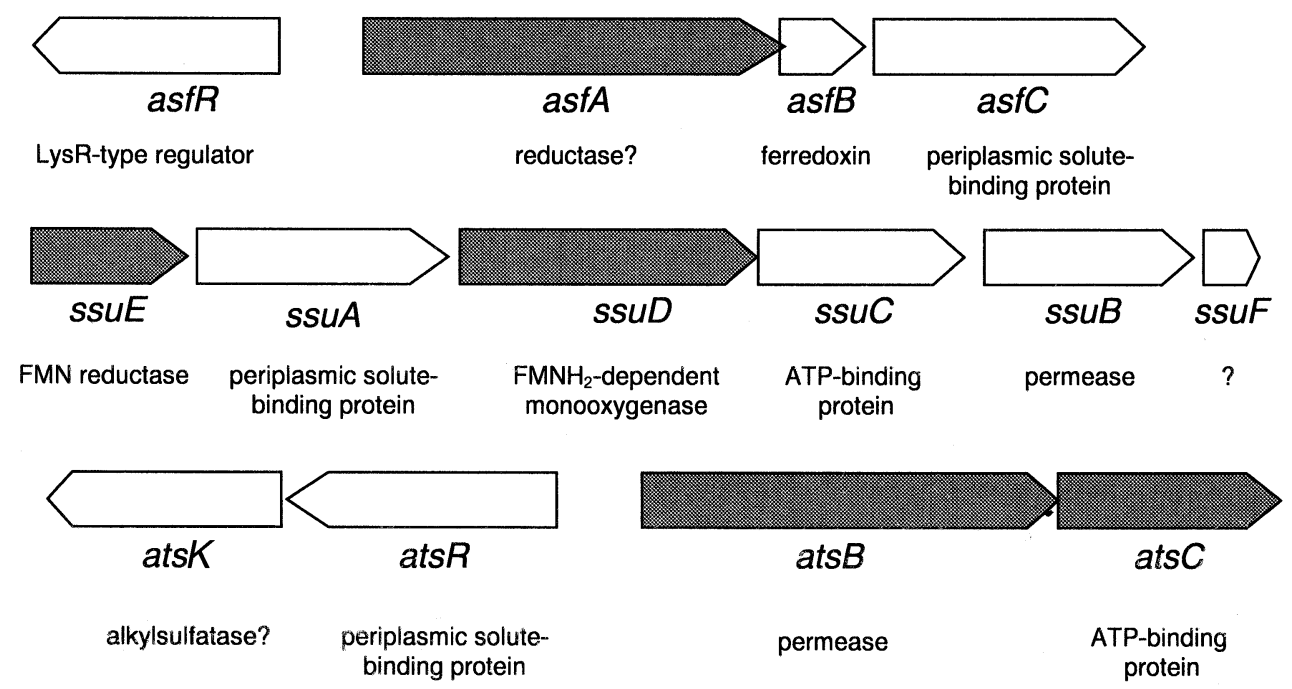

Fig. 10. Genes required for growth with aromatic sulfonates in P. putida S-313. Three separate gene clusters (asf, ssu and ats) were identified by transposon mutagenesis and selection for desulfonation-negative mutants [185]. Putative functions of each gene product are shown. The shaded genes are those that are required for growth with aromatic sulfonates [132,185].

the individual genes of the $s s u$ operon showed that aromatic desulfonation required intact $s s u D$ and $s s u E$ genes. These encode the flavin reductase and $\mathrm{FMNH}_{2}$-dependent monooxygenase that were previously implicated in alkanesulfonate metabolism in this species, suggesting that the same monooxygenase system may be responsible for desulfonating not only alkanesulfonates, but also the full range of aromatic sulfonate substrates.

Many organisms can grow with alkanesulfonates as sulfur source, and the $s s u D$ gene is widespread. However, very few of these organisms can use aromatic sulfonates as sulfur source. Therefore, either the P. putida SsuD protein is specifically adapted to allow desulfonation of aromatic substrates, or a factor is required for the aromatic desulfonation which is not needed for desulfurization of alkanesulfonates. Characterization of a second group of non-desulfonating mutants of $P$. putida S-313 led to the discovery of the asf operon (Fig. 10), which appears to be the key locus in controlling arylsulfonate utilization in this strain. It has been described as a 'toolbox' for arylsulfonate utilization [185], since it encodes a putative arylsulfonate binding protein (AsfC), an electron transport system (putative reductase (AsfA) and ferredoxin (AsfB)) and a divergently oriented LysR-type regulator (AsfR), but not the desulfonating oxygenase. When $P$. aeruginosa PAO1 was transformed with the asf $A B C$ genes behind a lac promoter, it gained the ability to grow with a variety of arylsulfonates, consistent with the hypothesis that the asf genes are the additional factor required to enable the SsuD protein to desulfurize aromatic sulfonates. A working model consistent with the current data is shown in Fig. 11.

The gene products of the asf operon have not yet been characterized biochemically, but their reconstitution promises to generate a novel, multicomponent monooxygenase system. Most monooxygenases either do not have a free ferredoxin component at all, or they contain a [2Fe-2S] plant-type ferredoxin. The three-component methanesulfonate monooxygenase of $M$. methylovora M2, for example, contains a Rieske-type [2Fe-2S] ferredoxin [194], which is related to the ferredoxin components of benzene and toluene monooxygenase systems. By contrast, the 12-kDa ferredoxin encoded by asf $B$ contains two [4Fe-4S] clusters in its $\mathrm{N}$-terminal domain. Ferredoxins of the $[4 \mathrm{Fe}-4 \mathrm{~S}]$ family are known in anaerobic organisms, where they are involved in coupling substrate oxidation (e.g. formate, pyruvate) to reduction of an electron acceptor (e.g. NAD ${ }^{+}$, $\mathrm{NADP}^{+}, \mathrm{FMN}, \mathrm{FAD}$ ), and in photosynthetic organisms [245]. The gene product of asf $A$ is similar to the flavoprotein subunit of fumarate reductases from several species (24-27\% identity). The role of AsfA and AsfB is not yet clear - whereas they may play a part in energizing the uptake of aromatic sulfonates into the cell, it seems more likely that they accept reducing equivalents from $\mathrm{FMNH}_{2}$ (especially since asf $A$ is related to the flavoprotein fumarate reductase), and transfer them to the oxygenase. Reduced FMN is highly unstable under aerobic conditions, as it is rapidly reoxidized by molecular oxygen, with concurrent release of damaging superoxide radicals [246]. The AsfAB system may therefore provide a mechanism for stabilizing reduced flavin equivalents such that they can subsequently be used to supply electrons for the aromatic desulfonation reaction (see Fig. 11).

A third locus is also required for aromatic desulfonation in $P$. putida S-313. Mutants in the atsB gene were not only defective in utilization of aromatic and aliphatic sulfate esters, as described above for $P$. aeruginosa, but were also unable to grow with aromatic sulfonates. This suggests that the uptake system encoded by atsRBC transports a broad range of sulfated and sulfonated substrates 


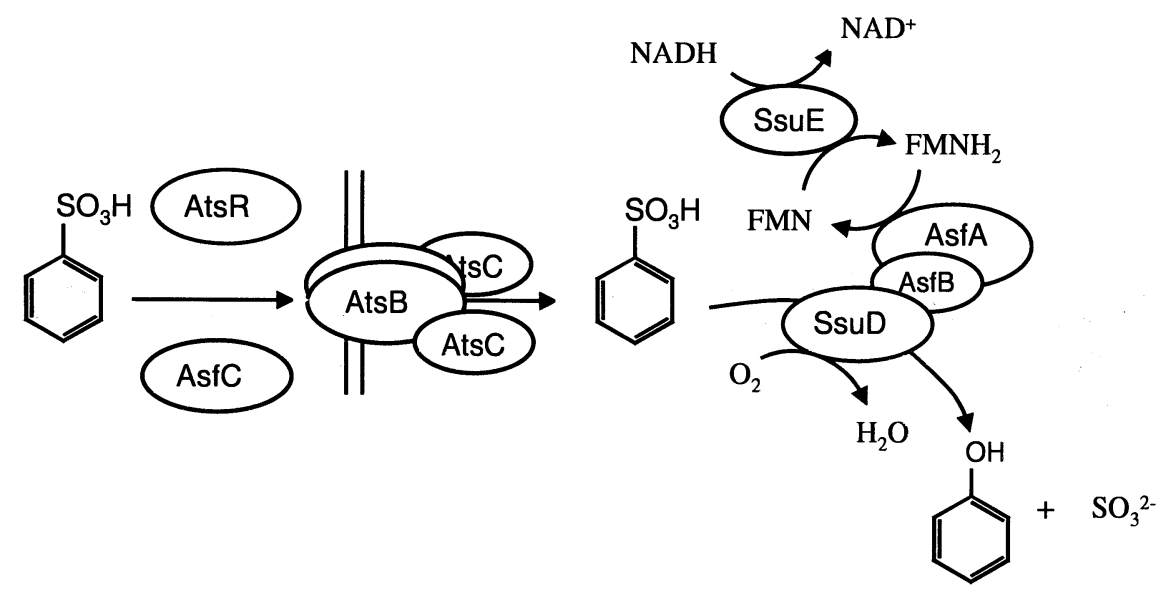

Fig. 11. Working model of aromatic desulfonation in P. putida S-313. Uptake of aromatic sulfonates into the cell is catalyzed by the AtsBC system, together with the solute binding proteins AsfC or AtsR. The desulfonation reaction is carried out by the $\mathrm{FMNH}_{2}$-dependent $\mathrm{SsuD}_{\mathrm{D}}$, with reduced flavin supplied by the flavin reductase encoded by $s s u E$. The role of AsfA and AsfB is not yet clear, but they may play a role in transferring reducing equivalents to the oxygenase [185]. The subunit stoichiometries in the desulfonation complex have not yet been determined.

into the cell, though biochemical studies to confirm this have not yet appeared. A $P$. putida mutant in ats $R$ was deficient in desulfurization of sulfate esters, but could grow with aromatic sulfonates, presumably because of the presence of the asfC gene in this organism. This was confirmed by the fact that aromatic desulfonation in a wild-type $P$. aeruginosa strain required the presence of only the asf $A B$ genes, but in an ats $R$ mutant the asfC gene product was also needed [185].

Although aromatic sulfonates have largely been regarded as xenobiotic compounds in the past, bacterial isolates that can desulfonate them can be readily isolated from natural environments. Enrichment cultures with a variety of such compounds (ranging from the simplest representative, benzenesulfonate, to complex sulfonated dyes) have yielded desulfonating isolates not only with inocula from wastewater treatment works, but also from environments with lower xenobiotic exposure, such as forest and garden soils, and rumen contents [252]. The strains obtained in this study were predominantly Pseudomonas species, though this may in part simply reflect the isolation strategy applied. Analysis of these desulfonating strains revealed the presence of a highly conserved $s s u D$ gene in most of them ( $>90 \%$ amino acid identity). An asf $A$ gene was found in all the $P$. putida isolates, but not in other strains. If Asf AB indeed constitutes an electron transport system delivering electrons to the monooxygenase in $P$. putida, then this function must be fulfilled by other proteins in other species. In this context, it is interesting to note that $P$. aeruginosa also carries an asf $A B C$ homologue in its genome, even though it cannot grow with aromatic sulfonates. The $P$. aeruginosa AsfA homologue is $29 \%$ identical to the $P$. putida asf $A$ gene product. The two ferredoxins are even more closely related $35 \%$ identity), and though the $P$. aeruginosa AsfB is somewhat smaller than the $P$. putida counterpart, it also contains two putative $[4 \mathrm{Fe}-4 \mathrm{~S}]$ clusters.
Two of the loci involved in aromatic desulfonation, ats and $s s u$, have been shown in $P$. aeruginosa to be upregulated during growth with a variety of sulfur sources, and repressed in the presence of sulfate, cysteine or thiocyanate, and they therefore represent typical sulfate starvation-induced systems $[20,24,136]$. The asf operon, by contrast, is also controlled by its own substrate. Expression studies with asf $A$ and $a s f R$ showed that AsfR was a negative regulator of the asf $A B C$ operon, and that in addition, asf $R$ was subject to positive autoregulation [185]. In the presence of toluenesulfonate, asf $R$ expression was repressed, and the resulting fall in cellular AsfR levels apparently derepressed the asf $A B C$ genes, since expression of asf $A$ increased dramatically during growth with toluenesulfonate. Interestingly, the toluenesulfonate-mediated repression of $P$. putida asf $R$ expression appeared to be partly independent of the AsfR protein, since it was also observed with a $P$. putida asf $R:: x y l E$ fusion in $P$. aeruginosa, in the absence of a functional asf $R$ gene. This suggests the presence of an additional, unidentified factor in this response. During growth with toluenesulfonate and sulfate, asf $A$ expression was repressed, and this effect was found to be at least in part mediated by the global control protein CysB [185].

Under sulfate limitation conditions, $P$. aeruginosa synthesizes increased levels of two antioxidant proteins, a putative thiol-specific antioxidant (TSA; also called a thiol peroxidase), encoded by the $l s f A$ gene (accession number AF075709), and the alkylhydroperoxide reductase AhpC $[20,24]$. The latter protein is also upregulated during sulfate starvation in $E$. coli [22]. The lsf $A$ gene is located immediately upstream of the $s s u$ operon in $P$. putida, and $3.0 \mathrm{~kb}$ upstream of $s s u E$ in $P$. aeruginosa (in $P$. putida $l s f A$ and $s s u E$ are transcribed separately, but in $P$. aeruginosa this has not yet been examined). LsfA and AhpC show $30-65 \%$ sequence identity to a number of antioxidant proteins grouped together as the TSA/AhpC family 
[247], and the $P$. aeruginosa LsfA protein, which has recently been overexpressed and purified, indeed displays the anticipated thiol-specific antioxidant activity [248]. The relevance of these antioxidant proteins in the sulfate starvation response may be linked to sulfonate utilization. In the absence of sulfonated compounds, induction of ssuE (and $m s u E$ in $P$. aeruginosa [14]) by sulfate starvation will lead to an excess of reduced flavin nucleotides in the cell, and consequently to an increase in radical-caused damage. Increased synthesis of LsfA and AhpC under sulfate-limited conditions may represent the cell's response to this threat. However, since the cell's main defense to oxidative stress consists of superoxide dismutase and catalase activities, which are not regulated by the sulfur supply to the cell, it is not clear why an increase in LsfA and AhpC levels should be necessary.

LAS is the best investigated of the arylsulfonates from a degradation standpoint. Commercial LAS is a mixture of many different isomers and homologues that are a degradative challenge for bacterial populations, especially under anaerobic conditions and in sediments, where significant levels of LAS can accumulate (e.g. [65]). The proposed mechanism by which LAS is mineralized was first proposed by Willetts and Cain [249], and evidence for it has been reviewed by Swisher [60] and Schöberl [250]. Degradation is initiated by the oxidation of the methyl group on the alkane chain that is more distant from the aromatic ring (the so-called distance principle [60]), followed by a series of $\beta$-oxidation steps that give rise to a sulfophenylalkanoate compound such as sulfophenylbutyrate. Further degradation of this aromatic sulfonated intermediate proceeds via oxygenative desulfonation and ring cleavage, and probably occurs in a separate organism from the initial $\beta$-oxidation steps [251]. Commercial LAS surfactants are generally regarded as being readily biodegradable $[67,252,253]$, although impurities generated as byproducts in the industrial synthesis (e.g. dialkyltetralinsulfonates, DATS) may be more of a problem ([253,254], but cf. [255]).

Direct desulfonation of complex LAS surfactant mixtures has also been observed [244] when LAS was supplied only as a sulfur source for bacterial growth. It yielded the corresponding long-chain-substituted phenols. Interestingly, the selectivity of this sulfate-limited desulfonation process is exactly reversed to that observed during carbon-limited degradation. Under carbon-limited conditions, longer-chain isomers are degraded more rapidly, and there is a preference for positional isomers in which the sulfophenyl ring is near the end of the chain [60]. Under sulfurlimited conditions the reverse is true, as the short-chain isomers are preferentially desulfonated, and centrally substituted isomers are degraded faster than 2-substituted LAS [244]. In the presence of inorganic sulfate no direct desulfonation occurs [244], and so although this reversed selectivity has possible potential in wastewater treatment, a different genetic control must first be introduced, since wastewaters commonly contain high levels of inorganic sulfate. It is to be hoped that genetic studies such as the above will lead to an understanding of the mechanism by which these genes are repressed in the presence of sulfate, and development of methods to circumvent this for practical applications.

\section{Biodesulfurization of condensed thiophenes}

The desulfurization of fossil fuels continues to be the subject of intensive research. Sulfur constitutes up to $5 \%$ $(\mathrm{w} / \mathrm{w})$ of crude oils, and most of it is present in organically bound form [256]. On combustion, organosulfur compounds are converted to corrosive sulfur oxides, which return to earth in acid rain. As legislative limits to sulfur emissions become tighter, the need to remove the organosulfur from fuel has become more pressing, and efforts to develop biodesulfurization methods to replace the current hydrodesulfurization process have increased (see the excellent recent reviews by McFarland and coworkers [52,257]).

More than $60 \%$ of the sulfur in higher boiling fractions of crude oil is present as DBT and substituted dibenzothiophenes [256], and DBT has therefore been the model compound of choice for investigating the molecular basis of biodesulfurization. DBT can be used as a carbon source by a number of Gram-negative species, including several pseudomonads (e.g. [258,259]) and a Rhizobium meliloti isolate [260], but in most cases DBT conversion occurs co-metabolically during growth with another carbon source [256]. DBT biodegradation under these conditions takes place via dioxygenase attack on the benzene ring, followed by meta cleavage of the resulting dihydroxyDBT, and oxidative decarboxylation to 3-hydroxy-2-formylbenzothiophene via the 'Kodama' pathway [261]. In pseudomonads this pathway is plasmid-encoded [262]. The dioxygenase carrying out the initial reaction in Pseudomonas sp. strain C18 (a DBT-metabolizing soil isolate) was identical with $P$. putida naphthalene dioxygenase [263], and was required for metabolism not only of DBT, but also of naphthalene and phenanthrene. Purified naphthalene dioxygenase indeed catalyzes dioxygenation of DBT, but can also oxidize the DBT sulfur atom to the sulfoxide [264].

However, although DBT metabolism via the Kodama pathway leads to a reduction in the toxicity of the starting compounds, it does not remove the sulfur, and it involves some loss of carbon, thereby reducing the fuel value of the product. Bacteria that can remove the sulfur atom from DBT without attacking the carbon backbone have been isolated by selecting for strains that could utilize DBT as a sulfur source for growth. The isolates obtained have been almost exclusively rhodococci [265-272] and other Gram-positive species [273-275], including two thermophilic Paenibacillus strains [276]. Under sulfur-limiting conditions, desulfurization of DBT proceeds via the path- 


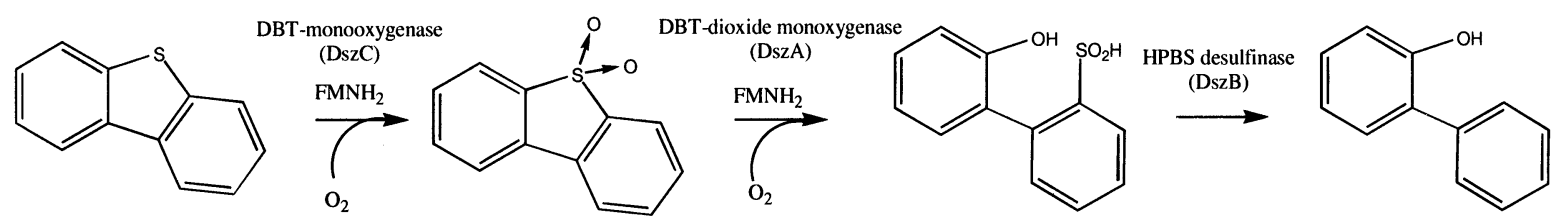

Fig. 12. Desulfurization of dibenzothiophene by the R. erythropolis IGTS8 pathway. The thiophene sulfur is oxidized in two steps by DBT-monooxygenase to DBT-dioxide, which is then cleaved by DBT-dioxide monooxygenase to 2-(2-hydroxyphenyl)benzenesulfonate (HPBS). The sulfinate group is finally released by HPBS sulfinase. Reduced FMN for the two oxygenolytic steps is provided by the FMN reductase DszD. Adapted from [15].

way shown in Fig. 12. The enzymes concerned have been characterized from $R$. erythropolis IGTS8 [15], but the pathway appears to be very similar in all organisms studied, including two Gram-negative organisms $[277,278]$. DBT is initially oxidized in two steps to DBT$S, S$-dioxide by DBT monooxygenase (the product of the $d s z C$ gene). The first C-S bond is then cleaved oxygenolytically, by DBT-S,S-dioxide monooxygenase (DszA), and the desulfurized product is released after reductive removal of the resultant sulfinate moiety by a novel desulfinase enzyme (DszB). The genes encoding these enzymes are encoded in the $d s z A B C$ operon. Expression of this operon is repressed during growth with sulfate, cysteine or methionine [271,279] but derepressed in the presence of DMSO or DBT. Further analysis is required to determine whether expression of the $d s z$ genes reflects a general response to sulfate limitation, or whether they are only upregulated in the presence of a suitable inducer (as seen for e.g. the arylsulfonate degradation system asf $A B C$ [185]). Band-shift analysis of the $d s z$ promoter region revealed that a putative repressor protein may play a role in the downregulation observed with sulfate [279], but this has not yet been explored further.

The two oxygenases in this pathway both require reduced FMN for activity, and the pathway is therefore clearly related to that for the cleavage of sulfonates reported above. Indeed, the second step in DBT desulfurization, cleavage of the thiophene C-S bond to yield hydroxybiphenylsulfinate (Fig. 12), resembles an intramolecular version of the aromatic sulfonate desulfonation found in P. putida. Despite the apparent similarity in the reaction mechanisms of this initial C-S cleavage reaction, the DszA protein is only $26 \%$ identical to the SsuD protein of $P$. putida, and the two systems are also catalytically distinct from each other; $P$. putida cannot desulfurize DBT [185], and a $R$. erythropolis strain which was able to grow with aromatic sulfonates and contained the $s s u D$ gene did not grow with DBT [280]. Like other oxygenases of this family [14,224,226,281], the DszA and DszC oxygenases do not contain a tightly bound flavin cofactor [15]. Instead, they use $\mathrm{FMNH}_{2}$ as a cosubstrate. Reduction of FMN to provide $\mathrm{FMNH}_{2}$ is catalyzed by an NADH-dependent FMN reductase (DszD) [15], but this can be replaced in vitro by other FMN reductases [282]. The $25-\mathrm{kDa}$ DszD protein does not contain bound flavin, unlike the related FMN reductases involved in EDTA, NTA and pristinamycin metabolism [224,226,281] (33-37\% identity). In rhodococci, the $d s z$ operon is carried on a plasmid $100-150 \mathrm{~kb}$ in size (pSOX) [229,283,284], and is associated with putative insertion sequence elements, IS1166 and IS1295 [285]. The DszD protein is not encoded with the rest of the $d s z$ operon, and it will be interesting to discover whether it is also encoded on the pSOX plasmid, or whether the $d s z D$ gene is chromosomally located.

Most of the DBT-degrading organisms studied are Gram-positive, and it has been speculated that the desulfurization pathway observed in strain IGTS8 (Fig. 12) might even be Rhodococcus-specific, due to a requirement for an additional, as yet unidentified factor [283,284]. However, DBT desulfurization under sulfate-limiting growth conditions has also recently been reported for two Gram-negative organisms, Agrobacterium sp. strain MC501 [277] and Sphingomonas sp. strain AD109 [278]. Both these organisms used the same pathway for DBT degradation as strain IGTS8, yielding hydroxybiphenyl as the desulfurized product. The $d s z$ genes of Sphingomonas sp. AD109 were found to have the same organization as in Rhodococcus sp. IGTS8, and the deduced proteins were also found to be closely related to the rhodococcal enzymes (67-76\% identity). In addition, desulfurization of DBT has recently been demonstrated in specifically designed recombinant Pseudomonas strains [286]. The $d s z A B C$ genes of $R$. erythropolis IGTS8 were cloned behind the tac promoter and introduced into P. putida and $P$. aeruginosa either on the broad-host-range plasmid pVLT31 or in single copy using a mini-Tn5 derivative. The resultant strains grew more quickly than $R$. erythropolis IGTS8 with DBT as sole sulfur source, and converted DBT quantitatively to hydroxybiphenyl [286]. Since Pseudomonas strains are quite solvent-tolerant [287], this approach promises to provide useful strains for desulfurization applications. Use of the constitutive tac promoter also alleviates the most pressing problem in industrial biodesulfurization applications, that the system is repressed in the presence of sulfate.

\section{Regulation of bacterial organosulfur metabolism}

One of the main discoveries to arise from recent studies on organosulfur metabolism in Gram-negative bacteria is that the CysB protein, whose main characterized role was 
in assimilation of inorganic sulfate, is also required for expression of systems involved in transport and metabolism of sulfate esters and sulfonates both in enteric bacteria and in pseudomonads, and hence controls sulfur metabolism on a larger scale. CysB of E. coli is a homotetramer consisting of $36-\mathrm{kDa}$ subunits encoded by the $c_{s} B$ gene. It is a member of the LysR family of transcriptional activators, a large class of proteins which carry a helix-turn-helix DNA binding motif in the $\mathrm{N}$-terminal domain [288] (residues 19-38 of CysB). CysB acts as a class I transcriptional activator, binding to activation sites located just upstream of the -35 region of the cysJ, cysK and $\operatorname{cys} P$ promoters and presumably interacting with the carboxy-terminal portion of the RNA polymerase $\alpha$ subunit [289]. In the presence of $N$-acetylserine, CysB activates transcription from the above promoters; the initial binding of the CysB protein to the DNA does not require the presence of $N$-acetylserine, but the presence of the coinducer stimulates the binding in specific ways at the different cys promoters [5]. For the closely related $K$. pneumoniae CysB protein a dissociation constant of $4 \mathrm{mM}$ has been reported for $N$-acetylserine [290], though this seems remarkably high for a regulatory molecule. CysB also binds directly to its own promoter, where it acts as a repressor, and to several other sites upstream of the activated promoters. Consensus binding sites for CysB have been defined in E. coli and S. typhimurium in a number of detailed studies by the group of Kredich (summarized in [5]), but the consensus sequence is relatively poorly conserved, and does not allow confident prediction of further sites of activation by CysB. This is unfortunate, because recent work has shown that CysB is a truly global regulator - in addition to regulating cysteine biosynthesis, and organosulfur metabolism, it is also involved in acid resistance in E. coli [291,292], in alginate biosynthesis in
P. aeruginosa [293], and in pectinolysis and cellulolysis in Erwinia carotovora [294].

The most obvious feature that links the expression of genes involved in cysteine biosynthesis and those of organosulfur metabolism is that they require sulfate-limited conditions for full expression. The basis of this regulation has been investigated in detail for the sulfate assimilation pathway in enteric bacteria, and is also CysB-mediated. Two main levels of control exist. Firstly, the endproduct of the pathway, cysteine, exerts feedback inhibition on serine transacetylase, which converts serine to $O$-acetylserine (Fig. 1). This controls the levels of acetylserine in the cell, and hence the level of CysB-activated transcription (Fig. 13). A second level of control is mediated by sulfide and thiosulfate (Fig. 13), which act as anti-inducers of the cys regulon, probably competing with acetylserine for binding to the CysB-DNA complex [295]. CysB was found to be very similar in structure to the sulfate binding protein, with a binding pocket where either acetylserine or thiosulfate are thought to bind as co-inducer and anti-inducer, respectively [295]. Sulfate does not itself act as an anti-inducer, so it was interesting that the crystal structure revealed a sulfate anion bound in the substrate pocket. The relative contributions of cysteine-mediated inhibition of serine transacetylase and sulfide/thiosulfate anti-induction in controlling the cys regulon have been assessed in $S$. typhimurium. Sulfide repressed expression of the cysDNC operon (encoding the proteins that catalyze sulfate activation to PAPS) almost as well in a cys $K$ cys $M$ background as in the wild-type strain. Since the cysK cys $M$ strain is unable to convert sulfide to cysteine, this suggests that anti-induction by sulfide is the main regulatory factor in this species [296].

The genes involved in sulfonate metabolism in $E$. coli, $\operatorname{tau} A B C D$ and $s s u E A D C B$, were initially identified either

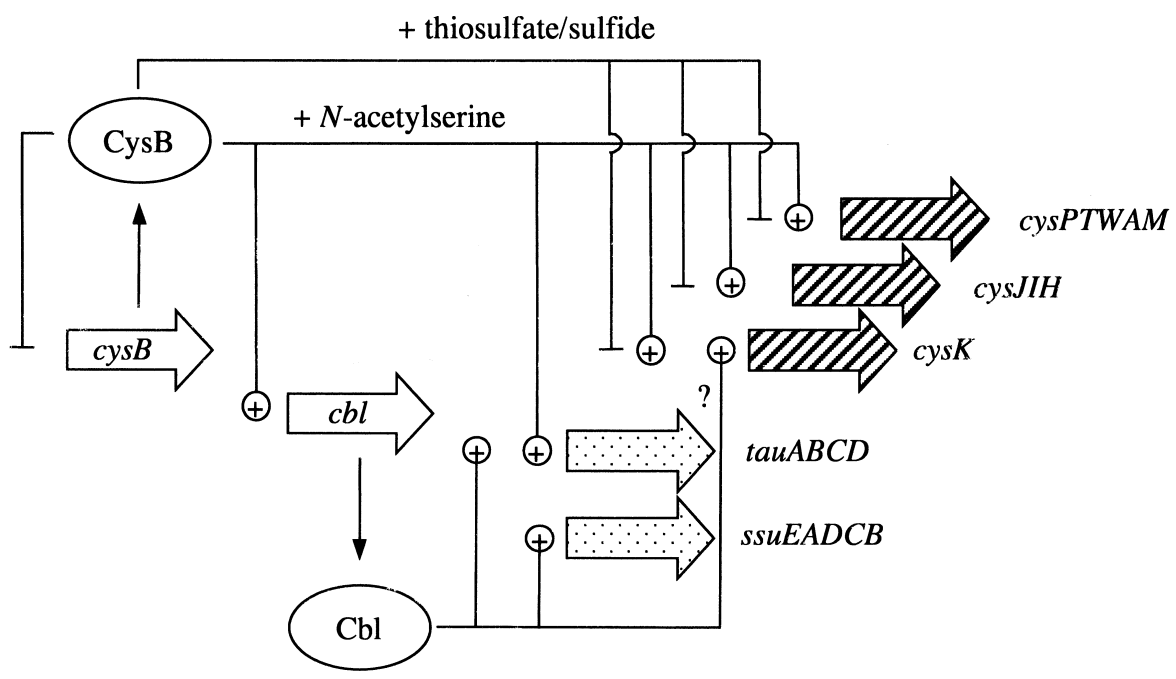

Fig. 13. Regulation of organosulfur assimilation pathways in $E$. coli. The positive regulator protein CysB interacts with the co-inducer $N$-acetylserine to activate transcription of the cys biosynthetic operons [5] and the $c b l$ gene [298]. Thiosulfate or sulfide act as anti-inducers. CysB also binds to the tau and $s s u$ operators; it is required for tau activation [297], but not for transcription of $s s u$ [222]. The Cbl protein acts as a positive regulator of the tau and ssu operons [297]. 
as sulfate-repressed lac $Z$ fusions [218] or, because synthesis of the encoded proteins was determined by 2D-PAGE to be repressed in the presence of sulfate [22]. Expression of both the tau and the $s s u$ operons requires the CysB protein [222,297], and these operons are therefore new members of the cys regulon. However, it was interesting that repression of the tau genes in the presence of sulfate was much more stringent than that observed for genes of the cysteine biosynthetic pathway [297]. This phenomenon was partly explained when it was discovered that expression of these genes requires not only CysB, but also a second, closely related regulator protein, the 'CysB-like' protein, Cbl, [297]. Like CysB, the $\mathrm{Cbl}$ protein is a member of the LysR family of transcriptional activators, and exhibits $41 \%$ amino acid identity to the CysB protein of E. coli. Expression of $c b l$ is itself positively regulated by CysB, and CysB was shown to bind to the promoter region of the $c b l$ gene [298]. Cbl also appears to be involved in the synthesis of other sulfate starvation-induced proteins, including the sulfate binding protein Sbp, and the acetylserine (thiol) lyase CysK [297]. Interestingly, E. coli contains second copies of both of these enzymes (CysP and CysM, respectively), and so the additional regulation by $\mathrm{Cbl}$ may represent a strategy to allow fine tuning of the cellular response to sulfate starvation.

More detailed studies of the role of $\mathrm{Cbl}$ have been carried out with the tau and ssu promoters. Cbl was found to bind upstream of the -35 region of both these promoters, and since expression of tau $A:: \operatorname{lac} Z$ and $s s u E:: l a c Z$ fusion required the presence of an intact $c b l$ gene, it seems likely that $\mathrm{Cbl}$ is acting as a transcriptional activator for both these operons [222,297]. CysB also bound to both promoters, and binding was stimulated by $O$-acetylserine and by thiosulfate. At the tau promoter, CysB may well be acting as a co-activator, either binding together with $\mathrm{Cbl}$, or changing the binding of $\mathrm{Cbl}$ in such as way as to stimulate transcriptional activation. For $s s u$, the situation is different. Band-shift studies suggested that the CysB binding site at the ssu promoter lies close to the transcription start site, and $\mathrm{CysB}$ may therefore act as a repressor. Although a $s s u E:: l a c Z$ fusion was not expressed in a $c y s B$ mutant, expression of the $c b l$ gene behind a trc promoter restored ssuE expression [222]. This showed that the requirement for $\mathrm{CysB}$ is indirect ( $c b l$ expression is itself part of the cys regulon, and therefore under CysB control).

Unlike for $\mathrm{CysB}, \mathrm{Cbl}$ binding to tau or ssu promoter fragments was not stimulated by the addition of acetylserine. Sulfate did not enhance binding of either protein to the tau promoter, and thiosulfate did not stimulate binding to the $s s u$ promoter region (in fact, the $\mathrm{Cbl} / \mathrm{ssu}$ interaction was slightly weaker in the presence of $5 \mathrm{mM}$ thiosulfate). The identity of the co-regulator of $\mathrm{Cbl}$ binding is therefore still unclear. As discussed above, structural studies of $K$. pneumoniae CysB have revealed the presence of a sulfate or acetylserine binding pocket in that protein [295], and many of the residues required for the interaction of
CysB with inducer or anti-inducer are conserved in $\mathrm{Cbl}$ [222]. It therefore seems possible that the putative co-regulators of $\mathrm{Cbl}$ binding are also low-molecular-mass anions, but this remains to be demonstrated.

Control of sulfate assimilation by CysB appears to be very similar in $E$. coli and $S$. typhimurium [5,299]. It is therefore of interest that the $c b l$ gene appears to be absent in S. typhimurium [297], and that this organism is also not able to grow with alkanesulfonates as sulfur source. In $K$. pneumoniae, by contrast, both the $c y s B$ and $c b l$ genes are present, though the $\mathrm{Cbl}$ protein has not yet been characterized at a biochemical level. The CysB and Cbl proteins of $K$. pneumoniae are very closely related to their E. coli homologues ( $93 \%$ and $86 \%$ identity, respectively). $K$. pneumoniae is able to grow with taurine and other alkanesulfonates as sulfur source (unpublished), and presumably CysB and $\mathrm{Cbl}$ also play a role in controlling sulfonate-sulfur assimilation in this species.

The role of $\mathrm{CysB}$ and $\mathrm{Cbl}$ in the expression of the arylsulfatase operon $\left(a t s B A_{K p}\right)$ in $K$. pneumoniae has not yet been established. Expression of the ats $B A_{K p}$ operon is subject to complex regulation as part of the moa regulon in $K$. pneumoniae [135], but in the absence of tyramine or other related compounds its expression is repressed independently by sulfate or by cysteine [100]. This regulatory pattern is atypical for a purely CysB-controlled gene, but may correspond to combined $\mathrm{CysB} / \mathrm{Cbl}$ control, as seen for taurine metabolism in E. coli.

In pseudomonads the situation is a little different. In $P$. aeruginosa cysteine biosynthesis differs from the wellcharacterized pathway of $E$. coli in that sulfate activation is catalyzed by only two proteins $(\mathrm{CysDN})$, rather than three (CysDNC), and that sulfide is transferred to $O$-succinylhomoserine (rather than $O$-acetylserine), giving homocysteine as the initial organosulfur product (Fig. 1) [19]. Cysteine is then generated by reverse transsulfurylation via cystathionine [148]. The presence of the reverse transsulfurylation pathway allows $P$. aeruginosa to grow readily with methionine as sole sulfur source, in contrast to $E$. coli, which grows only very slowly under these conditions. A cysB mutant of $P$. aeruginosa can grow with sulfite or with methionine as sole sulfur sources, demonstrating that sulfite reductase and the reverse transsulfurylation pathway from methionine to cysteine are independent of CysB [14]. However, a cysB mutant was unable to utilize either sulfate esters or sulfonates. Expression studies with the ats $R$ and atsBCA genes of $P$. aeruginosa confirmed that expression of the ats genes required an intact $c y s B$ gene. Analysis of the $P$. aeruginosa genome sequence shows only one gene that resembles $E$. coli cys $B$, and so there appears to be no equivalent to the $c b l$ gene that is found in enteric bacteria.

However, an additional regulatory factor(s) must nonetheless be present. Arylsulfatase synthesis in P. aeruginosa is repressed independently by sulfite and sulfide, but not by sulfate [20], whereas methanesulfonatase synthesis is 
repressed by all three compounds independently [14] (Fig. 14). Sequence analysis of the ats and $m s u$ promoter regions did not provide any evidence for a $\mathrm{CysB}$ binding site, though it should be stressed that the consensus for these sites is weak. It will therefore be interesting to see whether future binding studies confirm a direct role for CysB in regulating these genes, or lead to the conclusion that CysB-mediated regulation is also indirect, involving additional, as yet unidentified factors. Additional factors could provide the means for adjusting the response to sulfate limitation, as seen for the $\mathrm{Cbl}$ protein in $E$. coli.

In some cases the sulfate starvation response is also modulated by a positive regulator that responds not only to sulfate limitation but to the presence of specific alternative sulfur sources. Regulation of asf $A B C$ by AsfR, for instance, is positively affected by toluenesulfonate or benzenesulfonate, and repressed in the presence of sulfate this repression appears to be partly CysB-mediated [185]. AsfR is related ( $34 \%$ identity) to $\mathrm{SdsB}$, the positive regulator protein involved in dodecylsulfate utilization in Pseudomonas sp. ATCC 19151 [166], and a further protein of the same family (45\% identity to AsfR) is encoded downstream of ats $R$ in $P$. putida (unpublished). It is not yet known how these latter two genes are controlled, but their close relatedness to AsfR and CysB makes it likely that they are involved in regulating some aspect of organosulfur metabolism.
Organosulfur metabolism in fungi and cyanobacteria is regulated by other mechanisms. In the filamentous fungus Neurospora crassa, sulfatase expression is positively regulated by the CYS3 protein, a bZIP DNA binding protein that is subject to positive autoregulation, and controls expression of genes encoding cysteine biosynthesis, sulfate permeases, cholinesulfatase and arylsulfatase [300,301]. The cys3 gene is subject to negative regulation by two further proteins, the products of the sconl and scon2 genes. The CYS3 protein is also subject to rapid turnover in response to changes in sulfur supply [302]. Related control mechanisms are also present in the yeast $S$. cerevisiae [9,303]. In the cyanobacterium Synechococcus sp. strain PCC7942 a further type of regulator is involved. The CysR protein, a protein of the Crp family, has been implicated in the expression of several plasmid-encoded genes of sulfur metabolism [304,305]. The green alga Chlamydomonas reinhardtii requires the $\mathrm{SAC} 1$ protein for survival during sulfur deprived conditions, and for expression of the arylsulfatase gene [306]. SAC1 appears to be an integral membrane protein, and the regulatory effect may therefore be due to import of an essential regulatory molecule. A related gene is also found in the cyanobacterium Synechocystis [142], and it will be interesting to see whether it also plays a role in controlling the cellular response to sulfur deprivation.

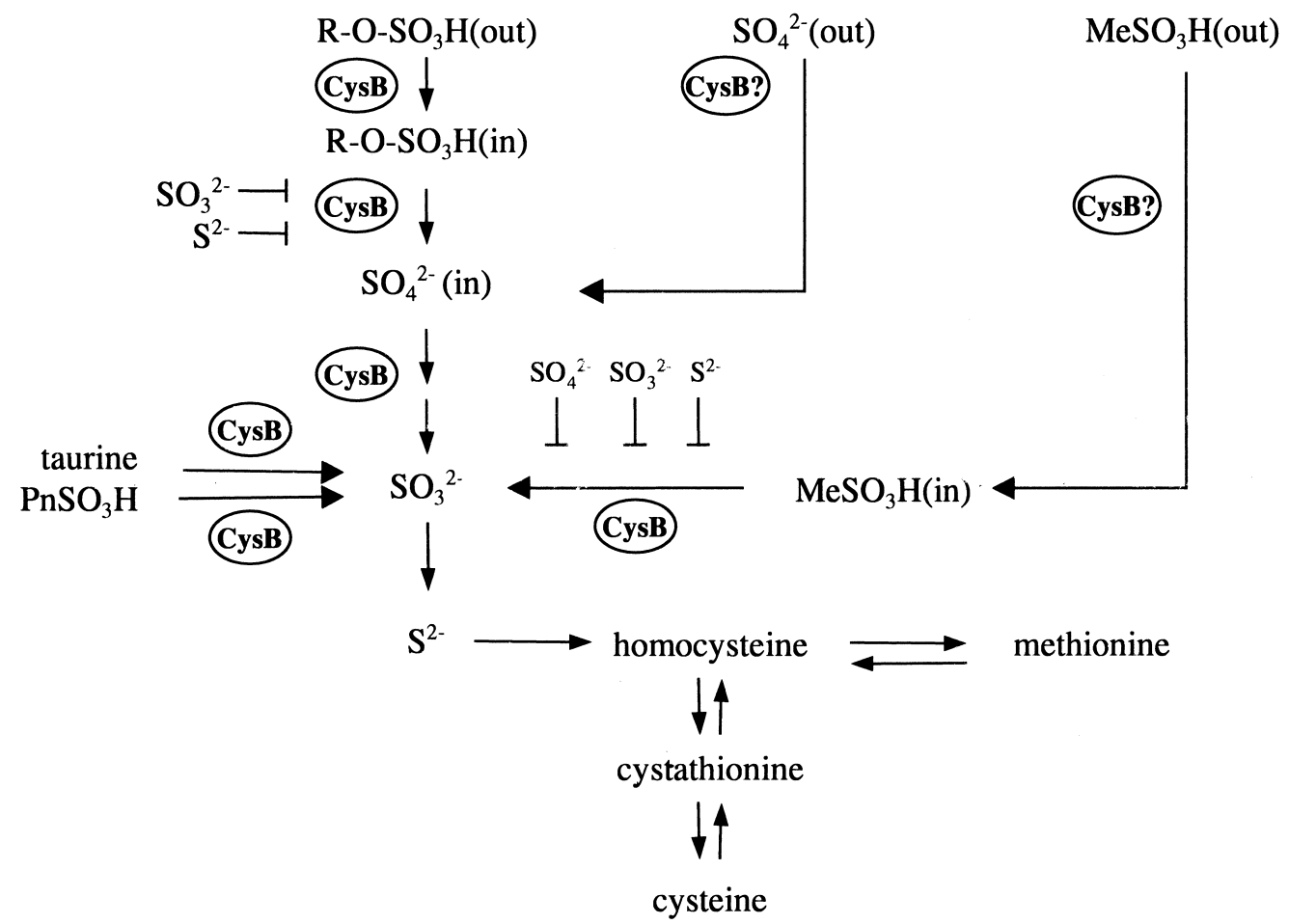

Fig. 14. Regulation of organosulfur assimilation pathways in $P$. aeruginosa. Growth of $P$. aeruginosa with sulfate, sulfonates or sulfate esters requires the CysB protein. Expression of arylsulfate transport and of arylsulfatase requires CysB and the latter is repressed by sulfite or sulfide, but not sulfate. Methanesulfonatase synthesis requires CysB and is repressed independently by sulfate, sulfite or sulfide. CysB is not required for growth with methionine or sulfite. 


\section{Uptake of sulfonates and sulfate esters}

Even a superficial inspection of the list of sulfate starvation-induced proteins identified in 2D-PAGE studies (Table 1) reveals that synthesis of several periplasmic solute binding proteins is regulated by sulfur supply. This result may in part reflect the soluble nature of these proteins, and the fact that they are readily extracted from the cell and visualized by 2D-PAGE, but it also suggests that induction of transport systems is an important part of the bacterial cell's response to sulfate limitation. This hypothesis is confirmed by the fact that the transcriptional units encoding the sulfatase or sulfonatase genes themselves often also contain genes for putative ABC-type transport systems (Figs. 6, 8 and 10). Hence, the tauD gene of E. coli is preceded by $\operatorname{tau} A B C$ [297], and the $s s u D$ gene of $B$. subtilis is located in the same operon as $s s u A B C$ [223], as is also the case for the ssuD genes of both $P$. putida and $P$. aeruginosa. The three loci that are required for arylsulfonate desulfonation in P. putida (ssu, ats and asf, Fig. 10 [185]) all contain genes which appear to encode components of ABC-type transporters. From mutant studies, the AtsRBC system catalyzes sulfate ester transport in $P$. aeruginosa and $P$. putida $[131,136]$, and its expression is also repressed during growth with sulfate. Most of the intracellular (Cys-type) sulfatase genes in Fig. 6 are also associated with transport systems of some nature, whereas the periplasmic (Ser-type) homologues are not. The requirement for sulfate ester and sulfonate transport systems is not surprising, since these compounds are completely ionized at physiological $\mathrm{pH}$, and active transport systems are required to allow them to enter the cell.

When the known periplasmic binding proteins for sulfonates and sulfate esters are compared (Fig. 15) considerable similarity is found among them [24]. These proteins form an independent family of binding proteins separate from those previously defined by Tam and Saier [307], being $22-45 \%$ identical to each other, but sharing less than $15 \%$ sequence identity with the families of solute binding proteins that have previously been described. Surprisingly, they are also only moderately related to Sbp and CysP, the periplasmic sulfate and thiosulfate binding proteins, respectively. These two proteins are closely related to each other and show an overlapping substrate specificity [308].

To date, the only detailed biochemical study of arylsulfonate transport into the cell reported an inducible secondary proton symport system for uptake of toluenesulfonate by Comamonas testosteroni T-2 [309]. This study was complicated by the fact that the strain uses toluenesulfonate as a carbon and energy source, and that the sulfonate was therefore metabolized further immediately after entry into the cell. The genes encoding the inducible desulfonation system for toluenesulfonate in this strain have recently been reported (tsaMBCD/tsaR) [310], but the transport system was not encoded in the same locus, and one can

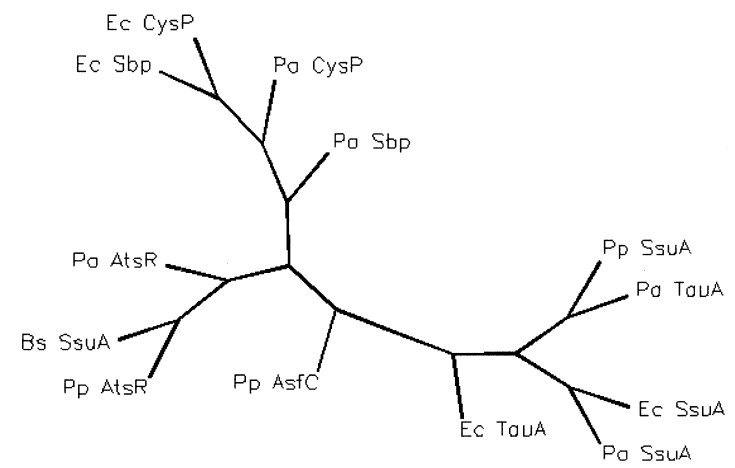

Fig. 15. Phylogenetic tree for sulfate, thiosulfate, sulfonate and sulfate ester binding proteins. The proteins shown are the putative sulfonate binding protein SsuA from B. subtilis (Bs), P. aeruginosa $(\mathrm{Pa})$, E. coli (Ec), and $P$. putida (Pp), the sulfate ester binding protein AtsR from $P$. putida and $P$. aeruginosa, the taurine binding protein TauA from $E$. coli and $P$. aeruginosa, the putative arylsulfonate binding protein AsfC from $P$. putida, and the sulfate and thiosulfate binding proteins Sbp and CysP from $E$. coli and $P$. aeruginosa. The mature protein sequences (after removal of the signal peptides) were aligned using CLUSTALW, and the phylogenetic tree produced with DRAWTREE.

therefore only speculate on its relationship to the sulfateregulated transport systems described above.

Specific permeases that catalyze the uptake of several different sulfate esters have also been identified in N. cras$s a$ [31]. Synthesis of these proteins is controlled by the CYS3 protein and repressed during growth with preferred sulfur sources. Sulfate-repressed uptake of alkanesulfonic acids has also been observed in algae [311,312], and in cyanobacteria [312,313], but the regulatory mechanism has not yet been explored in these species.

\section{Organosulfur utilization without oxygen}

Sulfonates and sulfate esters in soils are present not only in aerobic niches, but are also found in deeper, anaerobic soils [45]. A range of anaerobic bacteria have been identified which can make use of sulfonates. Most of these isolates belong to novel genera, and this uncharted biodiversity is just starting to be explored [7].

Under anaerobic conditions, sulfonates and sulfate esters can in principle provide not only a source of assimilable sulfur but can also be used in dissimilatory pathways (reviewed recently by Cook et al. [7] and by Lie et al. [8]). The first anaerobes reported to assimilate sulfonate sulfur were $C$. pasteurianum $\mathrm{C} 1$, which desulfurizes isethionate, taurine, or toluenesulfonate [314] and Clostridium beijerincki EV4, which grows with toluenesulfonate as sulfur source [315]. The mechanism by which this aromatic desulfonation takes place is still unclear, but is clearly different from the desulfonative process catalyzed by $P$. putida. NMR and LC-MS analyses of the isolated desulfonation products suggested that the aromatic ring may undergo further substitution before desulfonation occurs (unpublished results). Further enrichments for isolates that can 
assimilate toluenesulfonate sulfur have also yielded Clostridium species [316], and it is possible that this ability is limited to this genus. By contrast, a facultatively anaerobic Klebsiella isolate was able to utilize cysteate sulfur under fermentative conditions, but could not desulfurize taurine, isethionate or toluenesulfonate [314], and a novel anaerobic member of the $\gamma$-proteobacteria related to Shewanella and Aeromonas, strain RZLAS, was able to grow with LAS as sole sulfur source [317].

Sulfonates can also serve either as electron donors or electron acceptors in respiration, or as substrate in disproportionation reactions under fermentative conditions. Various sulfate-reducing bacteria use isethionate, cysteate or taurine as electron acceptor $[8,318,319]$. The taurine desulfonation reaction is catalyzed by transamination to sulfoacetaldehyde and subsequent desulfonative hydrolysis to acetate, formally the same mechanism as used by pseudomonads during growth with taurine as a carbon source $[200,203,213]$. Taurine desulfonation as electron acceptor was also found in a sulfate non-reducer, the Gram-negative anaerobe Bilophila wadsworthia RZATAU [318]. In this organism the enzymes of taurine transformation were reported to be constitutively expressed [7] (by contrast, in Desulfovibrio the taurine aminotransferase is inducible [319]). The sulfite released by $B$. wadsworthia sulfoacetaldehyde hydrolase may be reduced to sulfide by desulfoviridin, which was detected in extracts of this strain [7].

Sulfonates are also used as electron donors by an Alcaligenes strain [205] and a Paracoccus denitrificans isolate [320], in the presence of nitrate as electron acceptor. In Alcaligenes sp. strain NKNTAU taurine was desulfonated to sulfite, which was quantitatively oxidized to sulfate [205], and similar results were obtained with isethionate and cysteate in other species [7]. A novel, obligately anaerobic Gram-negative isolate, named Desulforhopalus singaporensis, could ferment taurine, but not other sulfonates, to sulfide [321]. Two Gram-positive species have also been identified that are able to ferment cysteate or taurine. Taurine was converted by strain GKNTAU (which belongs to a novel genus within the Clostridium group [7]) to thiosulfate, presumably via transamination to sulfoacetaldehyde [207]. A Desulfovibrio isolate was also able to ferment cysteate to equimolar amounts of sulfite and sulfide [322].

In contrast to the extensive recent work on the anaerobic utilization of sulfonates, very little is known about how sulfate esters are degraded under anaerobic conditions. Clostridia were able to grow with nitrocatechol sulfate or 5-bromo-4-chloro-3-indolylsulfate, but the corresponding phenol products were not detected, suggesting that sulfate ester utilization in these species is catalyzed by a fundamentally different enzyme from the arylsulfatases that have been characterized in Gram-negative, aerobic bacteria [316]. Further studies are required to determine the nature of sulfate ester utilization in clostridia, and biodiversity studies on the distribution of Cys- and Sertype sulfatases in aerobic and anaerobic niches are also still outstanding.

\section{Conclusions and perspectives}

The purpose of this article has been to present an overview of recent advances in our understanding of how Gram-negative bacteria contribute to the global sulfur cycle by their metabolism of organosulfur compounds such as sulfate esters and sulfonates. By concentrating on enzymes and enzyme systems whose synthesis is controlled by the sulfur supply to the cell, it has emphasized a new aspect which has become particularly relevant in the last few years. Sulfate esters and sulfonates can be used as sulfur sources for growth by a variety of bacterial species, but the number of organisms that can carry out complete mineralization of these compounds is more limited. The substrate specificity of enzymes that are induced as part of a sulfate-starvation response is often quite broad, allowing the cell considerable flexibility in scavenging sulfur from the environment. Whereas this characteristic has obvious advantages in designing practical applications for such enzyme systems, there are also grave disadvantages - enzymes that are used to provide the organism with sulfur are usually present only in low amounts in the cell, and their synthesis is switched off in the presence of better sulfur sources such as sulfate or sulfite.

The understanding of sulfur-regulated systems is, however, providing means to avoid these drawbacks. Thus, the first steps have been taken towards practical coal and oil biodesulfurization using the dibenzothiophene desulfurization genes by removing the sulfate control of their expression, and starting to optimize a desulfurization strain [286]. Similar work is still required for strains that desulfurize aromatic sulfonates. Whereas many such sulfonates are readily biodegradable, others are persistent and appear in drinking water after bank filtration. Most of the genetic understanding of aromatic desulfonation processes as part of the sulfur cycle comes from $P$. putida, and it will be important to evaluate how far this knowledge is applicable to other organisms, and whether the genes identified are relevant in biodegradation under non-laboratory conditions.

This last question is also crucial for investigating a further outstanding aspect of organosulfur biochemistry, the question of soil organosulfur cycling. With the characterization of sulfonate and sulfate ester metabolic systems we now have first tools in hand for the elucidation of the molecular processes that occur in the microbially mediated cycling of sulfur between inorganic and organically bound forms in the soil. Practical applications can be readily visualized, with the aim of increasing the levels of plantaccessible sulfate in the soil, and increasing crop yields on sulfur-deficient soils. Such applications might involve 
field inoculation with genetically modified organisms, but it is perhaps more realistic to think of monitoring bacterial genetic markers in order suitably to modify fertilization regimes and thereby optimize release of soil sulfur for plant growth by indigenous bacteria. These genes also show promise as bio-indicators for available sulfur in the soil, but more work needs to be done to characterize their expression in native environments.

Regulation of the sulfonatase and sulfatase genes in Gram-negative bacteria has been found to be ultimately controlled by the CysB protein, which acts as a global regulator in all of sulfur metabolism. However, much remains to be learned about the fine tuning of this control. In at least two cases, additional regulatory proteins are required for sulfonatase gene expression $(\mathrm{Cbl}$ in enteric bacteria [297], and AsfR in P. putida [185]), and it is to be anticipated that more will be discovered, especially resulting from the new data that are appearing from whole genome analysis. Elucidating and manipulating the mechanisms by which these regulatory cascades function will provide interesting challenges for the coming years.

\section{Acknowledgements}

I am grateful to T. Leisinger for his continued support, and for his interest in my work. I thank A.M. Cook and T. Dierks for interesting and helpful discussions, and for sharing unpublished data, along with A. Schirmer, G. Huisman, J. van der Ploeg and E. Eichhorn. S. Vuilleumier and K. Kertesz-Chaloupkovà made invaluable comments on the manuscript. My thanks are also due to $\mathrm{P}$. Vermeij, J. Hummerjohann, C. Wietek, A. Kahnert, and all past and present co-workers whose work is cited in this review. Work in my laboratory is supported by the Swiss National Science Foundation and by the Swiss Federal Office for Education and Sciences (as part of the ECfunded program SUITE, ENV4-CT98-0723).

\section{References}

[1] Brown, K.A. (1982) Sulphur in the environment: a review. Environ. Pollut. Ser. B 3, 47-80.

[2] Stipanuk, M.H. (1986) Metabolism of sulfur-containing amino acids. Annu. Rev. Nutr. 6, 179-209.

[3] Hell, R. (1997) Molecular physiology of plant sulfur metabolism. Planta 202, 138-148.

[4] Leustek, T. (1996) Molecular genetics of sulfate assimilation in plants. Physiol. Plant. 97, 411-419.

[5] Kredich, N.M. (1996) Biosynthesis of cysteine. In: Escherichia coli and Salmonella, 2nd edn. (Neidhardt, F.C., Curtiss, R., Ingraham, J.L., Lin, E.C.C., Low, K.B., Magasanik, B., Reznikoff, W.S., Riley, M., Schaechter, M. and Umbarger, H.E., Eds.), pp. 514-527, ASM Press, Washington, DC.

[6] Neidhardt, F.C., Bloch, P.L. and Smith, D.F. (1974) Culture medium for Enterobacteria. J. Bacteriol. 119, 736-747.
[7] Cook, A.M., Laue, H. and Junker, F. (1998) Microbial desulfonation. FEMS Microbiol. Rev. 22, 399-419.

[8] Lie, T.J., Leadbetter, J.R. and Leadbetter, E.R. (1998) Metabolism of sulfonic acids and other organosulfur compounds by sulfate-reducing bacteria. Geomicrobiol. J. 15, 135-149.

[9] Marzluf, G.A. (1997) Molecular genetics of sulfur assimilation in filamentous fungi and yeast. Annu. Rev. Microbiol. 51, 73-96.

[10] Ono, B., Kijima, K., Ishii, N., Kawato, T., Matsuda, A., Paszewski, A. and Shinoda, S. (1996) Regulation of sulphate assimilation in Saccharomyces cerevisiae. Yeast 12, 1153-1162.

[11] Beil, S., Kehrli, H., James, P., Staudenmann, W., Cook, A.M., Leisinger, T. and Kertesz, M.A. (1995) Purification and characterization of the arylsulfatase synthesized by Pseudomonas aeruginosa PAO during growth in sulfate-free medium and cloning of the arylsulfatase gene (ats A). Eur. J. Biochem. 229, 385-394.

[12] Eichhorn, E., van der Ploeg, J.R., Kertesz, M.A. and Leisinger, T. (1997) Characterization of $\alpha$-ketoglutarate dependent taurine dioxygenase from Escherichia coli. J. Biol. Chem. 272, 23031-23036.

[13] Dierks, T., Miech, C., Hummerjohann, J., Schmidt, B., Kertesz, M.A. and von Figura, K. (1998) Posttranslational formation of formylglycine in prokaryotic sulfatases by modification of either cysteine or serine. J. Biol. Chem. 273, 25560-25564.

[14] Kertesz, M.A., Schmidt, K. and Wüest, T. (1999) A novel reduced flavin mononucleotide-dependent methanesulfonate sulfonatase encoded by the sulfur-regulated msu operon of Pseudomonas aeruginosa. J. Bacteriol. 181, 1464-1473.

[15] Gray, K.A., Pogrebinsky, O.S., Mrachko, G.T., Xi, L., Monticello, D.J. and Squires, C.H. (1996) Molecular mechanisms of biocatalytic desulfurization of fossil fuels. Nature Biotechnol. 14, 1705-1709.

[16] Cerbelaud, E.C., Conway, L.J., Galliher, P.M., Langer, R.S. and Cooney, C.L. (1986) Sulfur regulation of heparinase and sulfatases in Flavobacterium heparinum. Appl. Environ. Microbiol. 51, 640-646.

[17] Kredich, N.M. (1992) The molecular basis for positive regulation of cys promoters in Salmonella typhimurium and Escherichia coli. Mol. Microbiol. 6, 2747-2753.

[18] Grundy, F.J. and Henkin, T.M. (1998) The S box regulon: a new global transcription termination control system for methionine and cysteine biosynthesis genes in Gram-positive bacteria. Mol. Microbiol. 30, 737-749.

[19] Foglino, M., Borne, F., Bally, M., Ball, G. and Patte, J.C. (1995) A direct sulfhydrylation pathway is used for methionine biosynthesis in Pseudomonas aeruginosa. Microbiology 141, 431-439.

[20] Hummerjohann, J., Kuttel, E., Quadroni, M., Ragaller, J., Leisinger, T. and Kertesz, M.A. (1998) Regulation of the sulfate starvation response in Pseudomonas aeruginosa: role of cysteine biosynthetic intermediates. Microbiology 144, 1375-1386.

[21] Kertesz, M.A., Leisinger, T. and Cook, A.M. (1993) Proteins induced by sulfate limitation in Escherichia coli, Pseudomonas putida, or Staphylococcus aureus. J. Bacteriol. 175, 1187-1190.

[22] Quadroni, M., Staudenmann, W., Kertesz, M. and James, P. (1996) Analysis of global responses by protein and peptide fingerprinting of proteins isolated by two-dimensional gel electrophoresis: application to the sulfate-starvation response of Escherichia coli. Eur. J. Biochem. 239, 773-781.

[23] Dainese, P., Staudenmann, W., Quadroni, M., Korostensky, C., Gonnet, G., Kertesz, M. and James, P. (1997) Probing protein function using a combination of gene knockout and proteome analysis by mass spectrometry. Electrophoresis 18, 432-442.

[24] Quadroni, M., James, P., Dainese-Hatt, P. and Kertesz, M.A. (1999) Proteome mapping, mass spectrometric sequencing and reverse transcriptase-PCR for characterisation of the sulfate starvation-induced response in Pseudomonas aeruginosa PAO1. Eur. J. Biochem. in press.

[25] Wanner, B.L. (1996) Phosphorus assimilation and control of the phosphate regulon. In: Escherichia coli and Salmonella, 2nd edn. (Neidhardt, F.C., Curtiss, R., Ingraham, J.L., Lin, E.C.C., Low, K.B., Magasanik, B., Reznikoff, W.S., Riley, M., Schaechter, M. 
and Umbarger, H.E., Eds.), pp. 1357-1381, ASM Press, Washington, DC.

[26] Jiang, W.H., Metcalf, W.W., Lee, K.S. and Wanner, B.L. (1995) Molecular cloning, mapping, and regulation of Pho regulon genes for phosphonate breakdown by the phosphonatase pathway of Salmonella typhimurium LT2. J. Bacteriol. 177, 6411-6421.

[27] Hulett, F.M. (1996) The signal-transduction network for Pho regulation in Bacillus subtilis. Mol. Microbiol. 19, 933-999.

[28] Filloux, A., Bally, M., Soscia, C., Murgier, M. and Lazdunski, A. (1988) Phosphate regulation in Pseudomonas aeruginosa: cloning of the alkaline phosphatase gene and identification of phoB- and phoRlike genes. Mol. Gen. Genet. 212, 510-513.

[29] Mazel, D. and Marlière, P. (1989) Adaptive eradication of methionine and cysteine from bacterial light-harvesting proteins. Nature 341, 245-248.

[30] Roberts, R.B., Abelson, P.H., Cowie, D.B., Bolton, E.T. and Britten, R.J. (1955) Studies of Biosynthesis in Escherichia coli, Carnegie Institution, Washington, DC.

[31] Marzluf, G.A. (1994) Genetics and molecular genetics of sulfur assimilation in the fungi. Adv. Genet. 31, 187-206.

[32] Marzluf, G.A. (1993) Regulation of sulfur and nitrogen metabolism in filamentous fungi. Annu. Rev. Microbiol. 47, 31-55.

[33] De Hostos, E.L., Schilling, J. and Grossman, A.R. (1989) Structure and expression of the gene encoding the periplasmic arylsulfatase of Chlamydomonas reinhardtii. Mol. Gen. Genet. 218, 229-239.

[34] Hallmann, A. and Sumper, M. (1994) An inducible arylsulfatase of Volvox carteri with properties suitable for a reporter-gene system: Purification, characterization and molecular cloning. Eur. J. Biochem. 221, 143-150.

[35] Dodgson, K.S., White, G.F. and Fitzgerald, J.W. (1982) Sulfatases of Microbial Origin. CRC Press, Boca Raton, FL.

[36] Watwood, M.E., Fitzgerald, J.W. and Gosz, J.R. (1986) Sulfur processing in forest soil and litter along an elevational and vegetative gradient. Can. J. For. Res. 16, 689-695.

[37] Autry, A.R. and Fitzgerald, J.W. (1990) Sulfonate S - A major form of forest soil organic sulfur. Biol. Fertil. Soils 10, 50-56.

[38] Zehnder, A.J.B. and Zinder, S.H. (1980) The sulfur cycle. In: The Handbook of Environmental Chemistry (Hutzinger, O., Ed.), Vol. 1A, pp. 105-145, Springer, Berlin.

[39] White, R.H. (1985) Biosynthesis of coenzyme M (2-mercaptoethanesulfonic acid). Biochemistry 24, 6487-6493.

[40] Huxtable, R.J. (1992) Physiological actions of taurine. Physiol. Rev. $72,101-163$.

[41] Baker, S.C., Kelly, D.P. and Murrell, J.C. (1991) Microbial degradation of methanesulfonic acid - a missing link in the biogeochemical sulfur cycle. Nature 350, 627-628.

[42] Benning, C. (1998) Biosynthesis and function of the sulfolipid sulfoquinovosyl diacylglycerol. Annu. Rev. Plant Physiol. Plant Mol. Biol. 49, 53-75.

[43] Herbert, R.B. and Holliman, F.G. (1964) Aeruginosin B - a naturally occurring phenazinesulphonic acid. Proc. Chem. Soc. 1964, 19.

[44] Vairavamurthy, M.A., Maletic, D., Wang, S.K., Manowitz, B., Eglinton, T. and Lyons, T. (1997) Characterization of sulfur-containing functional groups in sedimentary humic substances by X-ray absorption near-edge structure spectroscopy. Energy Fuels 11, 546-553.

[45] Vairavamurthy, M.A., Zhou, W., Eglinton, T. and Manowitz, B. (1994) Sulfonates: a new class of organic sulfur compounds in marine sediments. Geochim. Cosmochim. Acta 58, 4681-4687.

[46] Visscher, P.T., Gritzer, R.F. and Leadbetter, E.R. (1999) Low-molecular-weight sulfonates, a major substrate for sulfate reducers in marine microbial mats. Appl. Environ. Microbiol. 65, 3272-3278.

[47] van Loon, W.M.G.M., Boon, J.J. and de Groot, B. (1993) Quantitative analysis of sulfonic acid groups in macromolecular lignosulfonic acids and aquatic humic substances by temperature resolved pyrolysis-mass spectrometry. Environ. Sci. Technol. 27, 2387-2396.

[48] Vairavamurthy, A., Mopper, K. and Taylor, B.F. (1992) Occurrence of particle-bound polysulfides and significance of their reaction with organic matters in marine sediments. Geophys. Res. Lett. 19, 20432046.

[49] Ghani, A., McLaren, R.G. and Swift, R.S. (1993) Mobilization of recently-formed soil organic sulphur. Soil Biol. Biochem. 25, 17391744.

[50] Ghani, A., McLaren, R.G. and Swift, R.S. (1993) The incorporation and transformations of sulfur-35 in soil: Effects of soil conditioning and glucose or sulphate additions. Soil Biol. Biochem. 25, 327335 .

[51] Stevenson, F.J. (1994) Humus Chemistry: Genesis, Composition, Reactions, 2nd edn., Wiley, New York.

[52] McFarland, B.L., Boron, D.J., Deever, W., Meyer, J.A., Johnson, A.R. and Atlas, R.M. (1998) Biocatalytic sulfur removal from fuels: Applicability for producing low sulfur gasoline. Crit. Rev. Microbiol. 24, 99-147.

[53] Zerbinati, O., Vincenti, M., Pittavino, S. and Gennaro, M.C. (1997) Fate of aromatic sulfonates in fluvial environment. Chemosphere 35, 2295-2305.

[54] Fichtner, S., Lange, F.T., Schmidt, W. and Brauch, H.J. (1995) Determination of aromatic sulfonates in the river Elbe by on-line ionpair extraction and ion-pair chromatography. Fresenius J. Anal. Chem. 353, 57-63.

[55] Hellmann, H. (1991) Area-detailed determination of anion-active surfactants (LAS) in flowing waters of the Federal Republic of Germany through the UV spectra of second order. Z. Wasser Abwasser Forsch. 24, 178-187.

[56] Zerbinati, O., Salomone, S. and Ostacoli, G. (1994) Sulfonated derivatives of naphthalene in water samples of an Italian river. Chemosphere 29, 2639-2643.

[57] Prats, D., Ruiz, F., Vazquez, B., Zarzo, D., Berna, J.L. and Moreno, A. (1993) LAS homolog distribution shift during wastewater treatment and composting: Ecological implications. Environ. Toxicol. Chem. 12, 1599-1608.

[58] deWolf, W. and Feijtel, T. (1998) Terrestrial risk assessment for linear alkyl benzene sulfonate (LAS) in sludge-amended soils. Chemosphere 36, 1319-1343.

[59] Ainsworth, S.J. (1996) Soaps and detergents. Chem. Eng. News 74 (4), 32-54.

[60] Swisher, R.D. (1987) Surfactant Biodegradation, Marcel Dekker, New York.

[61] Holmstrup, M. and Krogh, P.H. (1996) Effects of an anionic surfactant, linear alkylbenzene sulfonate, on survival, reproduction and growth of the soil-living collembolan Folsomia fimetaria. Environ. Toxicol. Chem. 15, 1745-1748.

[62] Hansen, B., Fotel, F.L., Jensen, N.J. and Wittrup, L. (1997) Physiological effects of the detergent linear alkylbenzene sulphonate on blue mussel larvae (Mytilus edulis) in laboratory and mesocosm experiments. Marine Biol. 128, 627-637.

[63] Utsunomiya, A., Watanuki, T., Matsushita, K. and Tomita, I. (1997) Toxic effects of linear alkylbenzene sulfonate, quaternary alkylammonium chloride and their complexes on Dunaliella sp. and Chlorella pyrenoidosa. Environ. Toxicol. Chem. 16, 1247-1254.

[64] Hofer, R., Jeney, Z. and Bucher, F. (1995) Chronic effects of linear alkylbenzene sulfonate (LAS) and ammonia on rainbow trout (Oncorhynchus mykiss) fry at water criteria limits. Water Res. 29, 27252729.

[65] Tabor, C.F. and Barber III, L.B. (1996) Fate of linear alkylbenzene sulfonate in the Mississippi River. Environ. Sci. Technol. 30, 161171.

[66] Krueger, C.J., Radakovich, K.M., Sawyer, T.E., Barber, L.B., Smith, R.L. and Field, J.A. (1998) Biodegradation of the surfactant linear alkylbenzenesulfonate in sewage-contaminated groundwater: A comparison of column experiments and field tracer tests. Environ. Sci. Technol. 32, 3954-3961.

[67] McAvoy, D.C., Eckhoff, W.S. and Rapaport, R.A. (1993) Fate of linear alkylbenzene sulfonate in the environment. Environ. Toxicol. Chem. 12, 977-987. 
[68] Nicholls, R.G. and Roy, A.B. (1971) Arylsulfatases. In: The Enzymes (Boyer, P.D., Ed.), Vol. 5, pp. 21-41, Academic, New York.

[69] Coughtrie, M.W.H. (1996) Sulphation catalysed by the human cytosolic sulphotransferases: Chemical defence or molecular terrorism? Hum. Exp. Toxicol. 15, 547-555.

[70] Coughtrie, M.W.H., Sharp, S., Maxwell, K. and Innes, N.P. (1998) Biology and function of the reversible sulfation pathway catalysed by human sulfotransferases and sulfatases. Chem.-Biol. Interact. 109, $3-$ 27.

[71] Kim, D.H., Kim, B., Kim, H.S., Sohng, I.S. and Kobashi, K. (1994) Sulfation of parabens and tyrosylpeptides by bacterial arylsulfate sulfotransferases. Biol. Pharm. Bull. 17, 1326-1328.

[72] Niehrs, C., Beisswanger, R. and Huttner, W.B. (1994) Protein tyrosine sulfation, 1993: An update. Chem.-Biol. Interact. 92, 257271.

[73] Ouyang, Y.B., Lane, W.S. and Moore, K.L. (1998) Tyrosylprotein sulfotransferase: Purification and molecular cloning of an enzyme that catalyzes tyrosine $O$-sulfation, a common posttranslational modification of eukaryotic proteins. Proc. Natl. Acad. Sci. USA 95, 28962901.

[74] Bundgaard, J.R., Vuust, J. and Rehfeld, J.F. (1997) New consensus features for tyrosine $\mathrm{O}$-sulfation determined by mutational analysis. J. Biol. Chem. 272, 21700-21705.

[75] Huttner, W.B. (1988) Tyrosine sulfation and the secretory pathway. Annu. Rev. Physiol. 50, 363-376.

[76] Ernst, S., Langer, R., Cooney, C.L. and Sasisekharan, R. (1995) Enzymatic degradation of glycosaminoglycans. Crit. Rev. Biochem. Mol. Biol. 30, 387-444.

[77] Freeman, C. and Hopwood, J. (1992) Lysosomal degradation of heparin and heparan sulfate. In: Heparin and Related Polysaccharides (Lane, D.A., Björk, I. and Lindahl, U., Eds.), pp. 121-134, Plenum Press, New York.

[78] Parenti, G., Meroni, G. and Ballabio, A. (1997) The sulfatase gene family. Curr. Opin. Genet. Dev. 7, 386-391.

[79] Painter, H.A. (1992) Anionic surfactants. In: The Handbook of Environmental Chemistry (Hutzinger, O., Ed.), Vol. 3F, pp. 1-88, Springer, Berlin.

[80] Lee, C., Russell, N.J. and White, G.F. (1995) Modelling the kinetics of biodegradation of anionic surfactants by biofilm bacteria from polluted riverine sites: A comparison of five classes of surfactant at three sites. Water Res. 29, 2491-2497.

[81] White, G.F., Russell, N.J. and Day, M.J. (1985) A survey of sodium dodecyl-sulfate (SDS) resistance and alkylsulfatase production in bacteria from clean and polluted river sites. Environ. Pollut. Series A 37, $1-11$.

[82] De Hostos, E.L., Togasaki, R.K. and Grossman, A. (1988) Purification and biosynthesis of a derepressible periplasmic arylsulfatase from Chlamydomonas reinhardtii. J. Cell Biol. 106, 29-38.

[83] Barbeyron, T., Potin, P., Richard, C., Collin, O. and Kloareg, B. (1995) Arylsulphatase from Alteromonas carrageenovora. Microbiology $141,2897-2904$.

[84] Hoshi, M. and Moriya, T. (1980) Arylsulfatase of sea-urchin sperm. 2. Arylsulfatase as a lysin of sea-urchins. Dev. Biol. 74, 343-350.

[85] Sasaki, H., Shimada, H., Akasaka, K. and Yamada, K. (1988) Complementary DNA sequence and expression of arylsulfatase of seaurchin arylsulfatase gene. Dev. Growth Diff. 30, 436.

[86] Yamada, K., Akasaka, K. and Shimada, H. (1989) Structure of seaurchin arylsulfatase gene. Eur. J. Biochem. 186, 405-410.

[87] Ross, D.J. and Speir, T.W. (1979) Biochemical activities of organic soils from subantarctic tussock grasslands on Campbell Island, New Zealand: 2. Enzyme activities. New Zealand J. Sci. 22, 173182.

[88] Ganeshamurthy, A.N. and Nielsen, N.E. (1990) Arylsulfatase and the biochemical mineralization of soil organic sulfur. Soil Biol. Biochem. 22, 1163-1165.

[89] Poux, N. (1966) Ultrastructural localization of arylsulfatase activity in plant meristematic cells. J. Histochem. Cytochem. 14, 932-933.
[90] Stott, D.E. and Hagedorn, C. (1980) Interrelations between selected soil characteristics and arylsulfatase and urease activities. Commun. Soil Sci. Plant Anal. 11, 935-955.

[91] Mohanty, R.K. and Padhan, S. (1992) Comparative studies on soil enzyme activities under two types of crops and adjacent grassland vegetation. Trop. Ecol. 33, 205-213.

[92] Falih, A.M.K. and Wainwright, M. (1996) Microbial and enzyme activity in soils amended with a natural source of easily available carbon. Biol. Fertil. Soils 21, 177-183.

[93] Freney, J.R., Melville, G.E. and Williams, C.H. (1975) Soil organic matter fractions as sources of plant available sulfur. Soil Biol. Biochem. 7, 217-221.

[94] Eriksen, J. (1997) Sulphur cycling in Danish agricultural soils: turnover in organic S fractions. Soil Biol. Biochem. 29, 1371-1377.

[95] Eriksen, J., Lefroy, R.D.B. and Blair, G.J. (1995) Physical protection of soil organic $\mathrm{S}$ studied by extraction and fractionation of soil organic matter. Soil Biol. Biochem. 27, 1011-1016.

[96] von Figura, K., Schmidt, B., Selmer, T. and Dierks, T. (1998) A novel protein modification generating an aldehyde group in sulfatases: its role in catalysis and disease. BioEssays 20, 505-510.

[97] Schmidt, B., Selmer, T., Ingendoh, A. and Figura, K.v. (1995) A novel amino acid modification in sulfatases that is defective in multiple sulfatase deficiency. Cell 82, 271-278.

[98] Miech, C., Dierks, T., Selmer, T., von Figura, K. and Schmidt, B. (1998) Arylsulfatase from Klebsiella pneumoniae carries a formylglycine generated from a serine. J. Biol. Chem. 273, 4835-4837.

[99] Murooka, Y., Ishibashi, K., Yasumoto, M., Sasaki, M., Sugino, H., Azakami, H. and Yamashita, M. (1990) A sulfur- and tyramineregulated Klebsiella aerogenes operon containing the arylsulfatase (atsA) gene and the atsB gene. J. Bacteriol. 172, 2131-2140.

[100] Adachi, T., Murooka, Y. and Harada, T. (1975) Regulation of arylsulfatase synthesis by sulfur compounds in Klebsiella aerogenes. J. Bacteriol. 121, 29-35.

[101] Murooka, Y. and Harada, T. (1981) Regulation of derepressed synthesis of arylsulfatase by tyramine oxidase in Salmonella typhimurium. J. Bacteriol. 145, 796-802.

[102] Henderson, M.J. and Milazzo, F.H. (1979) Arylsulfatase in Salmonella typhimurium: detection and influence of carbon source and tyramine on its synthesis. J. Bacteriol. 139, 80-87.

[103] Fowler, L.R. and Rammler, D.H. (1963) Sulfur metabolism of Aerobacter aerogenes. II. The purification and some properties of a sulfatase. Biochemistry 208, 230-237.

[104] Rammler, D.H., Grado, C. and Fowler, L.R. (1964) Sulfur metabolism of Aerobacter aerogenes. 1. A repressible sulfatase. Biochemistry 3, 224-230.

[105] Fitzgerald, J.W. and Milazzo, F.H. (1970) Arylsulfatase multiplicity in Proteus rettgeri. Can. J. Microbiol. 16, 1109-1115.

[106] Dodgson, K.S. (1959) Observations on the arylsulphatase of Proteus vulgaris. Enzymologia 20, 301-312.

[107] Murooka, Y., Yim, M.H. and Harada, T. (1980) Formation and purification of Serratia marcescens arylsulfatase. Appl. Environ. Microbiol. 39, 812-817.

[108] Fitzgerald, J.W. and George, J.R. (1977) Localization of arylsulfatase in Pseudomonas C12B. Appl. Environ. Microbiol. 34, 107-108.

[109] Delisle, G.J. and Milazzo, F.H. (1972) Characterization of arylsulfatase isoenzymes from Pseudomonas aeruginosa. Can. J. Microbiol. $18,561-568$.

[110] Fitzgerald, J.W. and Cline, M.E. (1977) The occurrence of an inducible arylsulphatase in Comamonas terrigena. FEMS Microbiol. Lett. 2, 221-224

[111] Mueller, S. and Schmidt, A. (1986) Substrate-dependent arylsulfatase activity in the cyanobacterium Plectonema 73110. Z. Naturforsch. C 41, 820-824.

[112] Fitzgerald, J.W. and Milazzo, F.H. (1975) Further studies on the heterogeneity of arylsulfatase from Proteus rettgeri and some properties of one chromatographic form of the enzyme. Int. J. Biochem. 6, 769-774. 
[113] Delisle, G. and Milazzo, F.H. (1970) The isolation of arylsulphatase isoenzymes from Pseudomonas aeruginosa. Biochim. Biophys. Acta 212, 505-508.

[114] Adachi, T., Murooka, Y. and Harada, T. (1973) Derepression of arylsulfatase synthesis in Aerobacter aerogenes by tyramine. J. Bacteriol. 116, 19-24.

[115] Harada, T. and Spencer, B. (1964) Repression and induction of arylsulphatase synthesis in Aerobacter aerogenes. Biochem. J. 93, 373-378.

[116] Tomioka, H., Saito, H., Sato, K. and Dawson, D.J. (1990) Arylsulfatase activity for differentiating Mycobacterium avium and Mycobacterium intracellulare. J. Clin. Microbiol. 28, 2104-2106.

[117] Falkinham III, J.O. (1990) Arylsulfatase activity of Mycobacterium avium, Mycobacterium intracellulare, and Mycobacterium scrofulaceum. Int. J. Syst. Bacteriol. 40, 66-70.

[118] Levy-Frebault, V.V. and Portaels, F. (1992) Proposed minimal standards for the genus Mycobacterium and for description of new slowly growing Mycobacterium species. Int. J. Syst. Bacteriol. 42, 315-323.

[119] Szameit, C., Miech, C., Balleininger, M., Schmidt, B., von Figura, K. and Dierks, T. (1999) The iron sulfur protein AtsB is required for posttranslational formation of formylglycine in the Klebsiella sulfatase. J. Biol. Chem. 274, 15375-15381.

[120] Okamura, H., Yamada, T., Murooka, Y. and Harada, T. (1976) Purification and properties of arylsulfatase of Klebsiella aerogenes: identity of the enzymes formed by non-repressed and derepressed synthesis. Agric. Biol. Chem. 40, 2071-2076.

[121] Holloway, B. (1955) Genetic recombination in Pseudomonas aeruginosa. J. Gen. Microbiol. 13, 572-581.

[122] Pseudomonas Genome Project (1999) Internet web site http:// www.pseudomonas.com/.

[123] Dierks, T., Schmidt, B. and von Figura, K. (1997) Conversion of cysteine to formylglycine: A protein modification in the endoplasmic reticulum. Proc. Natl. Acad. Sci. USA 94, 11963-11968.

[124] Knaust, A., Schmidt, B., Dierks, T., von Bulow, R. and von Figura, K. (1998) Residues critical for formylglycine formation and/or catalytic activity of arylsulfatase A. Biochemistry 37, 13941-13946.

[125] Dierks, T., Lecca, M.R., Schmidt, B. and von Figura, K. (1998) Conversion of cysteine to formylglycine in eukaryotic sulfatases occurs by a common mechanism in the endoplasmic reticulum. FEBS Lett. 423, 61-65.

[126] Selmer, T., Hallmann, A., Schmidt, B., Sumper, M. and Figura, K.v. (1996) The evolutionary conservation of a novel protein modification, the conversion of cysteine to serinesemialdehyde in arylsulfatase from Volvox carteri. Eur. J. Biochem. 238, 341-345.

[127] Lukatela, G., Krauss, N., Theis, K., Selmer, T., Gieselmann, V., von Figura, K. and Saenger, W. (1998) Crystal structure of human arylsulfatase A: The aldehyde function and the metal ion at the active site suggest a novel mechanism for sulfate ester hydrolysis. Biochemistry 37, 3654-3664.

[128] Bond, C.S., Clements, P.R., Ashby, S.J., Collyer, C.A., Harrop, S.J., Hopwood, J.J. and Guss, J.M. (1997) Structure of a human lysosomal sulfatase. Structure 5, 277-289.

[129] Schirmer, A. and Kolter, R. (1998) Computational analysis of bacterial sulfatases and their modifying enzymes. Chem. Biol. 5, 181186.

[130] Flachmann, R., Kunz, N., Seifert, J., Gutlich, M., Wientjes, F.J., Laufer, A. and Gassen, H.G. (1988) Molecular biology of pyridine nucleotide biosynthesis in Escherichia coli. Cloning and characterization of quinolinate synthesis genes $\operatorname{nadA}$ and $\operatorname{nadB}$. Eur. J. Biochem. 175, 221-228.

[131] Kahnert, A. and Kertesz, M.A., unpublished results.

[132] Kahnert, A., Vermeij, P., James, P., Leisinger, T. and Kertesz, M.A. (1999) The $s s u$ locus plays a key role in organosulfur metabolism in Pseudomonas putida S-313. Submitted for publication.

[133] Dotson, S.B., Smith, C.E., Ling, C.S., Barry, G.F. and Kishore, G.M. (1996) Identification, characterization, and cloning of a phos- phonate monoester hydrolase from Burkholderia caryophilli PG2982. J. Biol. Chem. 271, 25754-25761.

[134] Dierks, T., Lecca, M.R., Schlotterhose, P., Schmidt, B. and von Figura, K. (1999) Sequence determinants directing conversion of cysteine to formylglycine in eukaryotic sulfatases. EMBO J. 18, 2084-2091.

[135] Murooka, Y., Azakami, H. and Yamashita, M. (1996) The monoamine regulon including syntheses of arylsulfatase and monoamine oxidase in bacteria. Biosci. Biotechnol. Biochem. 60, 935-941.

[136] Hummerjohann, J. and Kertesz, M.A., unpublished results.

[137] Linton, K.J. and Higgins, C.F. (1998) The Escherichia coli ATPbinding cassette (ABC) proteins. Mol. Microbiol. 28, 5-13.

[138] Higgins, C.F. (1992) ABC transporters - from microorganisms to man. Annu. Rev. Cell Biol. 8, 67-113.

[139] Hyde, S.C., Emsley, P., Hartshorn, M.J., Mimmack, M.M., Gileadi, U., Pearce, S.R., Gallagher, M.P., Gill, D.R., Hubbard, R.E. and Higgins, C.F. (1990) Structural model of ATP-binding proteins associated with cystic fibrosis, multidrug resistance and bacterial transport. Nature 346, 362-365.

[140] Walker, J.E., Saraste, M., Runswick, M.J. and Gay, N.J. (1982) Distantly related sequences in the alpha- and beta-subunits of ATP synthase, myosin, kinases and other ATP-requiring enzymes and a common nucleotide binding fold. EMBO J. 1, 945-951.

[141] Kawasaki, S., Arai, H., Kodama, T. and Igarashi, Y. (1997) Gene cluster for dissimilatory nitrite reductase (nir) from Pseudomonas aeruginosa: Sequencing and identification of a locus for heme d-1 biosynthesis. J. Bacteriol. 179, 235-242.

[142] Kaneko, T., Sato, S., Kotani, H., Tanaka, A., Asamizu, E., Nakamura, Y., Miyajima, N., Hirosawa, M., Sugiura, M., Sasamoto, S., Kimura, T., Hosouchi, T., Matsuno, A., Muraki, A., Nakazaki, N., Naruo, K., Okumura, S., Shimpo, S., Takeuchi, C., Wada, T., Watanabe, A., Yamada, M., Yasuda, M. and Tabata, S. (1996) Sequence analysis of the genome of the unicellular cyanobacterium Synechocystis sp. strain PCC6803. II. Sequence determination of the entire genome and assignment of potential protein-coding regions. DNA Res. 3, 109-136.

[143] Altschul, S.F., Madden, T.L., Schaffer, A.A., Zhang, J., Zhang, Z., Miller, W. and Lipman, D.J. (1997) Gapped BLAST and PSIBLAST: a new generation of protein database search programs. Nucleic Acids Res. 25, 3389-3402.

[144] The Sanger Centre (1999) These sequence data were produced by the Yersinia pestis, Bordetella pertussis and Salmonella typhi Sequencing Groups at the Sanger Centre and can be obtained from the web sites ftp://ftp.sanger.ac.uk/pub/pathogens/yp/, ftp://ftp. sanger.ac.uk/pub/pathogens/bp/, and ftp://ftp.sanger.ac.uk/pub/ pathogens/st/.

[145] Blattner, F.R., Plunkett 3rd, G., Bloch, C.A., Perna, N.T., Burland, V., Riley, M., Collado Vides, J., Glasner, J.D., Rode, C.K., Mayhew, G.F., Gregor, J., Davis, N.W., Kirkpatrick, H.A., Goeden, M.A., Rose, D.J., Mau, B. and Shao, Y. (1997) The complete genome sequence of Escherichia coli K-12. Science 277, 14531474.

[146] Cole, S.T., Brosch, R., Parkhill, J., Garnier, T., Churcher, C., Harris, D., Gordon, S.V., Eiglmeier, K., Gas, S., Barry, C.E. and Tekaia, F. (1998) Deciphering the biology of Mycobacterium tuberculosis from the complete genome sequence. Nature 393, 537-544.

[147] Lucas, J.J., Burchiel, S.W. and Segel, I.H. (1972) Choline sulfatase of Pseudomonas aeruginosa. Arch. Biochem. Biophys. 153, 664-672.

[148] Günther, E., Petruschka, L. and Herrmann, H. (1979) Reverse transsulfuration pathway in Pseudomonas aeruginosa. Z. Allg. Mikrobiol. 19, 439-442.

[149] Yamashita, M., Azakami, H., Yokoro, N., Roh, J.H., Suzuki, H., Kumagai, H. and Murooka, Y. (1996) maoB, a gene that encodes a positive regulator of the monoamine oxidase gene (maoA) in Escherichia coli. J. Bacteriol. 178, 2941-2947.

[150] Yamashita, M. and Murooka, Y. (1984) Use of lac gene fusions to study regulation of tyramine oxidase, which is involved in derepres- 
sion of latent arylsulfatase in Escherichia coli. Agric. Biol. Chem. 48, $1459-1470$

[151] Azakami, H. and Murooka, H.S. (1992) Cloning and nucleotide sequence of a negative regulator gene for Klebsiella aerogenes arylsulfatase synthesis and identification of the gene as folA. J. Bacteriol. 174, 2344-2351.

[152] Matts, P.J., White, G.F. and Payne, W.J. (1994) Purification and characterization of the short-chain alkylsulphatase of coryneform B1a. Biochem. J. 304, 937-943.

[153] Singh, K.L., Kumar, A. and Kumar, A. (1998) Bacillus cereus capable of degrading SDS shows growth with a variety of detergents. World J. Microbiol. Biotechnol. 14, 777-779.

[154] Payne, W.J. and Faisal, V.E. (1963) Bacterial utilization of dodecylsulfate and dodecyl benzenesulfonate. Appl. Microbiol. 11, 339-344.

[155] Imperato, T.J., Wong, C.G., Chen, L.J. and Bolt, R.J. (1977) Hydrolysis of lithocholate sulfate by Pseudomonas aeruginosa. J. Bacteriol. $130,545-547$.

[156] Fitzgerald, J.W. and Scott, C.L. (1974) Utilization of choline-Osulphate as a sulphur source for growth by a Pseudomonas isolate. Microbios 10, 121-131.

[157] White, G.F., Dodgson, K.S., Davies, I., Matts, P.J., Shapleigh, J.P. and Payne, W.J. (1987) Bacterial utilization of short-chain primary alkyl sulphate esters. FEMS Microbiol. Lett. 40, 173-177.

[158] Davies, I., White, G.F. and Payne, W.J. (1990) Oxygen-dependent desulphation of monomethyl sulphate by Agrobacterium sp. M3C. Biodegradation 1, 229-241.

[159] Higgins, T.P., Snape, J.R. and White, G.F. (1993) Comparison of pathways for biodegradation of monomethyl sulphate in Agrobacterium and Hyphomicrobium species. J. Gen. Microbiol. 139, 29152920.

[160] Higgins, T.P., Hewlins, M.J.E. and White, G.F. (1996) A C-13NMR study of the mechanism of bacterial metabolism of monomethyl sulfate. Eur. J. Biochem. 236, 620-625.

[161] Thomas, O.R.T., Matts, P.J. and White, G.F. (1988) Localization by electron microscopy of alkylsulfatases in bacterial cells. J. Gen. Microbiol. 134, 1229-1236.

[162] Osteras, M., Boncompagni, E., Vincent, N., Poggi, M.C. and LeRudulier, D. (1998) Presence of a gene encoding choline sulfatase in Sinorhizobium meliloti bet operon: Choline- $O$-sulfate is metabolized into glycine betaine. Proc. Natl. Acad. Sci. USA 95, 11394 11399.

[163] Tazuke, Y., Matsuda, K., Adachi, K. and Tsukada, Y. (1994) Purification and properties of bile acid sulfate sulfatase from Pseudomonas testosteroni. Biosci. Biotechnol. Biochem. 58, 889-894.

[164] Yoji, T., Yasuhiko, T., Nariisa, O. and Kenichi, A. (1993) Bile acid sulfuric acid sulfatase gene, new recombinant DNA and production of bile acid sulfuric acid sulfatase. Japanese Patent no. 1993236957A 1.

[165] Hsu, Y.C. (1965) Detergent-splitting enzyme from Pseudomonas. Nature 207, 385-388.

[166] Davison, J., Brunel, F., Phanopoulos, A., Prozzi, D. and Terpstra, P. (1992) Cloning and sequencing of Pseudomonas genes determining sodium dodecyl sulfate biodegradation. Gene 114, 19-24.

[167] Tazuke, Y., Matsuda, K., Adachi, K. and Tsukada, Y. (1998) Purification and properties of a novel sulfatase from Pseudomonas testosteroni that hydrolyzed 3 beta-hydroxy-5-cholenoic acid 3-sulfate. Biosci. Biotechnol. Biochem. 62, 1739-1744.

[168] Roberton, A.M. and Wright, D.P. (1997) Bacterial glycosulphatases and sulphomucin degradation. Can. J. Gastroenterol. 11, 361-366.

[169] Tsai, H.H., Hart, C.A. and Rhodes, J.M. (1991) Production of mucin degrading sulphatase and glycosidases by Bacteroides thetaiotaomicron. Lett. Appl. Microbiol. 13, 97-101.

[170] Jansen, H.J., Hart, C.A., Rhodes, J.M., Saunders, J.R. and Smalley, J.W. (1999) A novel mucin-sulphatase activity found in Burkholderia cepacia and Pseudomonas aeruginosa. J. Med. Microbiol. 48, 551557.

[171] Melino, S., Capo, C., Dragani, B., Aceto, A. and Petruzzelli, R.
(1998) A zinc-binding motif conserved in glyoxalase II, beta-lactamase and arylsulfatases. Trends Biochem. Sci. 23, 381-382.

[172] Salyers, A.A. and Kotarski, S.F. (1980) Induction of chondroitin sulfate lyase activity in Bacteroides thetaiotaomicron. J. Bacteriol. $143,781-788$

[173] Hwa, V. and Salyers, A.A. (1992) Evidence for differential regulation of genes in the chondroitin sulfate utilization pathway of Bacteroides thetaiotaomicron. J. Bacteriol. 174, 342-344.

[174] Sugahara, K. and Kojima, T. (1996) Specificity studies of bacterial sulfatases by means of structurally defined sulfated oligosaccharides isolated from shark cartilage chondroitin sulfate D. Eur. J. Biochem. 239, 865-870.

[175] Bruce, J.S., McLean, M.W., Williamson, F.B. and Long, W.F. (1985) Flavobacterium heparinum 6- $O$-sulphatase for $N$-substituted glucosamine 6- $O$-sulphate. Eur. J. Biochem. 152, 75-82.

[176] Bruce, J.S., McLean, M.W., Long, W.F. and Williamson, F.B. (1985) Flavobacterium heparinum 3-O-sulphatase for $\mathrm{N}$-substituted glucosamine 3-O-sulphate. Eur. J. Biochem. 148, 359-365.

[177] McLean, M.W., Bruce, J.S., Long, W.F. and Williamson, F.B. (1984) Flavobacterium heparinum 2-O-sulphatase for 2-O-sulphatodelta 4, 5-glycuronate-terminated oligosaccharides from heparin. Eur. J. Biochem. 145, 607-615.

[178] Bruce, J.S., McLean, M.W., Long, W.F. and Williamson, F.B. (1987) Flavobacterium heparinum sulphamidase for D-glucosamine sulphamate. Purification and characterisation. Eur. J. Biochem. 165, 633-638.

[179] Cheng, Q., Hwa, V. and Salyers, A.A. (1992) A locus that contributes to colonization of the intestinal tract by Bacteroides thetaiotaomicron contains a single regulatory gene $(c h u R)$ that links two polysaccharide utilization pathways. J. Bacteriol. 174, 7185-7193.

[180] Hwa, V. and Salyers, A.A. (1992) Analysis of two chondroitin sulfate utilization mutants of Bacteroides thetaiotaomicron that differ in their abilities to compete with the wild type in the gastrointestinal tracts of germfree mice. Appl. Environ. Microbiol. 58, 869-876.

[181] Salyers, A.A. and O'Brien, M. (1980) Cellular location of enzymes involved in chondroitin sulfate breakdown by Bacteroides thetaiotaomicron. J. Bacteriol. 143, 772-780.

[182] Silva, M.E. and Dietrich, C.P. (1973) Studies on the induction of heparin-degrading enzymes in Flavobacterium heparinum. Biochimie 55, 1101-1106.

[183] Galliher, P.M., Linhardt, R.G., Conway, L.J., Langer, R.S. and Cooney, C.L. (1982) Regulation of heparinase synthesis in Flavobacterium heparinum. Eur. J. Appl. Microbiol. Biotechnol. 15, 252-257.

[184] Beil, S., Kertesz, M.A., Leisinger, T. and Cook, A.M. (1996) The assimilation of sulfur from multiple sources and its correlation with expression of the sulfate-starvation-induced stimulon in Pseudomonas putida S-313. Microbiology 142, 1989-1995.

[185] Vermeij, P., Wietek, C., Kahnert, A., Wüest, T. and Kertesz, M.A. (1999) Genetic organization of sulfur-controlled aryl desulfonation in Pseudomonas putida S-313. Mol. Microbiol. 32, 913-926.

[186] Thysse, G.J.E. and Wanders, T.H. (1972) Degradation of $n$-alkane1-sulfonates by Pseudomonas. Antonie van Leeuwenhoek 38, 53-63.

[187] Thysse, G.J.E. and Wanders, T.H. (1974) Initial steps in the degradation of $n$-alkane-1-sulphonates by Pseudomonas. Antonie van Leeuwenhoek 40, 25-37.

[188] Quick, A., Russell, N.J., Hales, S.G. and White, G.F. (1994) Biodegradation of sulphosuccinate: Direct desulphonation of a secondary sulphonate. Microbiology 140, 2991-2998.

[189] Reichenbecher, W. and Murrel, J.C. (1999) Linear alkanesulfonates as carbon and energy sources for gram-positive and gram-negative bacteria. Arch. Microbiol. 171, 430-438.

[190] Junker, F., Field, J.A., Bangerter, F., Ramsteiner, K., Kohler, H.P., Joannou, C.L., Mason, J.R., Leisinger, T. and Cook, A.M. (1994) Oxygenation and spontaneous deamination of 2-aminobenzenesulphonic acid in Alcaligenes sp. strain 0-1 with subsequent meta ring cleavage and spontaneous desulphonation to 2-hydroxymuconic acid. Biochem. J. 300, 429-436. 
[191] Thompson, A.S., Owens, N.J.P. and Murrell, J.C. (1995) Isolation and characterization of methanesulfonic acid-degrading bacteria from the marine environment. Appl. Environ. Microbiol. 61, 2388-2393.

[192] Holmes, A.J., Kelly, D.P., Baker, S.C., Thompson, A.S., De Marco, P., Kenna, E.M. and Murrell, J.C. (1997) Methylosulfonomonas methylovora gen. nov., sp. nov., and Marinosulfonomonas methylotropha gen. nov., sp. nov. Novel methylotrophs able to grow on methanesulfonic acid. Arch. Microbiol. 167, 46-53.

[193] Higgins, T.P., Davey, M., Trickett, J., Kelly, D.P. and Murrell, J.C. (1996) Metabolism of methanesulfonic acid involves a multicomponent monooxygenase enzyme. Microbiology 142, 251-260.

[194] Higgins, T.P., Demarco, P. and Murrell, J.C. (1997) Purification and molecular characterization of the electron transfer protein of methanesulfonic acid monooxygenase. J. Bacteriol. 179, 1974-1979.

[195] Kelly, D.P., Baker, S.C., Trickett, J., Davey, M. and Murrell, J.C. (1994) Methanesulphonate utilization by a novel methylotrophic bacterium involves an unusual monooxygenase. Microbiology 140, $1419-1426$

[196] Anthony, C. (1982) The Biochemistry of Methylotrophs. Academic Press, London

[197] De Marco, P., Moradas Ferreira, P., Higgins, T.P., McDonald, I., Kenna, E.M. and Murrell, J.C. (1999) Molecular analysis of a novel methanesulfonic acid monooxygenase from the methylotroph Methylosulfonomonas methylovora. J. Bacteriol. 181, 2244-2251.

[198] Byrne, A.M., Kukor, J.J. and Olsen, R.H. (1995) Sequence analysis of the gene cluster encoding toluene-3-monooxygenase from Pseudomonas pickettii PKO1. Gene 154, 65-70.

[199] Yen, K.M., Karl, M.R., Blatt, L.M., Simon, M.J., Winter, R.B., Fausset, P.R., Lu, H.S., Harcourt, A.A. and Chen, K.K. (1991) Cloning and characterization of a Pseudomonas mendocina KR1 gene cluster encoding toluene-4-monooxygenase. J. Bacteriol. 173, 5315-5327.

[200] Shimamoto, G. and Berk, R.S. (1979) Catabolism of taurine in Pseudomonas aeruginosa. Biochim. Biophys. Acta 569, 287-292.

[201] Shimamoto, G. and Berk, R.S. (1980) Taurine catabolism. II. Biochemical and genetic evidence for sulfoacetaldehyde sulfolyase involvement. Biochim. Biophys. Acta 632, 121-130.

[202] Kondo, H. and Ishimoto, M. (1987) Taurine dehydrogenase. Methods Enzymol. 143, 496-499.

[203] King, J.E., Jaouhari, R. and Quinn, J.P. (1997) The role of sulfoacetaldehyde sulfo lyase in the mineralization of isethionate by an environmental Acinetobacter isolate. Microbiology 143, 2339-2343.

[204] King, J.E. and Quinn, J.P. (1997) Metabolism of sulfoacetate by environmental Aureobacterium sp. and Comamonas acidovorans isolates. Microbiology 143, 3907-3912.

[205] Denger, K., Laue, H. and Cook, A.M. (1997) Anaerobic taurine oxidation: a novel reaction by a nitrate reducing Alcaligenes sp. Microbiology 143, 1919-1924.

[206] Chien, C.C., Leadbetter, E.R. and Godchaux, W. (1997) Taurine sulfur assimilation and taurine pyruvate aminotransferase activity in anaerobic bacteria. Appl. Environ. Microbiol. 63, 3021-3024.

[207] Denger, K., Laue, H. and Cook, A.M. (1997) Thiosulfate as a metabolic product: the bacterial fermentation of taurine. Arch. Microbiol. 168, 297-301.

[208] Harwood, J.L. and Nicholls, R.G. (1979) The plant sulpholipid, a major component of the sulphur cycle. Trans. Biochem. Soc. Lond. 7, 440-447.

[209] Seitz, A.P., Leadbetter, E.R. and Godchaux, W. (1993) Utilization of sulfonates as sole sulfur source by soil bacteria including Comamonas acidovorans. Arch. Microbiol. 159, 440-444

[210] Uria-Nickelsen, M.R., Leadbetter, E.R. and Godchaux III, W. (1993) Sulphonate utilization by enteric bacteria. J. Gen. Microbiol. 139, 203-208.

[211] Uria-Nickelsen, M.R., Leadbetter, E.R. and Godchaux, W. (1994) Comparative aspects of utilization of sulfonate and other sulfur sources by Escherichia coli K12. Arch. Microbiol. 161, 434 438.
[212] Uria-Nickelsen, M.R., Leadbetter, E.R. and Godchaux, W. (1993) Sulfonate sulfur assimilation by yeasts resembles that of bacteria. FEMS Microbiol. Lett. 114, 73-77.

[213] King, J.E. and Quinn, J.P. (1997) The utilization of organosulphonates by soil and freshwater bacteria. Lett. Appl. Microbiol. 24, 474-478.

[214] Seitz, A.P. and Leadbetter, E.R. (1995) Microbial assimilation and dissimilation of sulfonate sulfur. In: Geochemical Transformations of Sedimentary Sulfur. American Chemical Society Symposium Series 612 (Vairavamurthy, M.A. and Schoonen, M.A.A., Eds.), pp. 365-376, American Chemical Society, Washington, DC.

[215] Key, B.D., Howell, R.D. and Criddle, C.S. (1998) Defluorination of organofluorine sulfur compounds by Pseudomonas sp. strain D2. Environ. Sci. Technol. 32, 2283-2287.

[216] Kertesz, M.A. (1996) Desulfonation of aliphatic sulfonates by Pseudomonas aeruginosa PAO. FEMS Microbiol. Lett. 137, 221225.

[217] Uria-Nickelsen, M.R., Leadbetter, E.R. and Godchaux, W. (1994) Sulfonate-sulfur utilization involves a portion of the assimilatory sulfate reduction pathway in Escherichia coli. FEMS Microbiol. Lett. 123, 43-48.

[218] van der Ploeg, J.R., Weiss, M.A., Saller, E., Nashimoto, H., Saito, N., Kertesz, M.A. and Leisinger, T. (1996) Identification of sulfate starvation-regulated genes in Escherichia coli: a gene cluster involved in the utilization of taurine as a sulfur source. J. Bacteriol. $178,5438-5446$

[219] Prescott, A.G. (1993) A dilemma of dioxygenases (or where biochemistry and molecular biology fail to meet). J. Exp. Bot. 44, 849-861.

[220] De Carolis, E. and De Luca, V. (1994) 2-Oxoglutarate-dependent dioxygenase and related enzymes: Biochemical characterization. Phytochemistry 36, 1093-1107.

[221] Fukumori, F. and Hausinger, R.P. (1993) Purification and characterization of 2,4-dichlorophenoxyacetate/ $\alpha$-ketoglutarate dioxygenase. J. Biol. Chem. 268, 24311-24317.

[222] van der Ploeg, J.R., Iwanicka-Nowicka, R., Bykowski, T., Hryniewicz, M. and Leisinger, T. (1999) The Cbl-regulated ssuEADCB gene cluster is required for aliphatic sulfonate-sulfur utilization in Escherichia coli. J. Biol. Chem. 174, 29358-29365.

[223] van der Ploeg, J.R., Cummings, N.J., Leisinger, T. and Connerton, I.F. (1998) Bacillus subtilis genes for the utilization of sulfur from aliphatic sulfonates. Microbiology 144, 2555-2561.

[224] Witschel, M., Nagel, S. and Egli, T. (1997) Identification and characterization of the two-enzyme system catalyzing oxidation of EDTA in the EDTA-degrading bacterial strain DSM 9103. J. Bacteriol. 179, 6937-6943.

[225] Knobel, H.R., Egli, T. and van der Meer, J.R. (1996) Cloning and characterization of the genes encoding nitrilotriacetate monooxygenase of Chelatobacter heintzii ATCC 29600. J. Bacteriol. 178, 61236132.

[226] Thibaut, D., Ratet, N., Bisch, D., Faucher, D., Debussche, L. and Blanche, F. (1995) Purification of the two-enzyme system catalyzing the oxidation of the D-proline residue of pristinamycin II-B during the last step of pristinamycin II-A biosynthesis. J. Bacteriol. 177, 5199-5205.

[227] Oldfield, C., Pogrebinsky, O., Simmonds, J., Olson, E.S. and Kulpa, C.F. (1997) Elucidation of the metabolic pathway for dibenzothiophene desulphurization by Rhodococcus sp. strain IGTS8 (ATCC 53968). Microbiology 143, 2961-2973.

[228] Fieschi, F., Niviere, V., Frier, C., Decout, J.L. and Fontecave, M. (1995) The mechanism and substrate specificity of the NADPH:flavin oxidoreductase from Escherichia coli. J. Biol. Chem. 270, 30392 30400 .

[229] Denome, S.A., Oldfield, C., Nash, L.J. and Young, K.D. (1994) Characterization of the desulfurization genes from Rhodococcus sp. strain IGTS8. J. Bacteriol. 176, 6707-6716.

[230] Peterson, K.L., Galitz, D.S. and Srivastava, D.K. (1998) Influence 
of excision of a methylene group from Glu-376 (Glu376 $\rightarrow$ Asp mutation) in the medium chain acyl-CoA dehydrogenase-catalyzed reaction. Biochemistry 37, 1697-1705.

[231] Engel, P.C. (1992) Acyl-coenzyme A dehydrogenases. In: Chemistry and Biochemistry of Flavoenzymes, Vol. 3 (Müller, F., Ed.), pp. 597-655. CRC Press, Boca Raton, FL.

[232] DuPlessis, E.R., Pellett, J., Stankovich, M.T. and Thorpe, C. (1998) Oxidase activity of the acyl-CoA dehydrogenases. Biochemistry 37 , 10469-10477.

[233] Kertesz, M.A., Cook, A.M. and Leisinger, T. (1994) Microbial metabolism of sulfur- and phosphorus-containing xenobiotics. FEMS Microbiol. Rev. 15, 195-215.

[234] Cain, R.B. (1981) Microbial degradation of surfactants and 'builder' components. In: Microbial Degradation of Xenobiotics and Recalcitrant Compounds (Leisinger, T., Hütter, R., Cook, A.M. and Nüesch, J., Eds.), pp. 325-370.

[235] Nörtemann, B., Kuhm, A.E., Knackmuss, H.J. and Stolz, A. (1994) Conversion of substituted naphthalenesulfonates by Pseudomonas sp. BN6. Arch. Microbiol. 161, 320-327.

[236] Locher, H.H., Leisinger, T. and Cook, A.M. (1991) 4-Sulphobenzoate 3,4-dioxygenase. Purification and properties of a desulphonative two-component enzyme system from Comamonas testosteroni T-2. Biochem. J. 274, 833-842.

[237] Feigel, B.J. and Knackmuss, H.J. (1988) Bacterial catabolism of sulfanilic acid via catechol-4-sulfonic acid. FEMS Microbiol. Lett. $55,113-117$.

[238] Feigel, B.J. and Knackmuss, H.J. (1993) Syntrophic interactions during degradation of 4-aminobenzenesulfonic acid by a two species bacterial culture. Arch. Microbiol. 159, 124-130.

[239] Blümel, S., Contzen, M., Lutz, M., Stolz, A. and Knackmuss, H.J. (1998) Isolation of a bacterial strain with the ability to utilize the sulfonated azo compound 4-carboxy-4'-sulfoazobenzene as the sole source of carbon and energy. Appl. Environ. Microbiol. 64, 23152317.

[240] Junker, F. and Cook, A.M. (1997) Conjugative plasmids and the degradation of arylsulfonates in Comamonas testosteroni. Appl. Environ. Microbiol. 63, 2403-2410.

[241] Balashov, S.V. and Boronin, A.M. (1997) Benzenesulphonic and p-toluenesulphonic acid degradation plasmids of Comamonas testosteroni. Genetika 33, 604-609.

[242] Zürrer, D., Cook, A.M. and Leisinger, T. (1987) Microbial desulfonation of substituted naphthalenesulfonic acids and benzenesulfonic acids. Appl. Environ. Microbiol. 53, 1459-1463.

[243] Dudley, M.W. and Frost, J.W. (1994) Biocatalytic desulfurization of arylsulfonates. Bioorg. Med. Chem. 2, 681-690.

[244] Kertesz, M.A., Kölbener, P., Stockinger, H., Beil, S. and Cook, A.M. (1994) Desulfonation of linear alkylbenzenesulfonate surfactants and related compounds by bacteria. Appl. Environ. Microbiol. 60, 2296-2303.

[245] Bruschi, M. and Guerlesquin, F. (1988) Structure, function and evolution of bacterial ferredoxins. FEMS Microbiol. Rev. 54, 155176.

[246] Gaudu, P., Touati, D., Niviere, V. and Fontecave, M. (1994) The $\mathrm{NAD}(\mathrm{P}) \mathrm{H}$ :flavin oxidoreductase from Escherichia coli as a source of superoxide radicals. J. Biol. Chem. 269, 8182-8188.

[247] Chae, H.Z., Robison, K., Poole, L.B., Church, G., Storz, G. and Rhee, S.G. (1994) Cloning and sequencing of thiol-specific antioxidant from mammalian brain: Alkyl hydroperoxide reductase and thiol-specific antioxidant define a large family of antioxidant enzymes. Proc. Natl. Acad. Sci. USA 91, 7017-7021.

[248] Oertle, K. and Kertesz, M.A., unpublished results.

[249] Willetts, A.J. and Cain, R.B. (1972) Microbial metabolism of alkylbenzenesulphonates. Bacterial metabolism of undecylbenzene-psulphonate. Biochem. J. 129, 389-402.

[250] Schöberl, P. (1989) Basic principles of LAS biodegradation. Tenside Surf. Det. 26, 86-94.

[251] Van Ginkel, C.G. (1996) Complete degradation of xenobiotic sur- factants by consortia of aerobic microorganisms. Biodegradation 7, 151-164.

[252] Rapaport, R.A. and Eckhoff, W.S. (1990) Monitoring linear alkyl benzene sulfonate in the environment: 1973-1986. Environ. Toxicol. Chem. 9, 1245-1257.

[253] Trehy, M.L., Gledhill, W.E., Mieure, J.P., Adamove, J.E., Nielsen, A.M., Perkins, H.O. and Eckhoff, W.S. (1996) Environmental monitoring for linear alkylbenzene sulfonates, dialkyltetralin sulfonates and their biodegradation intermediates. Environ. Toxicol. Chem. 15, 233-240.

[254] Kölbener, P., Baumann, U., Leisinger, T. and Cook, A.M. (1995) Linear alkylbenzenesulfonate (LAS) surfactants in a simple test to detect refractory organic carbon (ROC): Attribution of recalcitrants to impurities in LAS. Environ. Toxicol. Chem. 14, 571-577.

[255] Nielsen, A.M., Britton, L.N., Beall, C.E., McCormick, T.P. and Russell, G.P. (1997) Biodegradation of coproducts of commercial linear alkylbenzene sulfonate. Environ. Sci. Technol. 31, 3397-3404.

[256] Kropp, K.G. and Fedorak, P.M. (1998) A review of the occurrence, toxicity, and biodegradation of condensed thiophenes found in petroleum. Can. J. Microbiol. 44, 605-622.

[257] McFarland, B.L. (1999) Biodesulfurization. Curr. Opin. Microbiol. 2, 257-264.

[258] Setti, L., Lanzarini, G. and Pifferi, P.G. (1995) Dibenzothiophene biodegradation by a Pseudomonas sp. in model solutions. Proc. Biochem. 30, 721-728.

[259] Kropp, K.G., Andersson, J.T. and Fedorak, P.M. (1997) Bacterial transformations of 1,2,3,4-tetrahydrodibenzothiophene and dibenzothiophene. Appl. Environ. Microbiol. 63, 3032-3042.

[260] Frassinetti, S., Setti, L., Corti, A., Farrinelli, P., Montevecchi, P. and Vallini, G. (1998) Biodegradation of dibenzothiophene by a nodulating isolate of Rhizobium meliloti. Can. J. Microbiol. 44, 289-297.

[261] Kodama, K., Umehara, K., Shimizu, K., Makatani, S., Minoda, Y. and Yamada, K. (1973) Identification of microbial products for dibenzothiophene and its proposed oxidation pathway. Agric. Biol. Chem. 37, 45-50.

[262] Monticello, D.J., Bakker, D. and Finnerty, W.R. (1985) Plasmidmediated degradation of dibenzothiophene by Pseudomonas species. Appl. Environ. Microbiol. 49, 756-760.

[263] Denome, S.A., Stanley, D.C., Olson, E.S. and Young, K.D. (1993) Metabolism of dibenzothiophene and naphthalene in Pseudomonas strains: Complete DNA sequence of an upper naphthalene catabolic pathway. J. Bacteriol. 175, 6890-6901.

[264] Resnick, S.M., Lee, K. and Gibson, D.T. (1996) Diverse reactions catalyzed by naphthalene dioxygenase from Pseudomonas sp. strain NCIB 9816. J. Ind. Microbiol. Biotechnol. 17, 438-457.

[265] Wang, P. and Krawiec, S. (1994) Desulfurization of dibenzothiophene to 2-hydroxybiphenyl by some newly isolated bacterial strains. Arch. Microbiol. 161, 266-271.

[266] Kayser, K.J., Bielaga-Jones, B.A., Jackowski, K., Odusan, O. and Kilbane, J.J. (1993) Utilization of organosulphur compounds by axenic and mixed cultures of Rhodococcus rhodochrous IGTS8. J. Gen. Microbiol. 139, 3123-3129.

[267] Izumi, Y., Ohshiro, T., Ogino, H., Hine, Y. and Shimao, M. (1994) Selective desulfurization of dibenzothiophene by Rhodococcus erythropolis D-1. Appl. Environ. Microbiol. 60, 223-226.

[268] Gallagher, J.R., Olson, E.S. and Stanley, D.C. (1993) Microbial desulfurization of dibenzothiophene - a sulfur-specific pathway. FEMS Microbiol. Lett. 107, 31-36.

[269] Ohshiro, T., Hirata, T. and Izumi, Y. (1996) Desulfurization of dibenzothiophene derivatives by whole cells of Rhodococcus erythropolis H-2. FEMS Microbiol. Lett. 142, 65-70.

[270] Gilbert, S.C., Morton, J., Buchanan, S., Oldfield, C. and McRoberts, A. (1998) Isolation of a unique benzothiophene-desulphurizing bacterium, Gordona sp. strain 213E (NCIMB 40816), and characterization of the desulphurization pathway. Microbiology 144, $2545-2553$. 
[271] Omori, T., Saiki, Y., Kasuga, K. and Kodama, T. (1995) Desulfurization of alkyl and aromatic sulfides and sulfonates by dibenzothiophene-desulfurizing Rhodococcus sp. strain SY1. Biosci. Biotechnol. Biochem. 59, 1195-1198.

[272] Rhee, S.K., Chang, J.H., Chang, Y.K. and Chang, H.N. (1998) Desulfurization of dibenzothiophene and diesel oils by a newly isolated Gordona strain, CYKS1. Appl. Environ. Microbiol. 64, 23272331.

[273] Afferden, M.v., Schacht, S., Klein, J. and Truper, H.G. (1990) Degradation of dibenzothiophene by Brevibacterium sp. DO. Arch. Microbiol. 153, 324-328.

[274] Nekodzuka, S., Nakajimakambe, T., Nomura, N., Lu, J. and Nakahara, T. (1997) Specific desulfurization of dibenzothiophene by Mycobacterium sp. strain G3. Biocat. Biotransform. 15, 17-27.

[275] Serbolisca, L., de Ferra, F. and Margarit, I. (1999) Manipulation of the DNA coding for the desulphurizing activity in a new isolate of Arthrobacter sp. Appl. Microbiol. Biotechnol. 52, 122-126.

[276] Konishi, J., Ishii, Y., Onaka, T., Okumura, K. and Suzuki, M. (1997) Thermophilic carbon-sulfur-bond-targeted biodesulfurization. Appl. Environ. Microbiol. 63, 3164-3169.

[277] Constanti, M., Giralt, J. and Bordons, A. (1996) Degradation and desulfurization of dibenzothiophene sulfone and other sulfur compounds by Agrobacterium MC501 and a mixed culture. Enzyme Microb. Technol. 19, 214-219.

[278] Darzins, A., Allen, D.L., Mrachko, G.T. and Squires, C.H. (1997) A Sphingomonas sp. strain AD109 gene cluster required for the specific desulfurization of dibenzothiophene. Submitted for publication.

[279] Li, M.Z., Squires, C.H., Monticello, D.J. and Childs, J.D. (1996) Genetic analysis of the $d s z$ promoter and associated regulatory regions of Rhodococcus erythropolis IGTS8. J. Bacteriol. 178, 64096418

[280] Sialm, M. and Kertesz, M.A., unpublished results.

[281] Uetz, T., Schneider, R., Snozzi, M. and Egli, T. (1992) Purification and characterization of a two-component monooxygenase that hydroxylates nitrilotriacetate from 'Chelatobacter' strain ATCC 29600. J. Bacteriol. 174, 1179-1188.

[282] Xi, L., Squires, C.H., Monticello, D.J. and Childs, J.D. (1997) A flavin reductase stimulates DszA and DszC proteins of Rhodococcus erythropolis IGTS8 in vitro. Biochem. Biophys. Res. Commun. 230, 73-75.

[283] Denis-Larose, C., Labbé, D., Bergeron, H., Jones, A.M., Greer, C.W., Al-Hawari, J., Grossman, M.J., Sankey, B.M. and Lau, P.C. (1997) Conservation of plasmid-encoded dibenzothiophene desulfurization genes in several rhodococci. Appl. Environ. Microbiol. 63, 2915-2919.

[284] Denis-Larose, C., Bergeron, H., Labbe, D., Greer, C.W., Hawari, J., Grossman, M.J., Sankey, B.M. and Lau, P.C.K. (1998) Characterization of the basic replicon of Rhodococcus plasmid pSOX and development of a Rhodococcus Escherichia coli shuttle vector. Appl. Environ. Microbiol. 64, 4363-4367.

[285] Denome, S.A. and Young, K.D. (1995) Identification and activity of two insertion sequence elements in Rhodococcus sp. strain IGTS8. Gene 161, 33-38.

[286] Gallardo, M.E., Ferrandez, A., De Lorenzo, V., Garcia, J.L. and Diaz, E. (1997) Designing recombinant Pseudomonas strains to enhance biodesulfurization. J. Bacteriol. 179, 7156-7160.

[287] Ramos, J.L., Duque, E., Rodriguez Herva, J.J., Godoy, P., Haidour, A., Reyes, F. and Fernandez Barrero, A. (1997) Mechanisms for solvent tolerance in bacteria. J. Biol. Chem. 272, 3887-3890.

[288] Brennan, R.G. and Matthews, B.W. (1989) The helix-turn-helix DNA binding motif. J. Biol. Chem. 264, 1903-1906.

[289] Giffard, P.M. and Booth, I.R. (1988) The rpoA341 allele of Escherichia coli specifically impairs the transcription of a group of positively-regulated operons. Mol. Gen. Genet. 214, 148-152.

[290] Lynch, A.S., Tyrrell, R., Smerdon, S.J., Briggs, G.S. and Wilkinson, A.J. (1994) Characterization of the CysB protein of Klebsiella aero- genes - direct evidence that $N$-acetylserine rather than $O$-acetylserine serves as the inducer of the cysteine regulon. Biochem. J. 299, 129136.

[291] Lin, J., Smith, M.P., Chapin, K.C., Baik, H.S., Bennett, G.N. and Foster, J.W. (1996) Mechanisms of acid resistance in enterohemorrhagic Escherichia coli. Appl. Environ. Microbiol. 62, 3094-3100.

[292] Shi, X. and Bennett, G.N. (1994) Effects of rpoA and cysB mutations on acid induction of biodegradative arginine decarboxylase in Escherichia coli. J. Bacteriol. 176, 7017-7023.

[293] Delic-Attree, I., Toussaint, B., Garin, J. and Vignais, P.M. (1997) Cloning, sequence and mutagenesis of the structural gene of Pseudomonas aeruginosa $\mathrm{CysB}$, which can activate $\operatorname{alg} D$ transcription. Mol. Microbiol. 24, 1275-1284.

[294] Hinton, J., Perombolon, M.C.M. and Salmond, G.P.C. (1987) Cloning of the cysB gene of Erwinia carotovora and the identification of its product. Mol. Gen. Genet. 207, 466-470.

[295] Tyrrell, R., Verschueren, K.H.G., Dodson, E.J., Murshudov, G.N., Addy, C. and Wilkinson, A.J. (1997) The structure of the cofactorbinding fragment of the LysR family member, CysB: a familiar fold with a surprising subunit arrangement. Structure 5, 1017-1032.

[296] Oppezzo, O.J. (1998) In vivo effects of anti-inducers of the cysteine regulon in Salmonella typhimurium. FEMS Microbiol. Lett. 163, 143-148.

[297] van der Ploeg, J.R., Iwanicka-Nowicka, R., Kertesz, M.A., Leisinger, T. and Hryniewicz, M.M. (1997) Involvement of CysB and Cbl regulatory proteins in expression of the $\operatorname{tau} A B C D$ operon and other sulfate starvation-inducible genes in Escherichia coli. J. Bacteriol. 179, 7671-7678.

[298] Iwanicka Nowicka, R. and Hryniewicz, M.M. (1995) A new gene, $c b l$, encoding a member of the LysR family of transcriptional regulators belongs to Escherichia coli cys regulon. Gene 166, 11-17.

[299] Colyer, T.E. and Kredich, N.M. (1996) In vitro characterization of constitutive CysB proteins from Salmonella typhimurium. Mol. Microbiol. 21, 247-256.

[300] Kanaan, M.N. and Marzluf, G.A. (1993) The positive-acting sulfur regulatory protein CYS3 of Neurospora crassa - nuclear localization, autogenous control, and regions required for transcriptional activation. Mol. Gen. Genet. 239, 334-344.

[301] Coulter, K.R. and Marzluf, G.A. (1998) Functional analysis of different regions of the positive acting CYS3 regulatory protein of Neurospora crassa. Curr. Genet. 33, 395-405.

[302] Tao, Y. and Marzluf, G.A. (1998) Synthesis and differential turnover of the CYS3 regulatory protein of Neurospora crassa are subject to sulfur control. J. Bacteriol. 180, 478-482.

[303] Thomas, D. and Surdin Kerjan, Y. (1997) Metabolism of sulfur amino acids in Saccharomyces cerevisiae. Microbiol. Mol. Biol. Rev. 61, 503-532.

[304] Nicholson, M.L. and Laudenbach, D.E. (1995) Genes encoded on a cyanobacterial plasmid are transcriptionally regulated by sulfur availability and CysR. J. Bacteriol. 177, 2143-2150.

[305] Nicholson, M.L., Gaasenbeek, M. and Laudenbach, D.E. (1995) Two enzymes together capable of cysteine biosynthesis are encoded on a cyanobacterial plasmid. Mol. Gen. Genet. 247, 623-632.

[306] Davies, J.P., Yildiz, F.H. and Grossman, A. (1996) Sac1, a putative regulator that is critical for survival of Chlamydomonas reinhardtii during sulfur deprivation. EMBO J. 15, 2150-2159.

[307] Tam, R. and Saier, M.H.J. (1993) Structural, functional, and evolutionary relationships among extracellular solute-binding receptors of bacteria. Microbiol. Rev. 57, 320-346.

[308] Sirko, A., Zatyka, M., Sadowy, E. and Hulanicka, D. (1995) Sulfate and thiosulfate transport in Escherichia coli K-12: Evidence for a functional overlapping of sulfate- and thiosulfate-binding proteins. J. Bacteriol. 177, 41344136.

[309] Locher, H.H., Poolman, B., Cook, A.M. and Konings, W.N. (1993) Uptake of 4-toluene sulfonate by Comamonas testosteroni T-2. J. Bacteriol. 175, 1075-1080.

[310] Junker, F., Kiewitz, R. and Cook, A.M. (1997) Characterization of 
the $p$-toluenesulfonate operon tsaMBCD and tsaR in Comamonas testosteroni T-2. J. Bacteriol. 179, 919-927.

[311] Biedlingmaier, S. and Schmidt, A. (1987) Uptake and metabolism of taurine in the green alga Chlorella fusca. Physiol. Plant. 70, 688-696.

[312] Biedlingmaier, S., Koest, H.P. and Schmidt, A. (1986) Utilization of sulfonic acids as the only sulfur source for growth of photosynthetic organisms. Planta 169, 518-523.

[313] Biedlingmaier, S. and Schmidt, A. (1987) Uptake and utilization of sulfonic acids in the cyanobacterial strains Anabaena variabilis and Plectonema 73110. Z. Naturforsch. C 42, 891-896.

[314] Chien, C.C., Leadbetter, E.R. and Godchaux, W. (1995) Sulfonatesulfur can be assimilated for fermentative growth. FEMS Microbiol. Lett. 129, 189-193.

[315] Denger, K., Kertesz, M.A., Vock, E.H., Schon, R., Magli, A. and Cook, A.M. (1996) Anaerobic desulfonation of 4-tolylsulfonate and 2-(4-sulfophenyl) butyrate by a Clostridium sp. Appl. Environ. Microbiol. 62, 1526-1530.

[316] Denger, K. and Cook, A.M. (1997) Assimilation of sulfur from alkyl and arylsulfonates by Clostridium spp. Arch. Microbiol. 167, 177-181.

[317] Denger, K. and Cook, A.M. (1999) Linear alkylbenzenesulphonate (LAS) bioavailable to anaerobic bacteria as a source of sulphur. J. Appl. Microbiol. 86, 165-168.
[318] Laue, H., Denger, K. and Cook, A.M. (1997) Taurine reduction in anaerobic respiration of Bilophila wadsworthia RZATAU. Appl. Environ. Microbiol. 63, 2016-2021.

[319] Lie, T.J., Pitta, T., Leadbetter, E.R. and Godchaux, W. (1996) Sulfonates: novel electron acceptors in anaerobic respiration. Arch. Microbiol. 66, 204-211.

[320] Mikosch, C., Denger, K., Schafer, E.M. and Cook, A.M. (1999) Anaerobic oxidations of cysteate: degradation via L-cysteate:2-oxoglutarate aminotransferase in Paracoccus pantotrophus. Microbiology 5, 1153-1160.

[321] Lie, T.J., Clawson, M.L., Godchaux, W. and Leadbetter, E.R. (1999) Sulfidogenesis from 2-aminoethanesulfonate (taurine) fermentation by a morphologically unusual sulfate-reducing bacterium, Desulforhopalus singaporensis sp nov. Appl. Environ. Microbiol. 65, 3328-3334.

[322] Laue, H., Denger, K. and Cook, A.M. (1997) Fermentation of cysteate by a sulfate-reducing bacterium. Arch. Microbiol. 168, 210214.

[323] David, M.B. and Mitchell, M.J. (1985) Sulfur constituents and cycling in waters, seston, and sediments of an oligotrophic lake. Limnol. Oceanogr. 30, 1196-1207. 